\title{
ARCABOUÇO TECTÔNICO DA PORÇÃO CENTRO-NORTE DA FAIXA BRASÍLIA COM BASE EM DADOS MAGNÉTICOS E GRAVIMÉTRICOS
}

Luciane Katiuscia Oliveira dos Reis

DISSERTAÇÃO DE MESTRADO № 103

Área de Concentração: Geofísica Aplicada

Brasília - DF

Setembro de 2016 


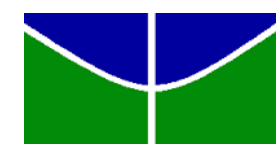

UNIVERSIDADE DE BRASÍLIA INSTITUTO DE GEOCIÊNCIAS

PROGRAMA DE PÓS-GRADUAÇÃO EM GEOCIÊNCIAS APLICADAS

\section{ARCABOUÇO TECTÔNICO DA PORÇÃO CENTRO-NORTE DA FAIXA BRASÍLIA COM BASE EM DADOS MAGNÉTICOS E GRAVIMÉTRICOS}

\section{Luciane Katiuscia Oliveira dos Reis}

Dissertação de mestrado apresentada junto ao curso de Pós-Graduação em Geociências Aplicadas - Área de concentração Geofísica Aplicada, para obtenção do título de mestre em Geofísica Aplicada.

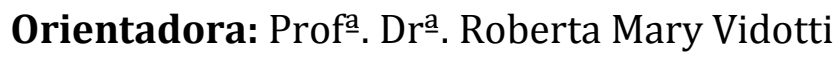

Co-orientador: Prof. Dr. Claudinei Gouveia de Oliveira 


\title{
ARCABOUÇO TECTÔNICO DA PORÇÃO CENTRO-NORTE DA FAIXA BRASÍLIA COM BASE EM DADOS MAGNÉTICOS E GRAVIMÉTRICOS
}

\author{
Luciane Katiuscia Oliveira dos Reis
}

DISSERTAÇÃO DE MESTRADO № 103

Área de Concentração: Geofísica Aplicada

Orientadora: Prof $\stackrel{\text { a }}{\text {. Dra }}$. Roberta Mary Vidotti

Co-Orientador: Prof. Dr. Claudinei Gouveia de Oliveira

Banca Examinadora:

Profa ${ }^{-}$. Dra ${ }^{a}$. Roberta Mary Vidotti (UnB, Orientadora)

Prof. Dr. Reinhardt Adolfo Fuck (UnB)

Prof. Dr. Marcelo Henrique Leão-Santos (UFG)

Brasília - DF

Setembro de 2016 
Universidade de Brasília -Instituto de Geociências - Programa de Pós-graduação em Geociências Aplicadas Arcabouço Tectônico da Porção Centro-Norte da Faixa Brasília com Base em Dados Magnéticos e Gravimétricos

Ficha catalográfica elaborada automaticamente. com os dados fornecidos pelo(a) autor(a)

Reia, Luciane Katiumcia Oliveira

Arcabouço Tectønico da Porçăo Centro-Norte da Faixa Brasilia com base em dados Magneticon e Gravimetricos / Luciane Katiuncia Oliveira Reia; orientador Roberta Nary Vidotti; co-orientador Claudinei Gouveia de Oliveira. -- Branflia, 2016. $73 \mathrm{p}$.

Dienertaç̄̃o (Meatrado - Meatrado em Geociencian Aplicadas) -- Univeraidade de Brasilia, 2016.

1. Faixa Brasilia. 2. Magnatoenetria. 3. Gravimetria. 4. Matched Filter. 5. Blocon Tect8nicon. I. Vidotti, Roberta Mary, orient. II. Gouveia de Oliveira, Claudinei, co-orient. III. Titulo. 


\section{AGRADECIMENTOS}

Agradeço a Deus e ao Universo por ter me guiado até aqui. Aos ensinamentos de Jesus que me ajudam a manter a fé. Aos meus pais Dilma e Antônio Luiz pelo amor incondicional. À minha melhor amiga, minha avó Lica Lima pelos preciosos conselhos. A toda minha família pelo incentivo.

À minha orientadora Roberta Vidotti pela oportunidade, ensinamentos e orientação. Ao professor Claudinei Gouveia, pela sugestão do tema deste trabalho e pelo conhecimento concedido. A banca examinadora pela honra de sua avaliação e presença.

Ao Instituto de Geociências e a Universidade de Brasília, pela infraestrutura. À CPRM - Serviço Geológico do Brasil, ao Governo do Estado de Goiás, ao IBGE - Instituto Brasileiro de Geografia e Estatística e à BGI - Bureau Gravimetrique International pelos dados cedidos, à CAPES - Coordenação de Aperfeiçoamento de Pessoal de Nível Superior, pela bolsa ofertada. Aos professores do Programa de Pós-Graduação de Geologia e Geociências Aplicadas, pela dedicação dada aos alunos e conhecimento oferecido;

Aos meus amigos Mara Letícia, Rafael Lima, Felipe Velásquez e Sébastien Pinel, pela companhia e força. À amiga dos tempos de escola, Lívia Fernanda e sua família por terem me acolhido. Aos colegas da geologia de Marabá, Luiz Antônio, Samille e Ana Rita pelo apoio na minha chegada à Brasília. Ao Robson Bolteri, pelo carinho e apoio nesta minha etapa de vida;

Aos colegas da pós-graduação, Lavoisiane, João Alberto, Endel, Polyanna, Marcelo, Elainy, Hudson, Alan, Daniel, Juliane Uchoa, Tamires, Lucas, Socorro Mendes e Fátima por terem compartilhado o que cada um tem de melhor.

Por fim, agradeço a todos que fizeram parte deste ciclo e que deixaram um pouco de sua sabedoria de vida para mim. 


\section{RESUMO}

A Faixa Brasília é a maior e mais complexa unidade da Província Tocantins, sendo um registro importante de episódios de formação do Gondwana Ocidental. Dentro das unidades se desenvolveram empurrões e falhas reversas em escala regional. Estas estruturas são fundamentais no entendimento da evolução de cinturões orogênicos, por marcarem limites dos terrenos e contribuirem para a exumação de rochas de alta pressão e temperatura. Sobre o processo de evolução da Faixa Brasília duas hipóteses principais foram consideradas. A primeira afirma que o Maciço de Goiás era um microcontinente que foi amalgamado à parte oeste do Cráton São Francisco no Neoproterozóico. A segunda hipótese considera que o Maciço de Goiás fazia parte da borda oeste do Paleocontinente São Francisco no início da orogenia Brasiliana e que seu embasamento estaria recoberto por rochas metassedimentares dos grupos Paranoá e Bambuí. Para reforçar uma destas hipóteses, o objetivo deste trabalho é a caracterização das assinaturas geofísicas dos blocos tectônicos, Arco Magmático de Goiás (AMG), Maciço de Goiás (MG) e Zona Externa (ZE), com base em dados de aeromagnetometria e gravimetria de satélite e terrestre, a fim definir regiões de contato entre estas unidades e indicar possíveis zonas de sutura crustal. Para conseguir isto, foram aplicadas técnicas de realce nos dados usados, a fim de facilitar a integração e interpretação dos dados tais como os mapas da Derivada Vertical, de Gradiente Horizontal Total, da Derivada Tilt e da Derivada Tilt do Gradiente Horizontal Total. As estruturas magnéticas apresentam trend NESW, que de acordo com matched filter se estendem até, pelo menos, $19 \mathrm{~km}$ de profundidade. $\mathrm{O}$ matched filter aplicado em sub-janelas para cada bloco indica que no bloco MG as fontes mais profundas $(10,2 \mathrm{~km})$ são mais rasas do que os blocos ZE e AMG $(12,1 \mathrm{~km}$ e $11,9 \mathrm{~km}$, respectivamente). Os mapas de anomalias Bouguer (modelo WGS 2012 e dados terrestres) confirmam o trend regional NE-SW, observado nos dados magnéticos. Ambos ressaltaram nos blocos ZE e MG anomalias de intensidade intermediária e no bloco AMG altos gravimétricos. Os altos gradientes no $\mathrm{MG}$ estão associados aos complexos máficosultramáficos. Com base nos dados observa-se que a Falha Rio Maranhão não é uma estrutura profunda, indicando que Maciço de Goiás constitui o embasamento do Paleocontinente São Francisco.

Palavras chaves: Faixa Brasília, blocos tectônicos, assinatura geofísica, Maciço de Goiás, zona de sutura. 


\begin{abstract}
The Brasília Belt is the larger and complex unity of Tocantins Province, in geotectonic context this is an important recording of important episodes of formation of West Gondwana. Among the units developed thrusts and reverse faults of regional scale. Regional Faults and shear zones are fundamental for understanding the evolution of orogenic belts, for marking boundaries of areas and facilitate the exhumation of high pressure and temperature rocks. For explaining the evolution process of Brasília Belt two main hypotheses were considered. The first affirm that the Goiás Massif was a microcontinent which was alloyed to the western part of the São Francisco Craton in the Neoproterozoic. The second hypothesis considers that the Goiás Massif was part of the western edge of paleocontinent São Francisco in the early Proterozoic and that its basement would be covered by metassediments of the Paranoá and Bambuí Groups. To test these hypotheses, the objective of this study is to characterize the geophysical signatures of tectonic blocks, Goiás Magmatic Arc (AMG), Goiás Massif (MG) and External Zone (ZE), based on aeromagnetic, satellite and ground gravity data , to define regions of contact between these units and indicate possible crustal suture zone. To achieve this, enhancement techniques were applied to data which were used in order to facilitate integration and interpretation of the data such as Vertical Derivative, Total Horizontal Gradient, Tilt Derivative and Tilt Derivative of total horizontal gradient. The magnetic data presents trends NE-SW which according matched filter extend to at least $19 \mathrm{~km}$ depth. The matched filter applied in windows for each block indicates that the MG block the deeper sources $(10.2 \mathrm{~km})$ are shallower than those for AMG and ZE blocks $(12,1 \mathrm{~km}$ and $11.9 \mathrm{~km}$, respectively). The Bouguer anomalies (WGS 2012 and ground data) confirm the regional trend NE-SW observed in the magnetic data. Both highlights, in the ZE and MG blocks, intermediate intensity anomalies and in the AMG block gravity anoamlies intensity are higher. The high gradients in the MG block are associated with mafic-ultramafic complex. Based on the data it is observed that the Rio Maranhão Fault is not a deep structure, indicating that Goiás Massif is the basement of the São Francisco paleocontinent.
\end{abstract}

Keywords: Brasília Belt, tectonic blocks, geophysical signature, Goiás Massif, suture zone. 


\section{SUMÁRIO}

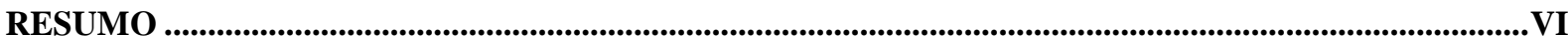

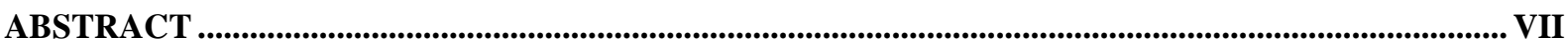

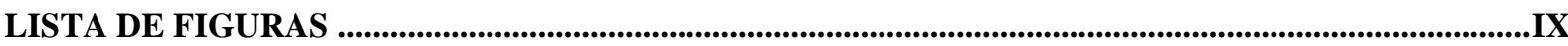

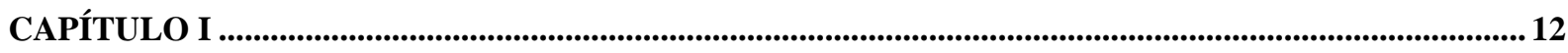

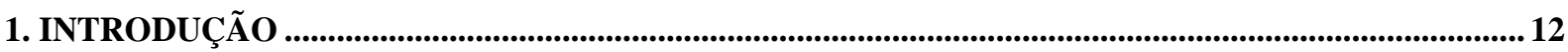

1.1 APRESENTAÇÃO

1.2 OBJETIVOS

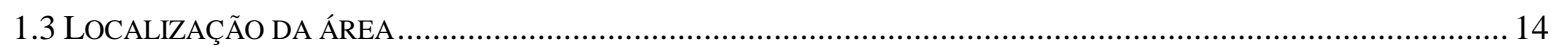

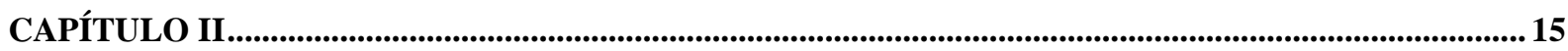

2. CONTEXTO GEOLÓGICO ............................................................................................................................. 15

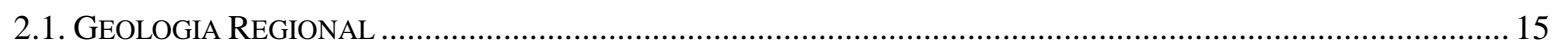

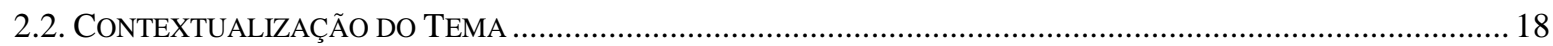

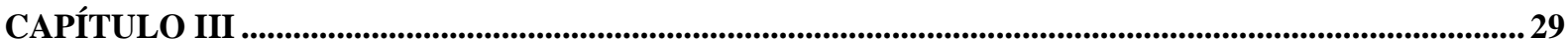

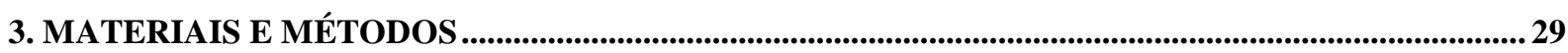

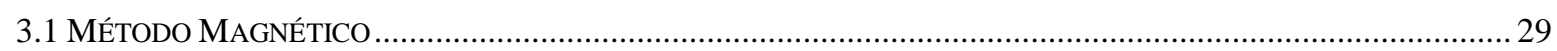

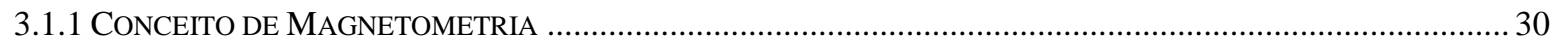

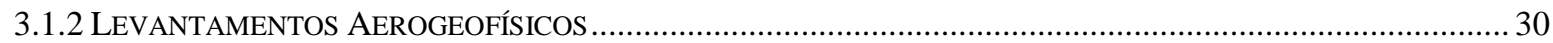

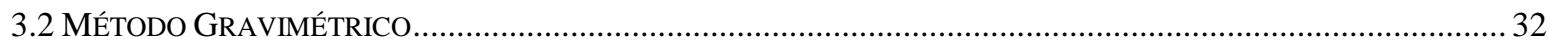

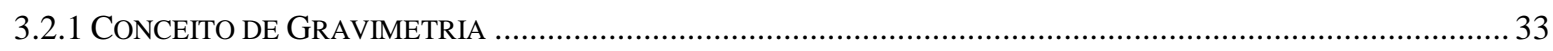

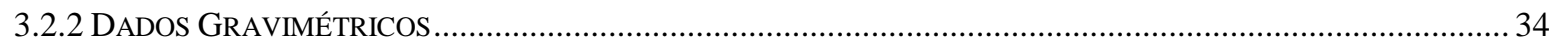

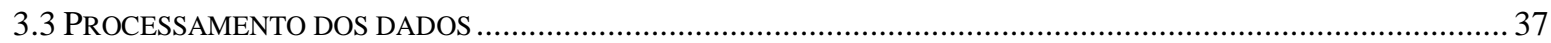

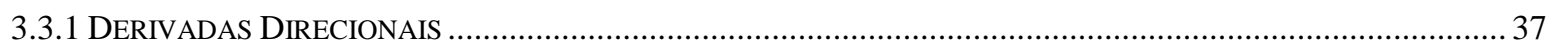

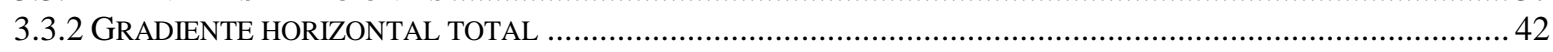

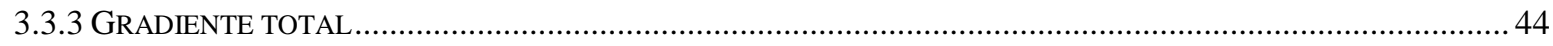

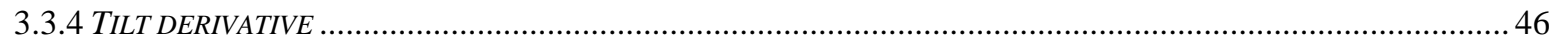

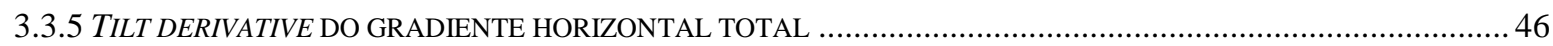

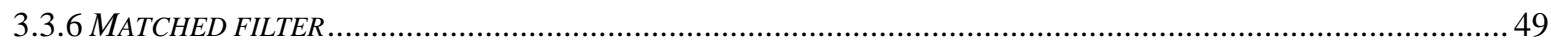

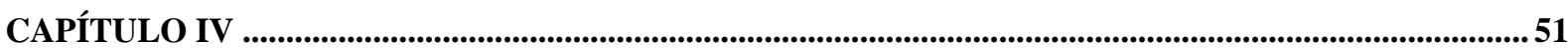

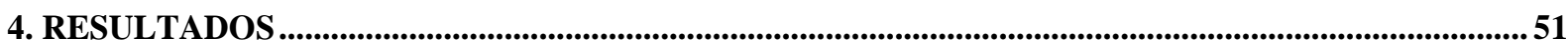

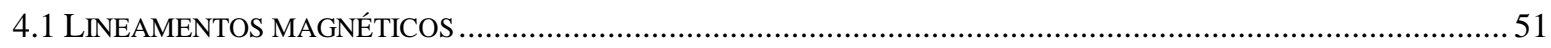

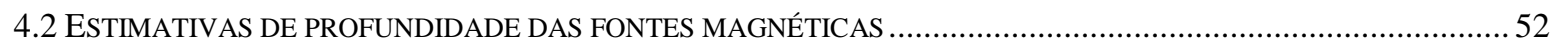

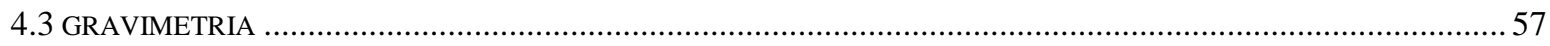

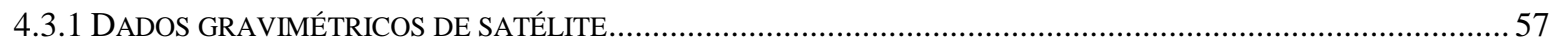

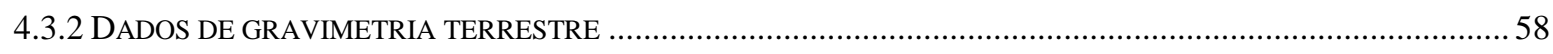

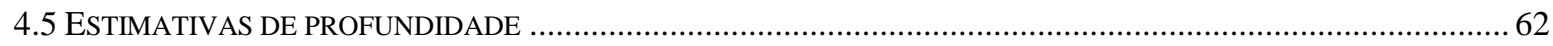

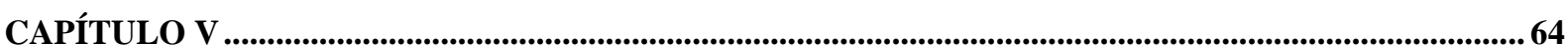

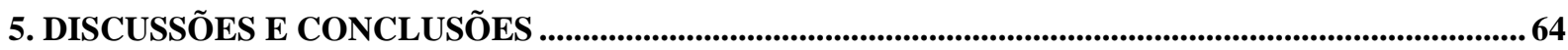

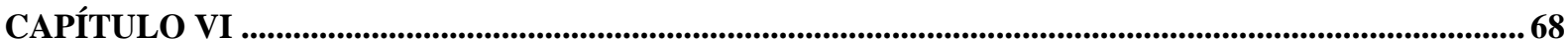

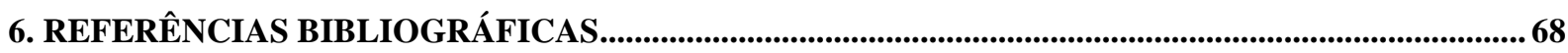




\section{LISTA DE FIGURAS}

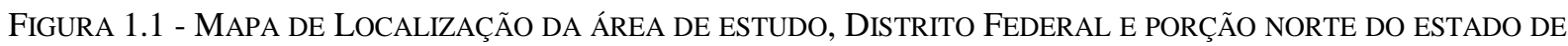
GOIÁS. LTB - LINEAMENTO TRANSBRASILIANO; FRB - FALHA RIO DOS BOIS; FRM - FALHA RIO MARANHÃO; AMG - ARCO MAGMÁtico DE GOIÁs; MG - MACIÇO DE GoIÁs; ZE - ZONA EXTERNA.

FigURA 2.1 - MAPA GEOLÓGICO SIMPLIFICADO COM AS PRINCIPAIS UNIDADES GEOTECTÔNICAS DA PORÇÃO CENTRAL DA FAIXA BRASília. (MODIFICADO DE VALERIANO ET AL., 2008 E FuCK ET AL., 2014). FRM - FALHA RIO MARANHÃO; FRB - FALHA RIO DOS BOIS; LTB - LINEAMENTO TRANSBRASILIANO

Figura 2.2 - - LocalizaÇão das Províncias TeCtônicas NeOPROTEROZOICAS Na Plataforma SulAmericana (Segundo Cordani \& Sato, 1999); (AM) Cráton Amazônico, (SF) São Francisco, (RP) Rio de La Plata, (SL) SÃo Luiz e (B) Província Borborema, (T) Província TOCANTINS, (M) ProvínCIA MANTIQUEIRA.

FIGURA 2.3 - AMALGAMAÇÃO DOS BLOCOS CRATÔNICOS E FORMAÇÃO DE ARCOS MAGMÁTICOS NO FECHAMENTO DO OCEANO GOIÁS-FARUSIANO E FORMAÇ̃̃o DO GONDWANA OCIDENTAL, EXTRAÍDO DE CORDANI ET AL. (2013). CRÁtONS: OA - OESTE AFriCANO; CA - CRÁTON AMAZÔNICO; CO - CONGO; SF SÃo FrANCISCO; FRAGMENTOS CRATÔNICOS MENORES: PB - PARNAÍBA; BO - BORBOREMA; MG Maciço de Goiás; PA - PARANAPANema; LA - Luiz Alves; RP - Rio de la Plata, ARCo dE ILHA: AG - ARCO MAGMÁTICO DE GOIÁS.

FigURA 2.4 - SUBDIVISÃO DAS UNIDADES SUPRACRUSTAIS DA FAIXA BRASÍLIA DE ACORDO COM A PROVÁVEL CONFIGURAÇÃO DE DEPOSIÇÃO, EXTRAÍDO DE PIMENTEL ET AL., (2011).

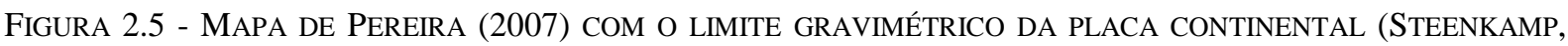
1998) COM LIMITE DO CRÁTON DO SÃO FRANCISCO (ALKMIM ET AL., 1993).

FigURA 2.6 - MODELO BIDIMENSIONAL, EXTRAÍDO DE SOARES ET AL., (2006) DA CROSTA E MANTO SUPERIOR SOB

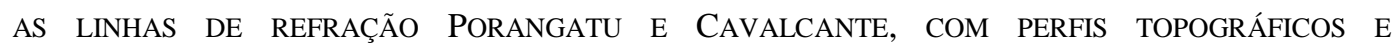
GRAVIMÉTRICOS, ONDE SE OBSERVA UMA DESCONTINUIDADE ACENTUADA ABAIXO DE MINAÇU COM MUDANÇA BRUSCA NA VELOCIDADE DO MANTO.

Figura 2.7 - SEÇão tRANSVERSAL DO PERFIL INTERPRETADO DE DADOS MAGNETOTELÚRICOS EXTRAÍDO DE PADILHA ET AL., (2013) COM BASE NO MODELO DE CONDUTIVIDADE E OUTROS CONTRASTES GEOFÍSICOS. A LINHA BRANCA TRACEJADA É UMA INTERPRETAÇÃO DA BORDA OCIDENTAL DO CRÁTON DO SÃO FRANCISCO SEGUNDO OS MESMOS AUTORES. AS LINHAS TRACEJADAS PRETAS SÃO INTERPRETAÇÕES COM BASE EM DADOS DE REFRAÇÃO SÍSMICA DA ESPESSURA DA CROSTA E GRANDES FALHAS DE SOARES ET AL. (2006).

FigURA 3.1 - MAPA COM PROJETOS AEROGEOFíSICOS QUE RECOBREM A ÁREA DE ESTUDO, REPRESENTADOS POR CÓDIGOS DOS LEVANTAMENTOS CONFORME A LEGENDA.

FigURA 3.2 - MAPA DO CMA A PARTIR DA INTEGRAÇÃO DOS LEVANTAMENTOS AEROMAGNÉTICOS. LTB LINEAMENTO TRANSBRASILIANO; FRM - FALHA RIO MARANHÃO; FRB - FALHA RIO DOS BOIS; AMG - ARCO MAGMÁTICO DE GOIÁs; MG - MACIÇO DE GOIÁs; ZE - ZONA EXTERNA.

FIGURA 3.3 - MODELO DE DEFORMAÇÃO DO GEOIDE: EFEITOS DE ESCALA CONTINENTAL. EXTRAÍdO DE REYNOLDS (1997).

Figura 3.4 - A) MaPa de anomalia Bouguer de satélite; B) MAPa DE pONTOS DE LeVANTAMentos TERRESTRES SOBRE O MODELO DIGITAL DE TERRENO; C) MAPA DE ANOMALIA BOUGUER DE DADO TERRESTRE. LIMITES TECTÔNICOS COM BASE EM PIMENTEL ET AL. (2004) E FUCK ET AL. (2014), LTB - LinEAMENTO TRANSBRASILIANO; FRB - FALHA Rio dos Bois; FRM - FALHA Rio MARANHÃo.

Figura 3.5 - MAPA DE DERIVADA EM X (GX) DO CMA COM ILUMinAÇÃO A 90 .LTB - LineAMENTO TRANSBRASILIANO, FRB - FALHA Rio DOS BoIS, FRM - FALHA Rio MARANHÃO.

Figura 3.6 - MAPA DA DERIVADA X (GX) DA ANOMALIA BOUGUER DOS DADOS GRAVIMÉTRICOS TERRESTRE. LTB - Lineamento Transbrasiliano, FRB - FalHa Rio dos Bois, FRM - FalHa Rio MARANHÃO.

Figura 3.7 - MAPA DE DERIVAdA Y (GY) DO CMA, COM IlUMinAÇÃo A $0^{\circ}$. LTB - LineAMENTO TRANSBRASILIANO, FRB - FALHA RIO DOS BOIS, FRM - FALHA RIO MARANHÃO. 40 
FigURA 3.8 - MAPA DA DERIVADA Y (GY) DA ANOMALIA BOUGUER DOS DADOS GRAVIMÉTRICOS TERRESTRE. LTB

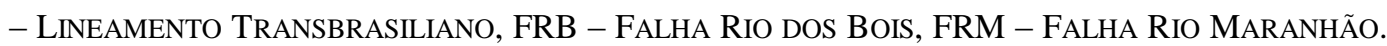

FIGURA 3.9 - MAPA DA DERIVADA Z (GZ) DO CMA, COM ILUMINAÇÃO A - $45^{\circ} \ldots \ldots \ldots \ldots$

FIGURA 3.10 - MAPA DA DERIVADA Z (Gz) DA ANOMALIA BOUGUER DOS DADOS GRAVIMÉTRICOS TERRESTRE. LTB - Lineamento TRANSBRAsiliano, FRB - FAlHa Rio dos BoIs, FRM - FalHa Rio MARANHÃO

FIGURA 3.11 - MAPA DO GRADIENTE HORIZONTAL TOTAL (GHT) DO CMA, REALÇANDO AS FEIÇÕES DE CONTATO DAS ANOMALIAS MAGNÉTICAS.

FIGURA 3.12 - MAPA DO GRADIENTE HORIZONTAL TOTAL DA ANOMALIA BOUGUER DE DADOS GRAVIMÉTRICOS TERRESTRE. LTB - LINEAMENTO TRANSBRASILIANO, FRB - FALHA RIO DOS BOIS, FRM - FALHA RIO MARANHÃO

FIGURA 3.13 - MAPA DO SINAL ANALÍTICO OU GRADIENTE TOTAL DO CAMPO MAGNÉTICO ANÔMALO.

FIGURA 3.14 - MAPA DO SINAL ANALÍTICO OU GRADIENTE TOTAL DA ANOMALIA BOUGUER DE DADOS GRAVIMÉTRICOS TERRESTRE. LTB - LINEAMENTO TRANSBRASILIANO, FRB - FALHA RIO DOS BOIS, FRM - FALHA RIO MARANHÃO.

FIGURA 3.15 - MAPA DO TILT DERIVATIVE DO CAMPO MAGNÉTICO ANÔMALO..

FigURA 3.16 - MAPA DO TILT DERIVATIVE DA ANOMALIA BOUGUER DE DADOS GRAVIMÉTRICOS TERRESTRE. LTB LINEAMENTO TRANSBRASILIANO, FRB - FALHA RIO DOS BOIS, FRM - FALHA RIO MARANHÃO. . 47

FIGURA 3.17 - MAPA TILT DERIVATIVE DO GRADIENTE HORIZONTAL TOTAL DO CAMPO MAGNÉTICO ANÔMALO... 48

FIGURA 3.18 - MAPA DO TILT DERIVATIVE DO GRADIENTE HORIZONTAL TOTAL DA ANOMALIA BOUGUER DOS DADOS GRAVIMÉTRICOS TERRESTRE. LTB - LINEAMENTO TRANSBRASILIANO, FRB - FALHA RIO DOS BOIS, FRM - FALHA RIO MARANHÃO.

FIGURA 3.19 - ESPECTRO DE POTÊNCIA GERADO DO DADO DO CAMPO MAGNÉTICO ANÔMALO, EM QUE FORAM MARCADOS OS INTERVALOS DE FONTES MAGNÉTICAS E OBTIDOS OS INTERVALOS DE PROFUNDIDADE. A LINHA VERDE REPRESENTA O ESPECTRO E A LINHA AZUL O AJUSTE DE ACORDO COM A INTERPRETAÇÃO DOS SEGMENTOS DE RETAS.

FigurA 3.20 - ESPECTRO DE POTÊNCIA GERADO A PARTIR DOS DADOS DE ANOMALIA BOUGUER TERRESTRE, A LINHA VERDE REPRESENTA O ESPECTRO DE POTÊNCIA E A LINHA AZUL O AJUSTE DE ACORDO COM A INTERPRETAÇÃO DOS DADOS, EM QUE FORAM CALCULADAS AS PROFUNDIDADES DAS FONTES E OS PARÂMENTROS DOS FILTROS.

FigURA 4.1 - MAPA DE LINEAMENTOS MAGNÉTICOS INTERPRETADOS A PARTIR DOS PRODUTOS DO CAMPO MAGNÉTICO ANÔMALO SOBRE O MAPA DO CMA, DIAGRAMA DE ROSETAS DOS DOMÍNIOS TECTÔNICOS ESTUDADOS EM DESTAQUE, LIMITES GEOTECTÔNICOS CONHECIDOS E LOCALIDADES DA REGIÃO. OS LIMITES GEOTECTÔNICOS DA ÁREA DE ESTUDOS COM BASE NO MAPA MODIFICADO DE PIMENTEL ET AL. (2004) E FUCK ET AL., (2014). LTB - LINEAMENTO TRANSBRASILIANO; FRB FalHa Rio dos BoIs; FRM - FalHa Rio MaRANHÃo; AMG - ARCO Magmático de GoiÁs; MG - MaCiço DE Goiás; ZE - Zona EXTERna; CSF - CRÁton SÃo FranCisCo.

FIGURA 4.2 - MAPAS OBTIDOS NO MATCHED FILTER PARA FONTES RASAS E INTERMEDIÁRIAS, A PARTIR DOS DADOS DO CMA, COM LIMITES TECTÔNICOS DE ACORDO COM MAPA DE PIMENTEL ET AL. (2004) E FUCK ET $A L$. (2014). AS LINHAS TRACEJADAS INDICAM PROJEÇÃO DO LINEAMENTO TRANSBRASILIANO. MAPAS DE FONTES: RASAS A 700 M (A); INTERMEDIÁRIAS A 2 KM (B), INTERMEDIÁRIAS A 8 KM (C); PROFUNDAS A 19 KM (D). LTB - LINEAMENTO TRANSBRASILIANO; FRB - FALHA RIO DOS BOIS; FRM - FALHA RIO MARANHÃO.

FigURA 4.3 - MAPAS COM LINEAMENTOS MAGNÉTICOS INTERPRETADOS NOS PRODUTOS DO MATCHED FILTER. MAPAS DE LINEAMENTOS DE FONTES: A 700 M (A); A 2 KM (B); A 8 KM (C), A 19 KM (D). LIMITES TECTÔNICOS DE ACORDO COM MAPA DE PIMENTEL ET AL. (2004) E FUCK ET AL. (2014). LTB LiNEAMENTO TRANSBRASILIANO; FRB - FALHA RIO DOS BOIS; FRM - FALHA RIO MARANHÃO.. 55

FIGURA 4.4 - MAPA DO CAMPO MAGNÉTICO ANÔMALO COM A LOCALIZAÇÃO DAS SUB-JANELAS ELABORADAS PARA ANÁLISE DE PROFUNDIDADE USANDO MATCHED FILTER DE CADA BLOCO TECTÔNICO...............56

Figura 4.5 - MAPA DE ANOMALIA Bouguer DO WGM 2012; Limites teCtÔNICOS COM BASE EM PiMENTEL ET AL. (2004) E FUCK ET AL. (2014) E AS FALHAS DE EMPURRÃO RiO MARANHÃO E RIO DOS BOIS. LTB 
- LinEAMENTO TRANSBRASILIANO; FRB - FALHA Rio DOS BOIS; FRM - FALHA RIO MARANHÃO. 58

Figura 4.6 - MAPA DE ANOMALIA BOUGUER DO WGM 2012; LiMITES TECTÔNICOS COM BASE EM PIMENTEL ET AL. (2004) E FUCK ET AL. (2014) E AS FALHAS DE EMPURRÃO RIO MARANHÃO E RiO DOS BOIS. LTB - LiNEAMENTO TRANSBRASILIANO; FRB - FALHA Rio DOS BOIS; FRM - FALHA Rio MARANHÃO.

Figura 5.1 - MAPA INTERPRETADO COM A GEOLOGIA ESTRUTURAL DE ACORDO COM BIZZI ET AL. (2003), COM BASE EM VALERIANO ET AL., (2008) E FUCK ET AL. (2014), SOBRE O MAPA DO MATCHED FILTER DE 19 KM, COM OS PRINCIPAIS LINEAMENTOS MAGNÉTICOS.

FIGURA 5.2 - MAPA DO MATCHED FILTER DE 15 KM DA ANOMALIA BOUGUER TERRESTRE, COM LOCALIZAÇÃO DE DADOS GEOCRONOLÓGICOS DE CORDEIRO ET AL., (2014) E FUCK ET AL., (2014) E DADOS ESTRUTURAIS DE ACORDO COM BIZZI ET AL. (2003), E COMPARTIMENTAÇÃO TECTÔNICA COM BASE EM PIMENTEL ET AL., (2004) E FUCK ET AL. (2014).

\section{LISTA DE TABELAS}

TABELA 3.1 - INFORMAÇÕES DOS PROJETOS GEOFÍSICOS USADOS NESTE TRABALHO. 31

TABELA 4.1 - INTERVALOS E MÉDIAS PARA CADA BLOCO TECTÔNICO OBTIDOS NO MATCHED FILTER. 


\section{Capítulo I}

\section{INTRODUÇÃO}

\subsection{APRESENTAÇÃO}

No Neoproterozóico ocorreram episódios marcantes de amalgamação e dispersão do supercontinente Rodínia e fusão paralela de porções cratônicas que formaram uma grande massa continental, Gondwana, via de uma série de eventos orogênicos (Rogers e Santosh, 2004). No decorrer desses eventos orogênicos formaram-se diversas faixas móveis na borda dos crátons, onde foram acomodadas convergências litosféricas resultante da fase final da amalgamação da porção oeste do Gondwana (Cordani et al., 2003).

Em meio a estes eventos formou-se a Faixa Brasília, como resultado da colisão entre os crátons Amazônico, a oeste, São Francisco-Congo, a leste, e um terceiro bloco (Paranapanema), na porção sul, atualmente escondido embaixo de sedimentos fanerozóicos da Bacia do Paraná (Pimentel et al. 1999). Trata-se de um espesso pacote sedimentar, composto de várias unidades estratigráficas, que foram deformadas e metamorfizadas ao longo da margem ocidental do Cráton do São Francisco durante a orogênia Brasiliana (Pimentel et al., 2011).

A evolução desta faixa é complexa, pois nela houve o desenvolvimento de outras unidades tectônicas, tais como o Maciço de Goiás, arcos magmáticos neoproterozóicos e sequências sedimentares meso-neoproterozóicas (Uhlein et al., 2012). A indicação de zonas de sutura relacionadas ao evento Transbrasiliano, têm papel de fundamentar o contexto geotectônico o qual este orógeno se formou. As zonas de sutura podem ser indicadas por grandes zonas de cisalhamento ou pela presença de complexos granulíticos associados às faixas orogênicas, que são consideradas como limites de diferentes domínios (Fuck et al., 2014).

Neste trabalho o estudo do arcabouço tectônico foi realizado por meio de métodos magnéticos e gravimétricos, cuja análise se baseia em modelo de blocos crustais, que considerou a compartimentação geotectônica sugerida por Pimentel et al., (2004), Valeriano et al. (2008) e Fuck et al. (2014), a qual esta região da faixa é subdividida em Zona Externa, Zona Interna (bloco ZE), Maciço de Goiás (bloco MG) e Arco Magmático de Goiás (bloco AMG), sendo os sistemas de falhas Rio Maranhão (FRM) e Rio dos Bois (FRB), os principais limites entre estas unidades. A área de trabalho está localizada na porção centro-norte da Faixa Brasília, geograficamente na porção norte do estado de Goiás, limitada pelas latitudes $-13^{\circ}$ e $-16^{\circ}$ e longitudes $-46^{\circ}$ e $-51^{\circ}$. 
Neste trabalho a Falha Rio Maranhão será a principal abordagem em função dos diferentes aspectos sobre a sua gênese, que tem sido estudada em trabalhos de geologia e geofísica, tais como de Soares et al. (2006), D’el Rey Silva et al. (2008), Ventura et al. (2011), Padilha et al. (2013), Pimentel et al. (2011) e Cordeiro et al. (2014). Estes trabalhos apresentam entendimentos diferentes sobre a origem desta estrutura, para fundamentar modelos tectônicos distintos sobre a evolução da Faixa Brasília.

Com relação à compartimentação tectônica da área, é importante ressaltar que há duas hipóteses em torno da evolução para a Faixa Brasília. A primeira considera que o Maciço de Goiás é um microcontinente amalgamado à parte oeste do Cráton São Francisco no Neoproterozóico, seguindo ideias propostas por Brito Neves e Cordani (1991), Blum e Pires (1996), Pimentel et al., (1999, 2000), Valeriano et al. (1995, 2008), Cordani et al. (2013). A segunda afirma que o Maciço de Goiás constituiria a borda oeste do Paleocontinente São Francisco no Mesoproterozóico, que foi fortemente afetada por uma série de eventos durante o Neoproterozóico, sendo esta proposta sugerida por Fuck (1994), Pereira e Fuck (2005), Soares et al. (2006), Carminatti (2006), MartinsNeto (2009), D’el-Rey Silva et al. (2008, 2011), Ventura et al. (2011), Brito Neves e Fuck (2013), Fuck et al. (2014). Esta segunda hipótese considera que o Paleocontinente São Francisco poderia ser o embasamento da cobertura metassedimentar da Faixa Brasília.

Para sugerir um significado geológico/ estrutural para o compartimento de blocos este trabalho teve como objetivo principal a aplicação de métodos de filtragem para realçar os sinais, verificar a assinatura geofísica de cada bloco tectônico, com isto, definir os limites entre eles, além da aplicação do Matched Filter para estimar os principais intervalos de profundidade de fontes magnéticas e gravimétricas que constituem esta região e com estes dados sugerir uma possível zona de sutura.

\subsection{OBJETIVOS}

O objetivo principal desta dissertação é analisar os modelos de blocos crustais na porção centro-norte da Faixa Brasília, com base em dados de magnetometria e gravimetria, para melhor compreender os limites estruturais estabelecidos pelas Falhas Rio Maranhão e Rio dos Bois em superfície e profundidade, e desta forma contribuir para o entendimento da configuração das principais unidades geotectônicas que compõem esta região do orógeno. Para isto, foi necessário desenvolver os seguintes objetivos específicos:

i. Aplicação dos métodos de filtragem nos dados para realçar os sinais e melhor definir seus limites; 
ii. Verificação da assinatura geofísica dos blocos tectônicos e caracterizá-los de acordo com sua assinatura;

iii. Aplicação de técnicas de estimativas de profundidade em cada bloco;

iv. Sugerir um significado geológico/estrutural para as falhas com base nos modelos existentes;

\subsection{LOCALIZAÇÃO DA ÁREA}

A área de estudo está localizada geograficamente na porção central do estado de Goiás e extremo sul do Tocantins, entre as cidades de Brasília, na porção sul, e Porangatu no norte da área (Figura 1.1), abrange ainda pequenas porções dos estados de Minas Gerais e Bahia. No contexto geológico a área está inserida na Província Tocantins, tendo como foco a Faixa Brasília. A área está limitada pelas latitudes $-13^{\circ}$ e $-16^{\circ}$ e longitude $-46^{\circ}$ e $-51^{\circ}$.

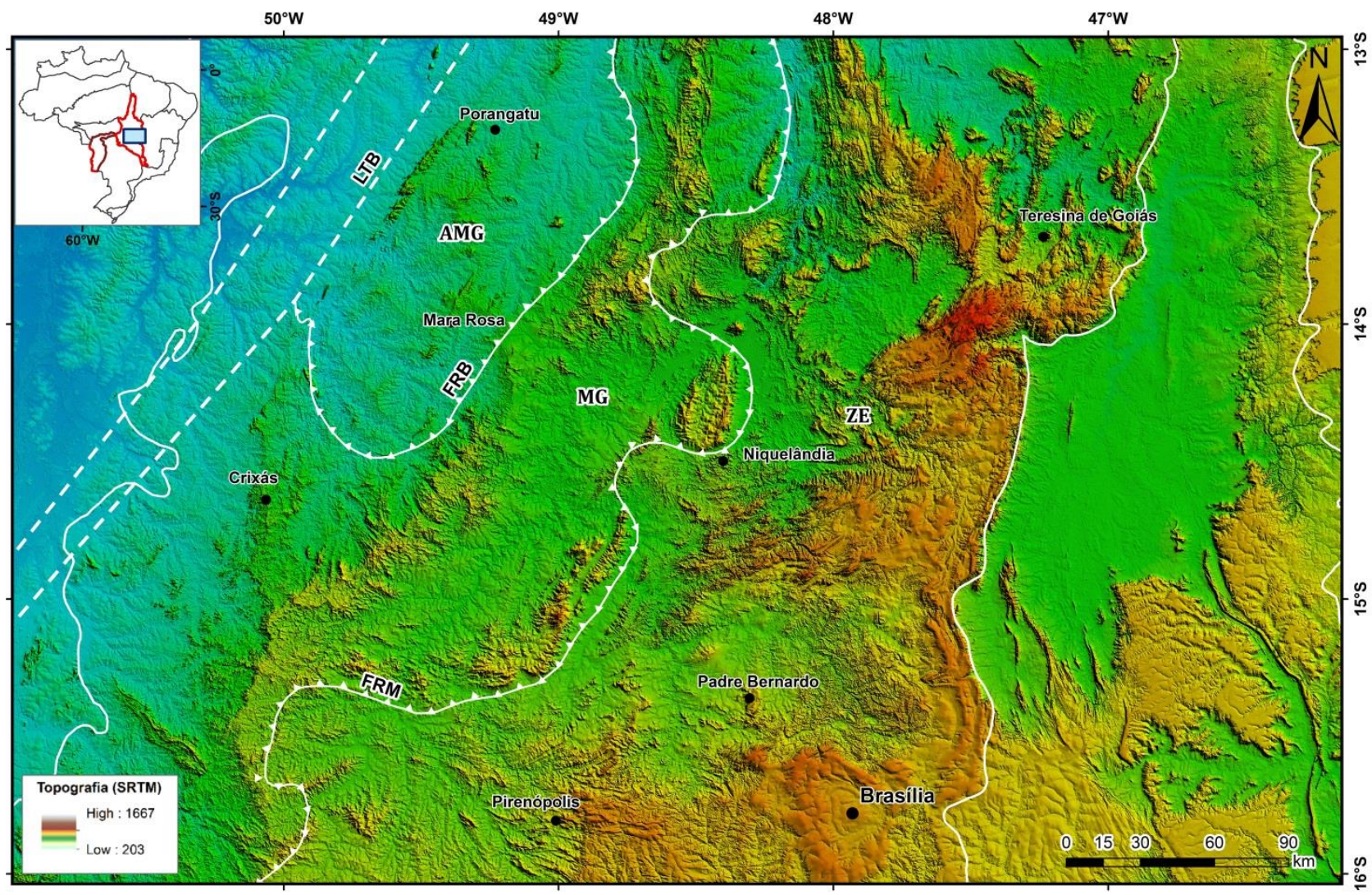

Figura 1.1 - Mapa de Localização da área de estudo, Distrito Federal e porção norte do estado de Goiás. LTB Lineamento Transbrasiliano; FRB - Falha Rio dos Bois; FRM - Falha Rio Maranhão; AMG - Arco Magmático de Goiás; MG - Maciço de Goiás; ZE - Zona Externa. 


\section{Capítulo II}

\section{CONTEXTO GEOLÓGICO}

\subsection{GEOLOGIA REGIONAL}

A Província Tocantins está localizada no Brasil Central, limitada pelo Cráton Amazônico, a oeste e Cráton do São Francisco, a leste e a sul pela Bacia do Paraná. Sua origem está ligada à orogenia Brasiliana, em que ocorreu a amalgamação da porção ocidental do supercontinente Gondwana (Fuck et al., 2014). A província está subdividida em três faixas orogênicas: Faixa Araguaia, Faixa Paraguai e Faixa Brasília (Lacerda Filho e Frasca, 2008). Sobre algumas porções da província ocorrem sedimentos de bacias sedimentares fanerozóicas.

A Faixa Brasília é uma unidade neoproterozóica com orientação N-S, que ocupa cerca de $1.000 \mathrm{~km}^{2}$ da porção central da Província Tocantins, foi inicialmente assim denominada por Almeida et al. (1981), Dardenne (1978), Dardenne et al. (1981), Fuck (1990), Fuck et al.(1993), Fuck (1994) e Pimentel et al.(2000). Fuck (1994) descreve a Faixa Brasília como um extenso sistema de dobramentos, de idade neoproterozóica edificado na borda oeste do Cráton do São Francisco. De acordo com Fuck (1994) e Fuck et al. (2014) a Faixa de dobramentos Brasília compreende domínios litotectônicos limitados por grandes falhas longitudinais: Arco Magmático de Goiás, zona Externa, zona Interna e Maciço de Goiás. No mapa geológico observa-se também a borda oeste do Cráton São Francisco, mas como não é o principal enfoque deste trabalho, não será caracterizada (Figura 2.1).

O Arco Magmático de Goiás é composto por rochas meta-vulcano-sedimentares, granitos e ortognaisses neoproterozóicos (Fuck, 1994). Este arco foi gerado em ambiente de subducção, seguido da colisão entre os crátons Amazônicos e do São Francisco durante a orogênese brasiliana (Pimentel e Fuck, 1987). De acordo com Pimentel e Fuck (1992) e Pimentel et al. (1993), o arco é uma crosta juvenil, que possui assinatura isotópica típica de arcos magmáticos intraoceânicos que teria sido acrescionada entre 930 e 600 Ma. Sua relação com a Zona Interna da Faixa Brasília ainda não está muito bem estabelecida, por isso não possui um limite muito bem definido com a mesma. 


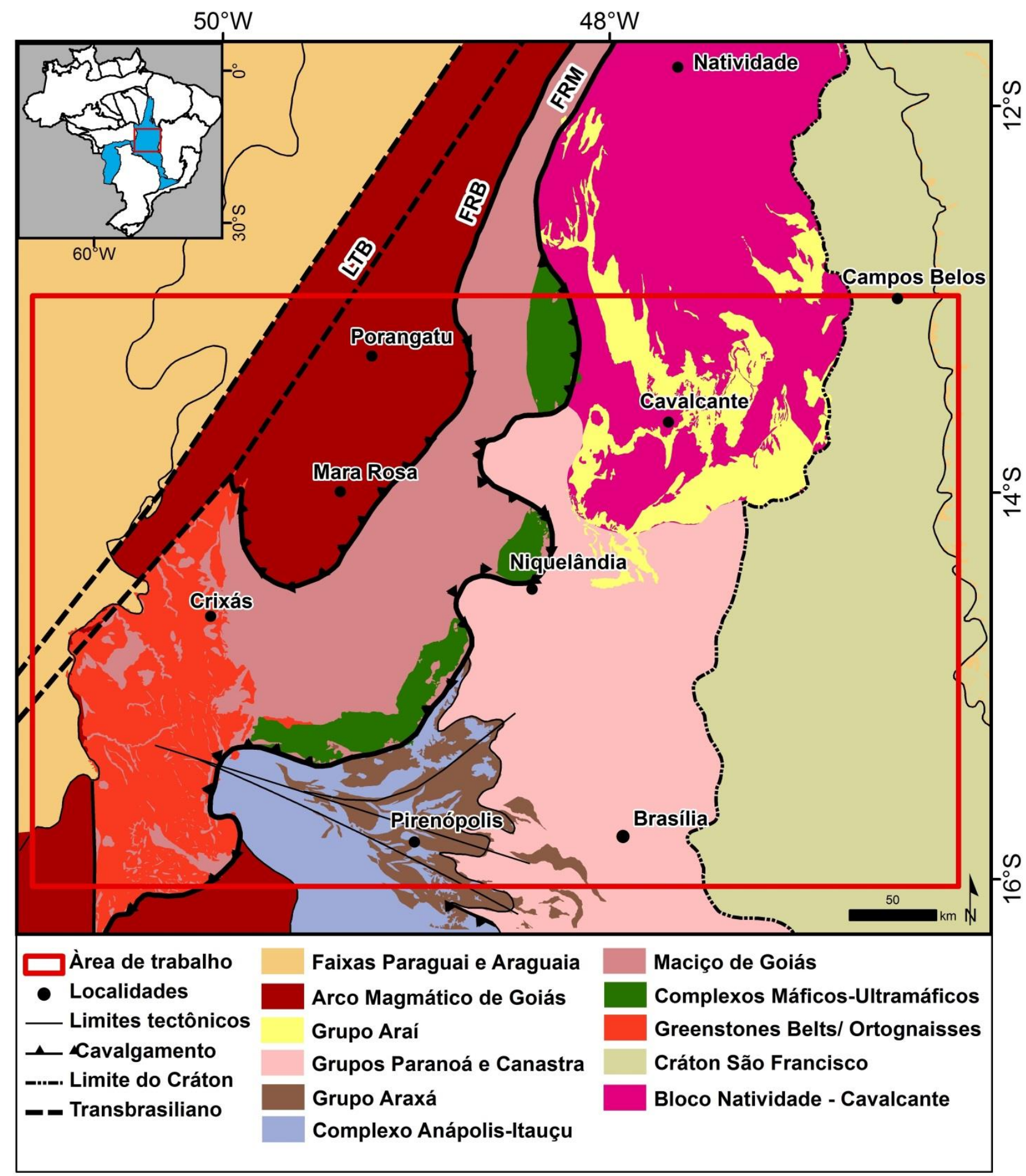

Figura 2.1 - Mapa geológico simplificado com as principais unidades geotectônicas da porção central da Faixa Brasília. (Modificado de Valeriano et al., 2008 e Fuck et al., 2014). FRM - Falha Rio Maranhão; FRB - Falha Rio dos Bois; LTB - Lineamento Transbrasiliano.

No Arco Magmático de Goiás estão os terrenos ortognáissicos e as sequências vulcanosedimentares com idade neoproterozóica de Sanclerlândia-Bom Jardim, Mara Rosa e Porangatu (Pimentel et al., 1991; Viana et al., 1995). Tectonicamente o Arco está limitado por importantes estruturas de escala regionall, a oeste pelo Lineamento Transbrasiliano e leste pela Falha Rio dos Bois. O Lineamento Transbrasiliano é um grande sistema de falha transcorrentes (Schobbenhaus et 
al., 1975) que se constituiu no final da orogenia Brasiliana- Pan Africano (Cordani et al., 2010b) considerado como um dos maiores exemplos de intracontinental strike slip (Fuck et al., 2013). A Falha Rio dos Bois marca o limite leste com o Maciço de Goiás, devido uma zona de superposição de crosta, relacionada ao choque de placas não se sabe ao certo quão profunda é esta estrutura, mas há ocorrências de rochas arqueanas, as quais algumas sofreram retrabalhamento ou mesmo metamorfismo em zona de cisalhamento.

Dentro do Maciço de Goiás estão os terrenos granito-greenstone arqueanos. Fuck (1994) o descreve como um fragmento crustal complexo, que apresentou um comportamento alóctone durante a orogenia Brasiliana. Possui limite ocidental com uma zona de cisalhamento transpressional que o separa do arco magmático (Fuck, 1994). Dentro desta unidade estão inclusos os complexos granito-gnáissicos arqueanos, ortognaisses paleoproterozóicos que em grande parte estão recobertos por sequências metassedimentares dobradas, e camadas de intrusões máficaultramáficasassociados a sequências meta-vulcanossedimentares mesoproterozoicas (Juscelândia, Palmeirópolis, Indianópolis), que estão adjacentes aos complexos máfico-ultramáficos acamadados meso- a neoproterozóicos (Barro Alto, Niquelândia e Cana Brava). Os terrenos ortognáissicos estão é constituído por as rochas metassedimentares do Grupo Serra da Mesa (Fuck, 1994).

A Zona Externa de acordo com Fuck (1994) é formada por rochas paleoproterozoicas do grupo Natividade, unidades metassedimentares, paleo-mesoproterozoicas dos grupos Araí e Paranoá, sequências metassedimentares neo-mesoproterozoicas das formações Canastra, Vazante e Ibiá, assim como algumas porções do embasamento, estruturadas em um cinturão de dobras e empurrões de antepaís (Rochas máfico-ultramáficas granulitizadas dos Complexos Cana Brava, Niquelândia e Barro Alto).

A Zona Interna constituída por rochas do grupo Araxá e rochas máficas toleíticas associadas, complexos ofiolíticos, fragmentos do embasamento e o complexo granulítico AnápolisItauçu, com assembleias minerais de alto metamorfismo.

A borda oeste do Cráton do São Francisco é sobreposta por uma sequência de rochas siliciclásticas e carbonáticas do Mesoproterozóico ao Neoproterozóico, genericamente pertencentes ao Grupo Bambuí (Alvarenga et al., 2012). 


\subsection{ConteXtualizaÇão DO TEMA}

A história de evolução da Plataforma Sul-Americana vem sendo investigada por diversos autores, desde a década de 50, partindo de Guimarães (1951), que publicou um estudo sobre o Escudo Brasil Central identificando regiões estabilizadas no Arqueano.

Almeida (1976) apresentou a primeira divisão tectônica da América do Sul, posteriormente modificações desta proposta foram realizadas por Cordani e Brito Neves (1982), Almeida e Hasui (1984), Schobbenhaus et al., (1984), Brito Neves et al. (1990) e Lacerda Filho (2000), entre outros. De acordo com estes autores a maior transformação desta Plataforma está relacionada à orogenia Brasiliano/Pan-Africano, que em princípio ocasionou eventos de deformação e metamorfismo ocorridos entre $700 \mathrm{Ma}$ a $520 \mathrm{Ma}$, e contribuiu para a definição das faixas orogênicas e crátons dentro da Plataforma.

As primeiras ideias de compartimentação tectônica da Plataforma Sul - Americana, tais como de Almeida (1976), afirmavam que ela é constituída por núcleos cratônicos estabilizados no fim do Ciclo Transamazônico $( \pm 2.000 \mathrm{Ma})$, bordejados por faixas móveis proterozóicas (Almeida, 1976; Almeida et al., 1977, 1981). Almeida e Hasui (1984) incluíram a estas unidades pequenas regiões de maciços e que após a estabilização foram recobertas por unidades sedimentares da orogenia brasiliana e sedimentos fanerozóicos. Com base em dados isotópicos de rochas graníticas, Cordani e Sato (1999), sugeriram classificação e nomenclatura para as unidades da plataforma, sendo os núcleos cratônicos, os crátons Amazônico e do São Francisco, os pequenos blocos cratônicos Rio de la Plata, São Luiz, e Luiz Alves (Figura 2.2), e as faixas móveis associadas à orogenia Brasiliana/ Pan-Africano, nomeadas de Faixa Brasília, Faixa Araçuaí, e Faixa Dom Feliciano.

A partir desta proposta de compartimentação, outros conceitos foram inseridos, tal como de Lacerda Filho (2000), que sugeriu uma estruturação geotectônica da Plataforma Sul-Americana na região central do Brasil, que seria subdividida em duas partes: a pré-Brasiliana e a Brasiliana. A parte pré-Brasiliana corresponderia aos crátons Amazônico e do São Francisco. A parte Brasiliana corresponderia à parte orogênica, com os eventos de deformação. 


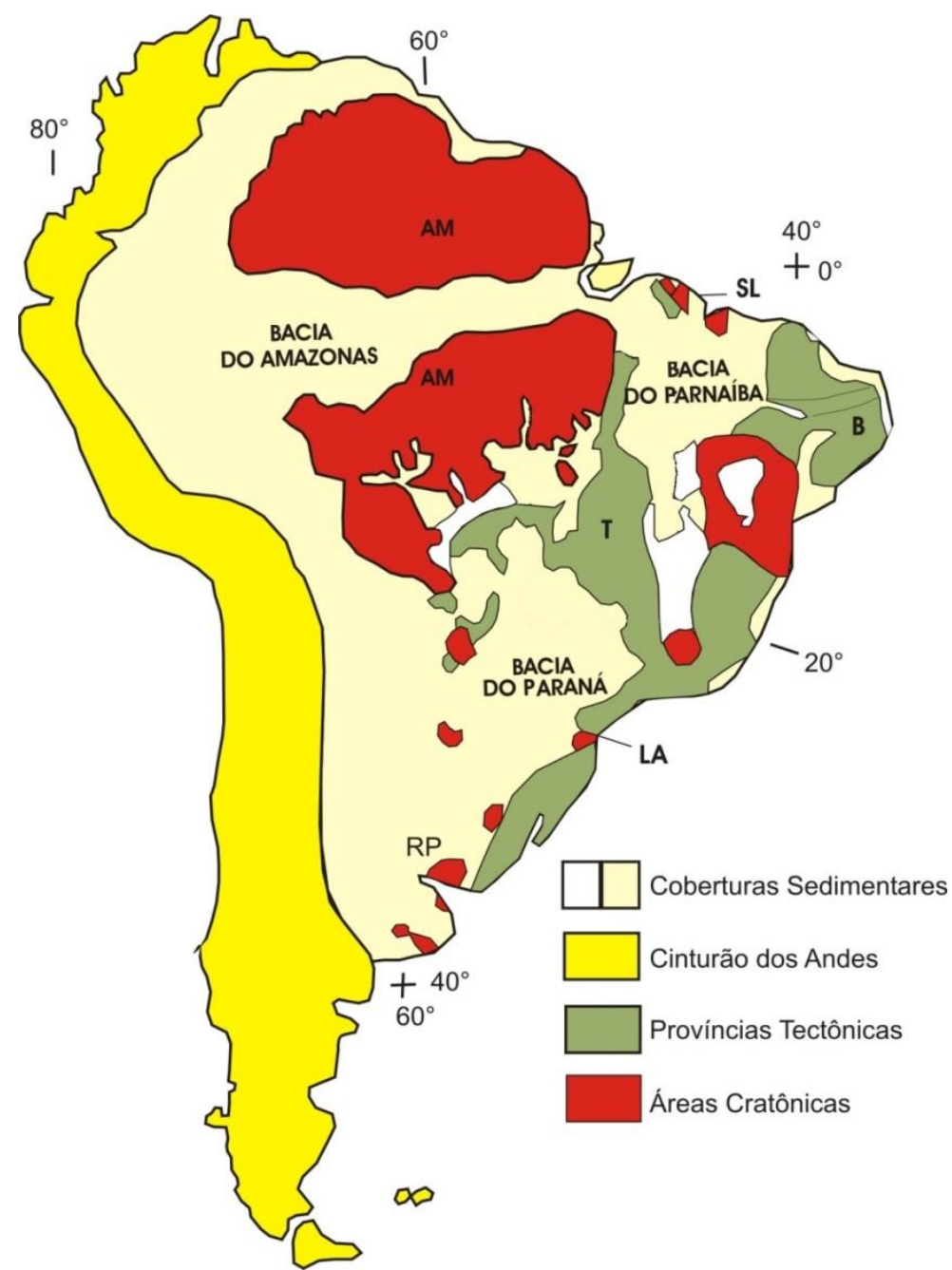

Figura 2.2 - - Localização das Províncias Tectônicas neoproterozoicas na Plataforma Sul-Americana (Segundo Cordani \& Sato, 1999); (AM) Cráton Amazônico, (SF) São Francisco, (RP) Rio de La Plata, (SL) São Luiz e (B) Província Borborema, (T) Província Tocantins, (M) Província Mantiqueira.

Outras propostas de estruturação foram sugeridas, como de Brito Neves \& Fuck (2013), que subdividiram a Plataforma em dois grandes domínios: O domínio do Cráton Amazônico e arredores (na porção noroeste-oeste) e o domínio extra-Amazônico (na porção central-sudeste). No primeiro domínio, a porção cratônica era muito mais influente, com relação aos processos neoproterozóicos que ocorriam de forma localizada, já o domínio extra-Amazônico, se refere às estruturas e formas desenvolvidas durante a formação de faixas móveis neoproterozóicas (Cordani et al. 1984, 2013; Brito Neves et al, 2014). Neste último, se desenvolveram quatro províncias estruturais: Províncias Pampeana, Tocantins, Borborema e Mantiqueira.

Esta estruturação simboliza o evento de fechamento do Oceano Goiás-Farusiano (Figura 2.3), que ocorreu do período Neoproterozóico ao início do Paleozoico, que seria o principal responsável pela orogenia Brasiliano/Pan-Africana, e que indica a existência do corredor Transbrasiliano-Kandi, na formação do Gondwana Ocidental (Trompette, 1994; Pimentel et al., 2000; Valeriano et al., 2008, Cordani et al., 2013). Este corredor estaria relacionado ao que 
conhecemos como Lineamento Transbrasiliano que teria se constituído no período de 950-650 Ma. O Corredor Trans-Brasiliano-Kandi poderia indicar a presença de zonas de sutura colisionais, que estariam distribuídas a quilômetros do eixo principal desta "megashear zone" (Cordani et al., 2013).

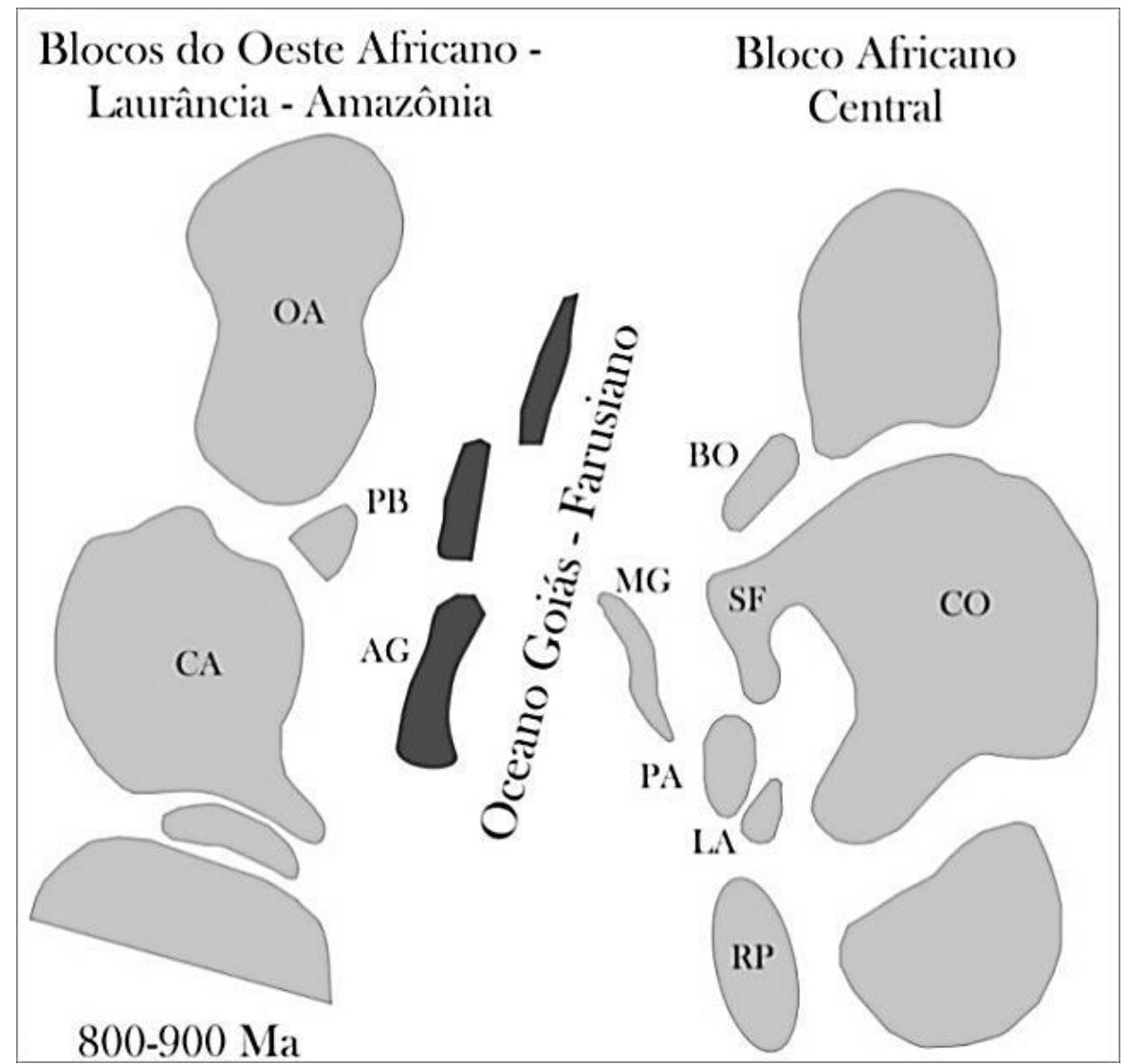

Figura 2.3 - Amalgamação dos blocos cratônicos e formação de arcos magmáticos no fechamento do oceano GoiásFarusiano e formação do Gondwana Ocidental, extraído de Cordani et al. (2013). Crátons: OA - Oeste Africano; CA Cráton Amazônico; CO - Congo; SF - São Francisco; Fragmentos cratônicos menores: PB - Parnaíba; BO Borborema; MG - Maciço de Goiás; PA - Paranapanema; LA - Luiz Alves; RP - Rio de la Plata, Arco de ilha: AG Arco Magmático de Goiás.

Em meio a este contexto formou-se a Faixa Brasília, que se destaca por ser considerada a maior e mais preservada faixa orogênica da orogenia Brasiliana/Pan-Africana que constitui a porção central do Brasil (Pimentel et al., 1999). Neste período esta faixa estaria constituída por blocos cratônicos, arcos magmáticos e coberturas sedimentares.

A formação desta faixa possui uma série de hipóteses sobre os eventos de acresção e rifteamento que geram incertezas sobre sua gênese. Para realização deste trabalho destacamos três unidades geotectônicas: Zona Externa, o Maciço de Goiás e o Arco Magmático de Goiás, sendo que perfazem contato com o Cráton São Francisco, a leste, e com as faixas Paraguai e Araguaia, a oeste, de acordo com zoneamento tectônico sugerido por Valeriano et al. (2008) e Fuck et al. (2014) (Figura 2.1). Dentre estas unidades dois grandes complexos de falhas são considerados como os 
principais limites tectônicos, a Falha Rio Maranhão e a Falha Rio dos Bois, ambas constituem os limites do Maciço de Goiás.

Para esta compartimentação tectônica duas hipóteses de evolução geotectônica se destacam: A primeira considera que o Maciço de Goiás é um microcontinente amalgamado à parte oeste do Cráton do São Francisco no Neoproterozóico. A segunda afirma que o Maciço de Goiás constitui a borda oeste do paleocontinente São Francisco, desde o Mesoproterozóico, e que foi fortemente afetada por uma série de eventos durante o Neoproterozóico, sendo que parte do paleocontinente estaria atualmente recoberta por camadas metassedimentares.

Sobre a primeira proposta, Brito Neves e Cordani (1991) afirmavam que um fragmento crustal independente no centro de Goiás representava um microcontinente que se envolveu nos processos colisionais durante o Brasiliano. Fuck (1994), ao tratar da compartimentação tectônica da Província Tocantins, considerou o zoneamento tectônico sugerido por Dardenne (1978) Dardenne et al. (1981), Fuck (1990) e Fuck et al.(1993), que seria: Zona cratônica, constituída por um embasamento recoberto por rochas do grupos Paranoá e Bambuí; Zona Externa; Zona Interna; Arco Magmático de Goiás e o Microcontinente, com os terrenos granito-greenstone que teriam se constituído no Arqueano. Sobre este microcontinente, o autor ressaltou que se tratava de um fragmento crustal que atuou de forma independente nos eventos orogênicos, e que no limite leste desta unidade a crosta inferior foi exposta através dos complexos máficos-ultramáficos que sofreram intenso metamorfismo granulítico.

Valeriano et al. (1995) por meio de análise estrutural de uma unidade que denominou de domínio autóctone, recoberta por rochas do Grupo Bambuí, concluíram que parte deste domínio formado por um maciço teria se estruturado antes do evento orogênico. Desta forma, estas unidades não poderiam estar incluídas ao Cráton do São Francisco no Neoproterozóico. Esta ideia corroborou trabalho de Marangoni et al.,(1995) que, pela anomalia Bouguer mostrou uma região de contato entre a Zona Externa e o Cráton São Francisco, com acentuado gradiente gravimétrico.

Blum e Pires (1996), com o estudo da superfície Curie na região central da Província Tocantins, mostraram que as relações de idades com as unidades não eram muito evidentes pelas profundidades mapeadas, o que enfatiza mais ainda a complexidade do sistema orogênico. Porém, ao sobrepor a dados gravimétricos da região, identificaram uma endentação de cunha rígida do Cráton do São Francisco sob o Cráton Amazônico, onde o gradiente indicava uma zona de sutura entre o que seria a paleoplaca São Francisco e o Maciço de Goiás. Esta região de sutura estaria relacionada com o evento colisional Brasiliano e seu limite corresponderia aos complexos máficosultramáficos. 
Pimentel et al. (2000) afirmaram que o Arco Magmático de Goiás começou a evoluir em um ambiente de arco de ilhas intraoceânico, em torno de 900 Ma. Afirmaram ainda que, apesar destas rochas terem um caráter juvenil, em alguns pontos dentro do arco magmático demostrava que havia o envolvimento de outros pequenos blocos continentais, talvez pertencentes ao Maciço de Goiás, quando o arco estava se estruturando.

No trabalho de Valeriano et al. (2008), consideraram que as unidades que constituem a Faixa Brasília se moveram em direção à margem passiva do cráton do São Francisco-Congo, no momento do fechamento do oceano Goiás-Farusiano. Neste momento o Maciço de Goiás já havia constituído um microcontinente, pelo fato de conter rochas com idade a partir de $3.0 \mathrm{Ga}$. Os autores consideraram ainda que a região de sutura desse oceano poderia estar localizada no Arco Magmático de Goiás e que teria continuidade na Província Borborema.

Pimentel et al. $(2004,2011)$ por meio de estudos de proveniência com base em dados de U-Pb de zircão detrítico, concluíram que a Faixa Brasília seria constituída por um arco neoproterozóico, o Arco Magmático de Goiás, onde os sedimentos seriam derivados do próprio arco; bacias sin-orogênicas com núcleo metamórfico, simbolizado por rochas dos grupos Araxá, Ibiá e possivelmente do Grupo Serra da Mesa; um ambiente de margem passiva, constituído por rochas dos grupos Paranoá, Canastra e Vazante, localizada na Zona Externa; e uma bacia de foreland, indicada por rochas do Grupo Bambuí, na porção oriental do orógeno, que recobrem uma grande região do Cráton São Francisco (Figura 2.4). Esta estruturação indica que o Maciço de Goiás constitui o embasamento das bacias sin-orogênicas. 


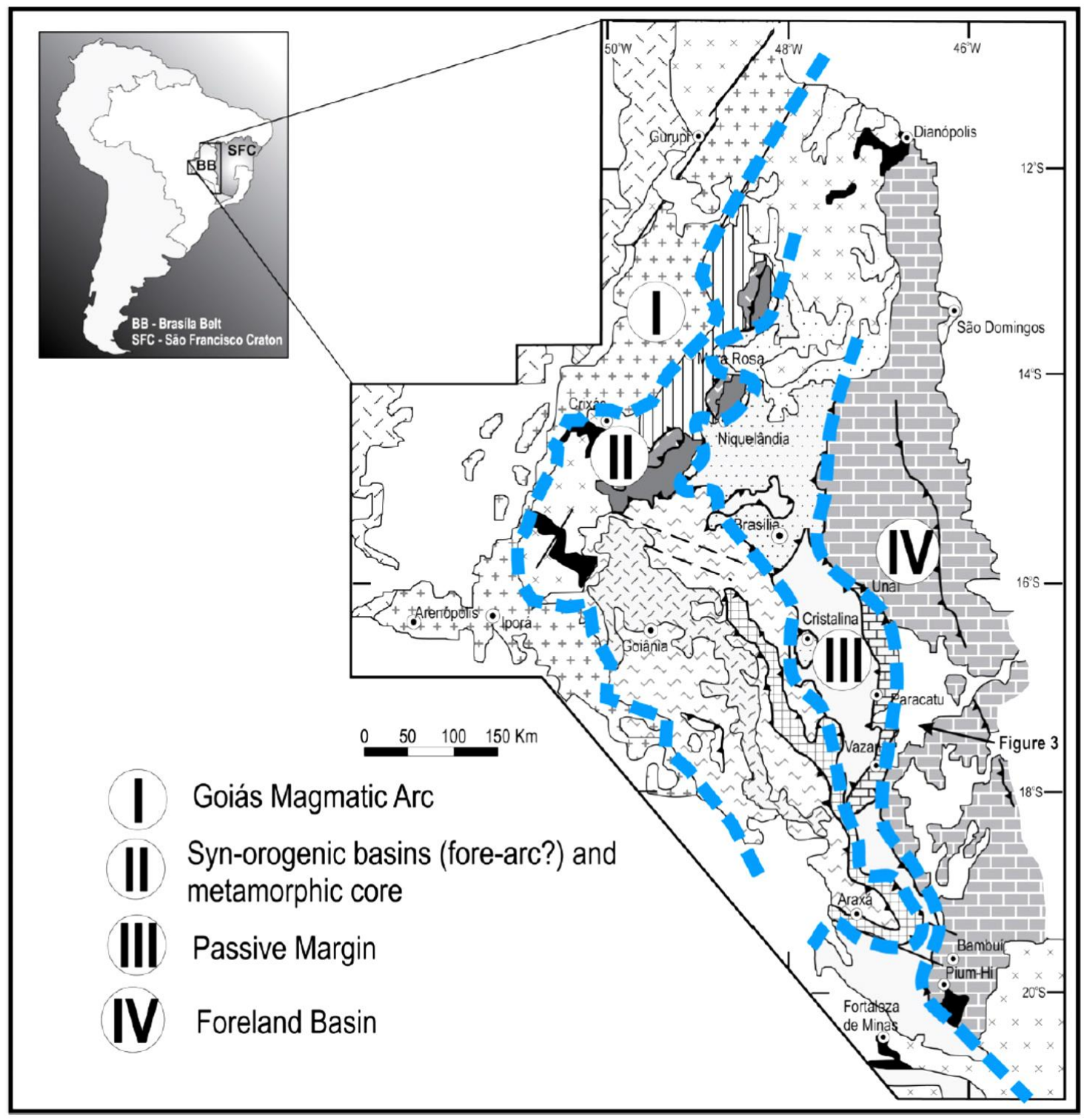

Figura 2.4 - Subdivisão das unidades supracrustais da Faixa Brasília de acordo com a provável configuração de deposição, extraído de Pimentel et al., (2011).

Com relação ao fechamento do oceano Goiás-Farusiano, Cordani et al. (2013), afirmaram que o início deste processo ocorreu em $900 \mathrm{Ma}$, estariam confinadas espessas camadas metassedimentares sobre embasamento paleoproterozóico; Com base nos dados geológicos disponíveis, afirmaram que este oceano tenha fechado em $600 \mathrm{Ma}$, e como resultado tenha deixado regiões de sutura, relacionadas ao processo de subducção. O principal registro deste fechamento estaria localizado no Arco Magmático, em que a composição cálcio-alcalina de algumas rochas indica ação de processo de margem ativa (Cordani et al., 2013).

Sobre a segunda hipótese, Pereira e Fuck (2005), por meio da interpretação de dados aeromagnéticos e gravimétricos, apontaram uma anomalia linear positiva, na região do Arco Magmático de Goiás, que perfazia limite com um baixo gravimétrico que corresponderia à placa 
continental paleoproterozóica. Sob este limite estaria o Cráton São Francisco, que estaria associado à zonas de sutura, que teria colaborado com a presença de rochas juvenis na faixa orogênica do Brasiliano (Figura 2.5). Um fato relevante sobre esta divisão é que Fuck et al. (1993) e Fuck (1994) individualizaram na Faixa Brasília dois segmentos, Zona Externa e Zona Interna que se diferem pela intensidade de deformação e grau de metamorfismo, que aumenta na direção da zona interna.

Soares et al. (2006) utilizaram dados de sísmica de refração, das linhas Porangatu e Cavalcante, para individualização de limites crosta e manto na região do Brasil Central, mostrando que os principais estruturas coincidem com os limites das unidades que constituem a Província Tocantins. Na região de Minaçu foi observada variação de velocidade da crosta, indicando uma descontinuidade na região da Falha Rio Maranhão (Figura 2.6). Este método indicou uma composição crustal félsica e a falta de crosta máfica-ultramáfica abaixo do Arco Magmático de Goiás, que teria sido removida por delaminação da crosta.
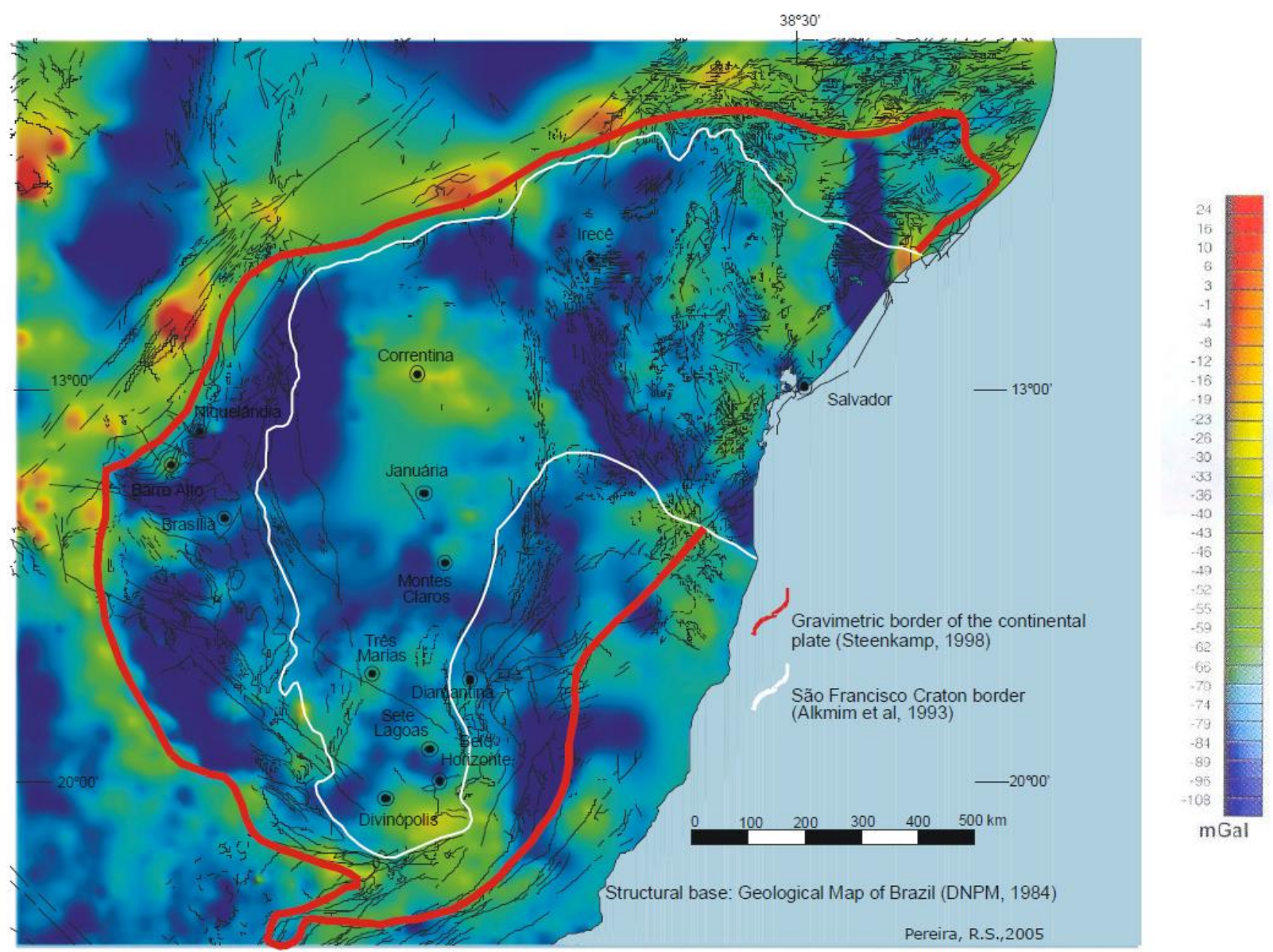

Figura 2.5 - Mapa de Pereira (2007) com o limite gravimétrico da placa continental (Steenkamp, 1998) com limite do cráton do São Francisco (Alkmim et al., 1993). 


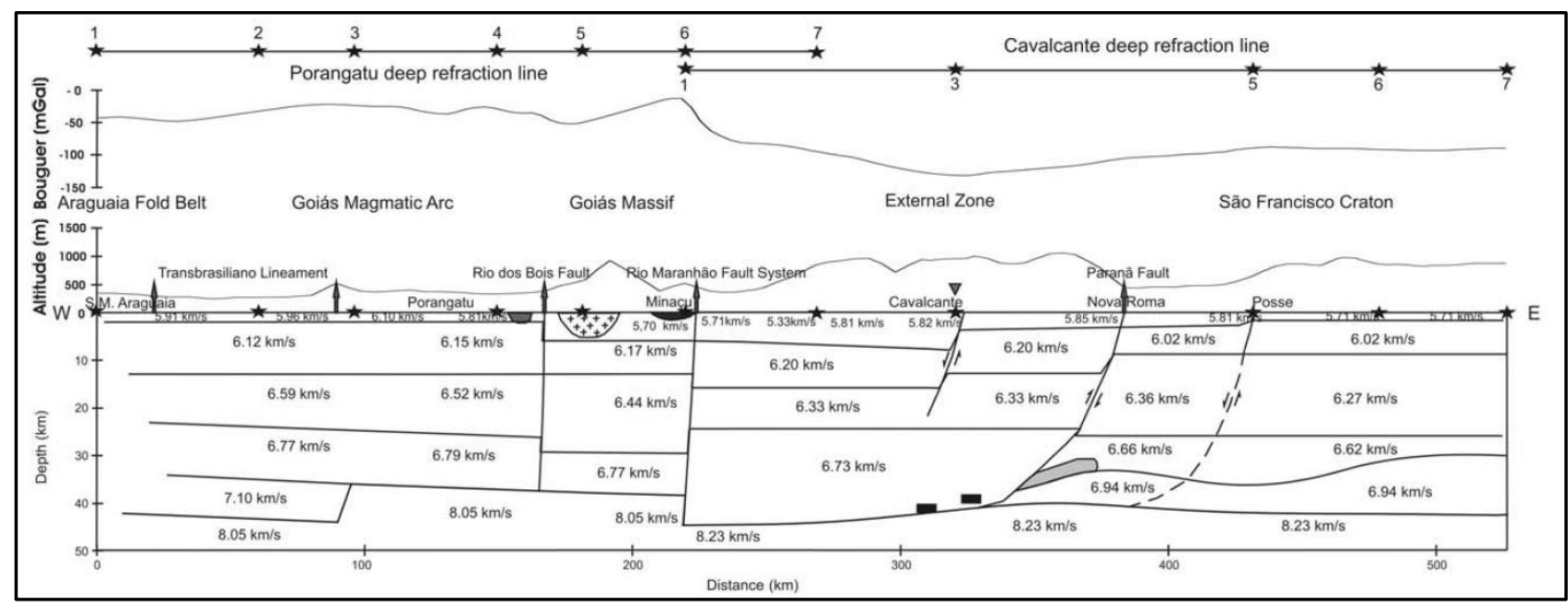

Figura 2.6 - Modelo bidimensional, extraído de Soares et al., (2006) da crosta e manto superior sob as linhas de refração Porangatu e Cavalcante, com perfis topográficos e gravimétricos, onde se observa uma descontinuidade acentuada abaixo de Minaçu com mudança brusca na velocidade do manto.

Concordando com esta ideia, D’el Rey Silva et al. (2008), com trabalho de geologia estrutural, mostrou que falhas reversas e de empurrão com mergulho para W marcam os limites entre as principais unidades da faixa, e que indicam claramente transporte tectônico para leste. Concluíram que a Falha Rio Maranhão se desenvolveu em um ambiente intraplaca, pelo fato de ser uma falha de baixo ângulo.

Dados sísmicos de Martins-Neto (2009) mostraram uma sequência de margem passiva, Canastra-Paranoá-Vazante de $1^{\text {a }}$ ordem, subdividida em duas sequências de $2^{\mathrm{a}}$ ordem, uma rifte e margem passiva, que teriam se depositado entre $1.73 \mathrm{Ga}$ a $630 \mathrm{Ma}$, durante a quebra do Rodínia. A sequência de $1^{\mathrm{a}}$ ordem do Grupo Bambuí, com idade entre 750-550 Ma, foi formado como uma deposição sobrecarga, relacionado ao encurtamento na Faixa Brasília, localizado no flanco ocidental do Cráton São Francisco, durante a formação do Gondwana. Estas informações indicam que havia um embasamento paleoproterozóico pré-estabelecido.

Carminatti (2006) realizou modelagem gravimétrica dos complexos máficos-ultramáficos de Cana Brava, Niquelândia e Barro Alto e das sequências vulcano-sedimentares que estão a oeste, pelo fato destes corpos apresentarem anomalia gravimétrica positiva bem definida. Os modelos gerados indicaram que o complexo Niquelândia constituiria a porção central de um único corpo envolvendo os demais complexos, e mesmo que separados, reagiram como um único bloco nas zonas de fraqueza em níveis diferentes na crosta continental, o que explicaria os altos gravimétricos em meio a uma região de transição de baixo gravimétrico (Carminatti, 2006). De acordo com o autor estas anomalias gravimétricas podem ser um indicativo de colagem de blocos crustais. 
Os dados magnetotelúricos (Padilha et al., 2013) apresentam forte contraste de condutividade entre a Zona Externa da Faixa Brasília e Maciço de Goiás, e que os autores interpretam como uma importante zona de sutura profunda correlacionada ao sistema de falhas Rio Maranhão (Figura 2.7), como foi observado por Soares et al. (2006). Além desta zona de sutura inferida, os autores observaram um grande condutor em profundidade, no manto superior, posicionado abaixo do Maciço de Goiás, interpretado como uma assinatura de eventos térmicos. Estas anomalias de condutividade na região do Complexo Niquelândia mostram que a assinatura é muito diferente das outras partes do Maciço de Goiás, indicando que o complexo era parte de um bloco alóctone acrescido à faixa durante os eventos neoproterozóicos.

Brito Neves e Fuck (2013) consideram que o evento orogênico não foi sincrônico em toda a Província Tocantins, em particular referente ao período Brasiliano. Com relação ao Arco Magmático de Goiás, tanto os domínios de Mara Rosa e Arenópolis, os eventos datados entre 930 Ma. e 800 Ma representam vulcanismo e plutonismo de arco oceânico primitivo. Em aproximadamente $660 \mathrm{Ma}$, o processo orogênico Brasiliano causou grande retrabalhamento de uma crosta mais antiga envolvida, e subsequente metamorfismo de alto grau, sendo este evento o indicativo da fase final da colagem de placas.

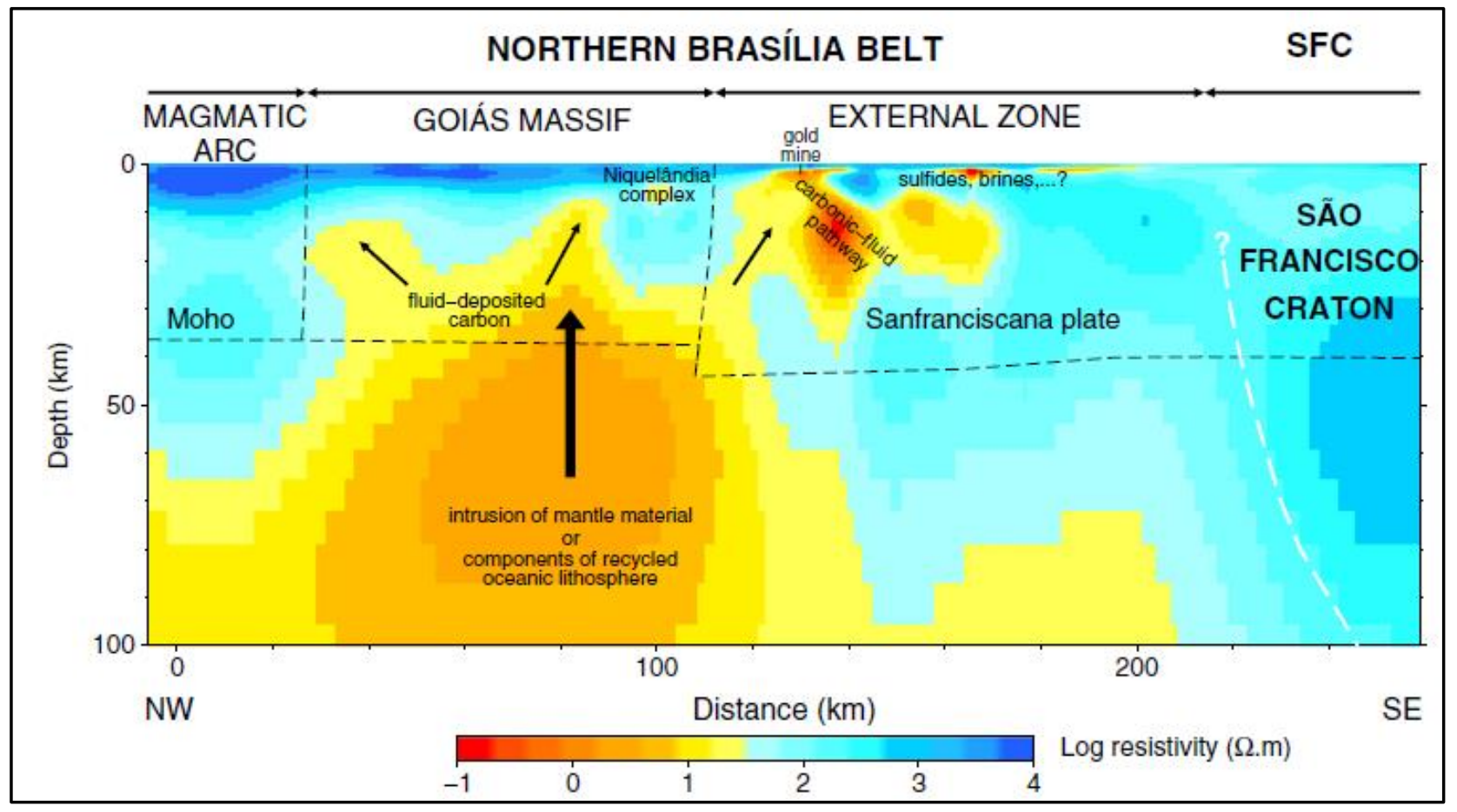

Figura 2.7 - Seção transversal do perfil interpretado de dados magnetotelúricos extraído de Padilha et al., (2013) com base no modelo de condutividade e outros contrastes geofísicos. A linha branca tracejada é uma interpretação da borda ocidental do cráton do São Francisco segundo os mesmos autores. As linhas tracejadas pretas são interpretações com base em dados de refração sísmica da espessura da crosta e grandes falhas de Soares et al. (2006). 
Fuck et al. (2014), ao descrever os principais eventos de acresção e retrabalhamento crustal na região central, com base em dados geocronológicos, destacam o Bloco Natividade-Cavalcante como parte do embasamento da Faixa Brasília e que poderia ser considerada como parte pertencente ao Cráton São Francisco, ressaltando que esta unidade deveria ser considerada na compartimentação tectônica do orógeno.

Cordeiro et al. (2014) enfatizaram que o termo Maciço de Goiás fosse definido como um embasamento cristalino, composto por rochas do Arqueano ao Mesoproterozóico, sobre os quais atuaram os eventos Brasilianos. Sobre este embasamento, magmatismo paleoproterozóico, ocasionado pelo rifteamento e posterior formação de bacia em 1.76 Ga que ocorreu no Rifte Araí, no Maciço de Goiás e no Rifte Espinhaço, no Cráton São Francisco, indicam que ambos os terrenos compartilharam do mesmo paleocontinente no Mesoproterozóico.

Ventura et al. (2011), com intuito de estabelecer um limite entre a Província Tocantins e Cráton Amazônico, realizaram um estudo de dados de sísmica de refração sobre as rochas do Maciço de Goiás, Arco Magmático de Goiás e Zona Externa da Faixa Brasília. Os autores indicaram que na região oeste de Serra Azul, a espessura de $50 \mathrm{~km}$ de crosta caracteriza uma região de superposição de crosta inferior e que possivelmente trata-se de uma lasca de rochas do embasamento do Cráton Amazônico que sofreu obducção. Este dado corrobora a hipótese de que poderia haver uma zona de sutura localizada sob esta região. Vale ressaltar que foi observado um comportamento diferenciado da zona de cisalhamento Rio dos Bois, onde há uma variação lateral de velocidade em todas as camadas crustais, que não se repete no Lineamento Transbrasiliano, nem o Sistema de Falhas Rio Maranhão, e que separa os terrenos do topo até a base da Moho.

Trindade et al. (2014) em estudo da espessura crustal com dados de função do receptor para mapeamento da profundidade da Moho, mostraram que esta superfície da Província Tocantins nesta região é irregular, e comparado com dados de gravimetria e topografia, indicaram que deveria ocorrer um equilíbrio isostático relacionado ao manto com pouca contribuição da crosta. Com estes dados, os autores indicaram que o limite do Paleocontinente São Francisco era formado pelo Cráton São Francisco e Zona Externa e que haveria uma região de sutura entre a Paleoplaca Amazônica e o Arco Magmático de Goiás.

Para as proposições de compartimentação de unidades tectônicas na Faixa Brasília, a indicação de zonas de sutura tem papel importante para fundamentar o contexto geotectônico em que este orógeno se formou. As zonas de sutura poderiam ser indicadas por grandes zonas de cisalhamento e pela presença de complexos granulíticos associados a faixas orogênicas, que podem ser consideradas como limites de diferentes domínios (Fuck et al., 2014). Considerando os complexos de falhas Rio Maranhão e Rio dos Bois, como os principais limites estruturais entre as 
unidades da porção central da Faixa Brasília, a presente dissertação terá como base métodos magnéticos e gravimétricos, para testar modelos de blocos crustais, nas unidades tectônicas que constituiam a área, Zona Externa, Maciço de Goiás, e Arco Magmático de Goiás, a fim indicar um significado geológico/estrutural para as falhas com base nos modelos preexistentes. 


\section{Capítulo III}

\section{MATERIAIS E MÉTODOS}

Os métodos geofísicos oferecem grande vantagem no estudo do interior da Terra, pois exploram partes inacecíveis para o estudo direto das suas rochas (Hinze et al., 2013). O processamento de dados tem como objetivo promover a melhoria da qualidade e representação de dados geofísicos para serem interpretados. Esta melhoria significa o realce de sinal, que pode ser feita em dados magnéticos e gravimétricos com aplicação de filtros. De acordo com Isles \& Rankin (2013), os filtros são operações matemáticas que permitem aos geofísicos aprimorar seus dados de acordo com a necessidade e objetivo de interpretação.

Em busca da melhor forma de individualizar as estruturas e propor um modelo de compartimentação dos blocos tectônicos que constituem a Faixa Brasília foram utilizados métodos de gravimetria e magnetometria do campo potencial. O método gravimétrico envolve medição do campo gravitacional, as anomalias gravimétricas são causadas por variações laterais de densidade, por outro ladoo campo magnético terrestre é medido com elevada precisão por magnetômetros (Hinze et al. 2013). Em geral, os dados de gravimetria e magnetometria podem ser adquiridos por meio de métodos aéreos, terrestres, marinhos e de satélite, e devem seguir etapas fundamentais de levantamento, tais como, planejamento, aquisição, processamento e interpretação.

\subsection{Método Magnético}

O método magnético é uma ferramenta de baixo custo, no caso de aerolevantamentos, que pode ser usada para diversos problemas relacionados à exploração de subsuperfície, e envolve variações horizontais das propriedades magnéticas das rochas próximo à base da crosta terrestre até a superfície (Hinze et al., 2013).

Reynolds (1997) diz que os métodos geomagnéticos podem ser usados em uma grande variedade de aplicações, desde pequena escala, como por exemplo, localizar tubos e cabos no solo, determinar um local para uma estrutura de engenharia, ou investigações em grandes escalas, como exploração de depósitos de ferro, onde muitas vezes o método gravimétrico também é aplicado para complementá-lo. Na prática geológica pesquisas geomagnéticas são principalmente realizadas na superfície do solo e do mar, em altitudes de até centenas de mestros por aeronaves, e em cerca de 350-650 km por satélites (Hinze et al. 2013). 
O campo geomagnético está sempre presente, mas isso varia tanto espacial como temporalmente que pode causar perturbações pontuais que necessitam ser tratadas para facilitar as interpretações (Hinze et al., 2013).

\subsubsection{Conceito de Magnetometria}

O campo magnético da Terra é a somatória dos componentes interno e externo , sendo que o principal campo é gerado por correntes de energia no núcleo externo, que é responsável por cerca de $80 \%$ deste campo geomagnético (Hinze et al., 2013). Os processos de convecção na parte líquida do núcleo de ferro dão origem a um campo magnético dipolar, que se assemelha a de um grande imã, ao longo do eixo de rotação da Terra. O manto transfere uma pequena parte desse magnetismo para as rochas da crosta, onde as alterações magnéticas são registradas nas rochas (Reeves, 2005).

\subsubsection{DAdos AERogeofísicos}

Foram utilizados dados magnéticos de sete levantamentos aerogeofísicos, um levantamento do Projeto Geofísico Brasil-Canadá (PGBC), dois do Projeto Geologia do Brasil (PGB) e quatro do Projeto Aerogeofísico do Estado de Goiás, disponibilizados pelo Governo do Estado de Goiás, por meio da Secretaria de Indústria e Comércio do Estado de Goiás/ Ministério de Minas e Energia (SIEG/MME), juntamente com a Companhia de Pesquisa de Recursos Minerais (CPRM), conforme mostra a figura 3.1 e tabela 3.1.

O processamento e integração dos dados magnéticos na área de trabalho foram realizados no âmbito do projeto Lineamento Transbrasiliano (Vidotti et al., 2011). Os levantamentos aeromagnéticos que recobrem a área de trabalho têm linhas de voo com direção N-S, com espaçamento entre 500 e $2000 \mathrm{~m}$. As linhas de controle possuem direção perpendicular às linhas de voo, variando de 5 a $22 \mathrm{~km}$, com altura de voo entre de 100 e $150 \mathrm{~m}$. 

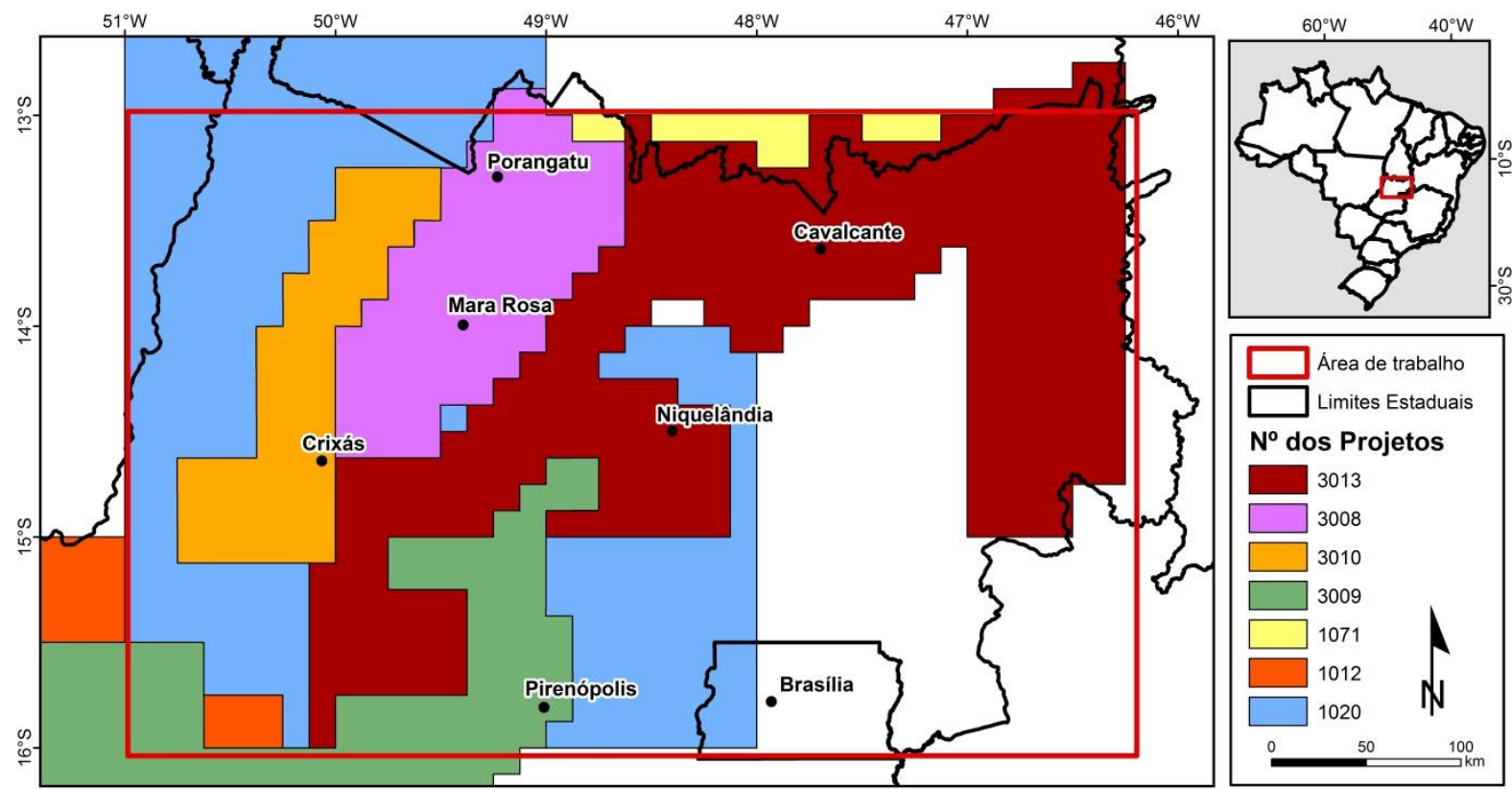

Figura 3.1 - Mapa com projetos aerogeofísicos que recobrem a área de estudo, representados por códigos dos levantamentos conforme a legenda.

Tabela 3.1 - Informações dos projetos geofísicos usados neste trabalho.

\begin{tabular}{|cccccccc|}
\hline Projeto & PGBC & Iporá & $\begin{array}{c}\text { Complemento } \\
\text { do Tocantins }\end{array}$ & $\begin{array}{c}\text { Arco Magmático } \\
\text { de Arenópolis - } \\
\text { Seq. Juscelandia }\end{array}$ & $\begin{array}{c}\text { Arco } \\
\text { Magmático de } \\
\text { Mara Rosa }\end{array}$ & $\begin{array}{c}\text { Oeste do Arco } \\
\text { Magmático de } \\
\text { Mara Rosa }\end{array}$ & $\begin{array}{c}\text { Paleo- } \\
\text { neoproterozóico } \\
\text { Nordeste de Goiás }\end{array}$ \\
\hline Ano & 1975 & 1973 & 2006 & 2004 & 2004 & 2005 & 2006 \\
\hline $\begin{array}{c}\text { Código do } \\
\text { Projeto }\end{array}$ & $\mathbf{1 0 2 0}$ & $\mathbf{1 0 1 2}$ & $\mathbf{1 0 7 1}$ & $\mathbf{3 0 0 9}$ & $\mathbf{3 0 0 8}$ & $\mathbf{3 0 1 0}$ & $\mathbf{3 0 1 3}$ \\
\hline $\begin{array}{c}\text { Organização } \\
\text { responsável }\end{array}$ & DNPM & CPRM & CPRM & CPRM & CPRM & CPRM & CPRM \\
\hline LV* & $2000 \mathrm{~m}$ & $1000 \mathrm{~m}$ & $500 \mathrm{~m}$ & $500 \mathrm{~m}$ & $500 \mathrm{~m}$ & $500 \mathrm{~m}$ & $500 \mathrm{~m}$ \\
\hline Direção LV* & $\mathrm{N}-\mathrm{S}$ & $\mathrm{N}-\mathrm{S}$ & $\mathrm{N}-\mathrm{S}$ & $\mathrm{N}-\mathrm{S}$ & $\mathrm{N}-\mathrm{S}$ & $\mathrm{N}-\mathrm{S}$ & $\mathrm{N}-\mathrm{S}$ \\
\hline Altura de Voo & $150 \mathrm{~m}$ & $150 \mathrm{~m}$ & $100 \mathrm{~m}$ & $100 \mathrm{~m}$ & $100 \mathrm{~m}$ & $100 \mathrm{~m}$ & $100 \mathrm{~m}$ \\
\hline LC** & $14 \mathrm{~km}$ & $22,5 \mathrm{~km}$ & $10 \mathrm{~km}$ & $5 \mathrm{~km}$ & $5 \mathrm{~km}$ & $5 \mathrm{~km}$ & $5 \mathrm{~km}$ \\
\hline
\end{tabular}

* LV - Linha de voo; ${ }^{* *}$ LC - Linha de controle.

Os dados aeromagnéticos foram pré-processados pela Lasa Engenharia e Prospecções, em que foi realizada a remoção da variação magnética diurna, correção do erro de paralaxe, nivelamento dos perfis, micronivelamento dos perfis, remoção do IGRF - International Geomagnetic Reference Field (Lasa Engenharia e Prospecções, 2004). Posteriormente, os grids dos levantamentos foram integrados (Vidotti et al., 2011). Os dados foram interpolados com o método bi-direcional com células de $500 \mathrm{~m}$. Neste trabalho foram aplicadas técnicas de realce a partir do mapa do campo magnético anômalo - CMA (figura 3.2). 


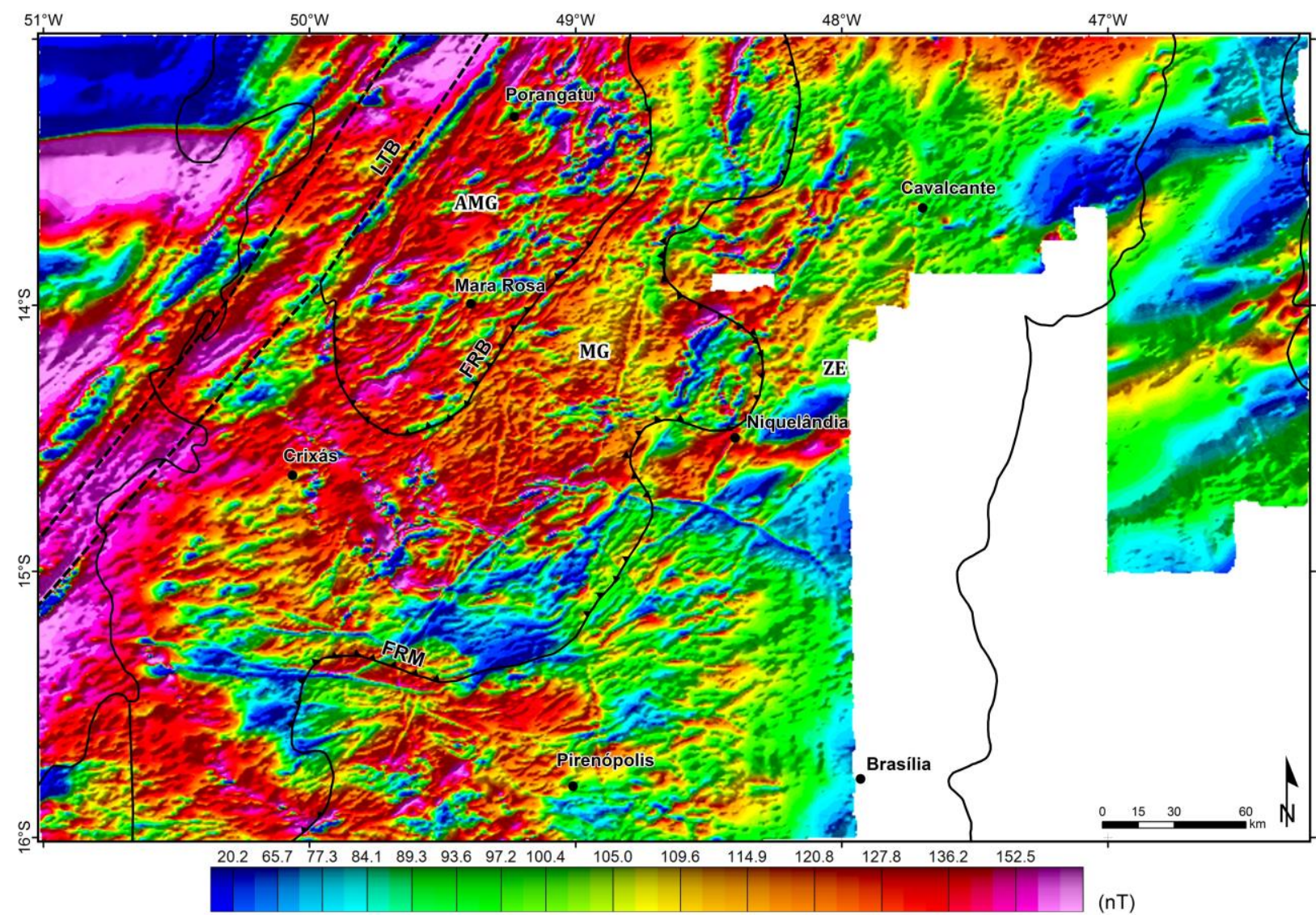

Figura 3.2 - Mapa do CMA a partir da integração dos levantamentos aeromagnéticos. LTB - Lineamento Transbrasiliano; FRM - Falha Rio Maranhão; FRB - Falha Rio dos Bois; AMG - Arco Magmático de Goiás; MG Maciço de Goiás; ZE - Zona Externa.

\subsection{Método Gravimétrico}

O método gravimétrico na exploração geofísica se baseia na medição do campo gravitacional cujas variações são causadas, entre outros, por variações de densidade horizontal no subsolo (Hinze et al., 2013). De acordo com os mesmos autores, o método de gravidade tem sido usado principalmente na caracterização regional da Terra para determinar a arquitetura da crosta, auxilia na identificação de regiões potencialmente favoráveis para exploração de recursos e desenvolvimento de modelos de exploração conceituais. Com a grande quantidade de dados de levantamentos gravimétricos, de satélite, aéreos e terrestres, além da relativa facilidade de medição, este método possui orçamento viável para realização de pesquisas acadêmicas e empresariais. Vale ressaltar que, para melhor acurácia dos levantamentos é sempre necessário combiná-lo a outros métodos. Neste trabalho foi associado ao método magnético.

O objetivo principal do uso da gravimetria em estudos de subsuperfície é a verificação de distribuição de massa dos corpos. Na presente dissertação foram usados dados de satélite para análise preliminar das principais estruturas e dados de gravimetria terrestre para melhor visualização das anomalias. 


\subsubsection{CONCEITO DE GRAVIMETRIA}

De acordo com Reynolds (1997), a base do método da gravidade está diretamente ligada a duas leis, a Lei da Gravitação Universal e a Lei do movimento, sendo estas a primeira e segunda lei da gravidade, definidas por Isaac Newton em 1687.

A primeira lei da gravidade de Newton, que define a lei da Gravitação Universal, afirma que força gravitacional $(\mathrm{F})$ entre as massas é proporcional ao produto das massas dos corpos ( $\mathrm{M} \mathrm{e}$ $m$ ) e inversamente proporcional ao quadrado da distância $\left(\mathrm{R}^{2}\right)$, onde $G$ é a constante gravitacional de Newton (Blakely, 1995):

$$
\mathrm{F}=\frac{G M m}{R^{2}}
$$

A constante gravitacional $\mathrm{G}=6.67 \times 10^{-11} \mathrm{Nm}^{2} \mathrm{Kg}^{-2}$

A segunda lei de Newton, a lei do movimento, afirma que uma força $(\mathrm{F})$ é igual à massa $(m)$ pela aceleração na direção vertical $(g)$, isto é, a gravidade (Reynolds, 1997).

$$
\mathrm{F}=m g(2)
$$

A equações 1 e 2 podem ser combinadas e obter uma outra relação simples:

$$
\mathrm{F}=\frac{G M m}{R^{2}}=m g
$$

Assim:

$$
g=\frac{G M}{R^{2}}(3)
$$

Reynolds (1997) apresenta esta equação que mostra a magnitude da aceleração da gravidade da Terra $(\mathrm{G})$ é diretamente proporcional à sua massa $(\mathrm{M})$ e inversamente proporcional ao quadrado do seu raio (R). Teoricamente, a aceleração da gravidade deve ser constante sobre a Terra. $\mathrm{Na}$ realidade a gravidade varia de lugar para lugar, pois a Terra possui a forma de um elipsoide, uma esfera achatada, que rotaciona e possui uma superfície topográfica irregular e com isso uma distribuição de massa variável (Reynolds, 1997).

A aceleração da gravidade, ou simplesmente gravidade, é medida em $\mathrm{N}$ ou $\mathrm{m} / \mathrm{s}^{2}$ no $\mathrm{SIu}$ Sistema Internacional de unidades (Hinze et al., 2013). Os mesmos autores mostram que, na exploração geofísica usa-se Gal para medidas de aceleração gravitacional, que equivale a $0,01 \mathrm{~m} / \mathrm{s}^{2}$ em SIu ou $1 \mathrm{~cm} / \mathrm{s}^{2}$ em CGSu (Sistema de unidades de medidas físicas). A unidade Gal é utilizada em homenagem a Galileu Galilei que no século XVI foi o pioneiro no estudo do movimento dos 
planetas em torno do Sol e da natureza da gravitação. Contudo o autor mostra que a unidade Gal é uma unidade grande, em comparação com as pequenas variações de gravidade relacionadas com as pequenas variações de massa na subsuperfície terrestre. Então, para captar essas pequenas variações em exploração geofísica, usa-se o miliGal (mGal).

O geoide que constitui a Terra é uma superfície equipotencial, que representa uma superfície sobre a qual o campo gravitacional tem seu valor igualado e coincide com o nível médio do mar (Figura 3.3). A distribuição irregular da massa, especialmente próximo à superfície da Terra, deforma o geoide de modo que não é idêntica à elipse de rotação (Reynolds, 1997). De acordo com o mesmo autor, as anomalias de grandes comprimentos de onda, as quais podem ser mapeadas utilizando satélite, referem-se a massas da profundeza do manto, enquanto que características de densidade em profundidades rasas com menor comprimento de onda devem causar menores deformações no geoide. Desta forma, as anomalias no campo gravitacional podem ser usadas para estimar a densidade dos corpos em subsuperfície.

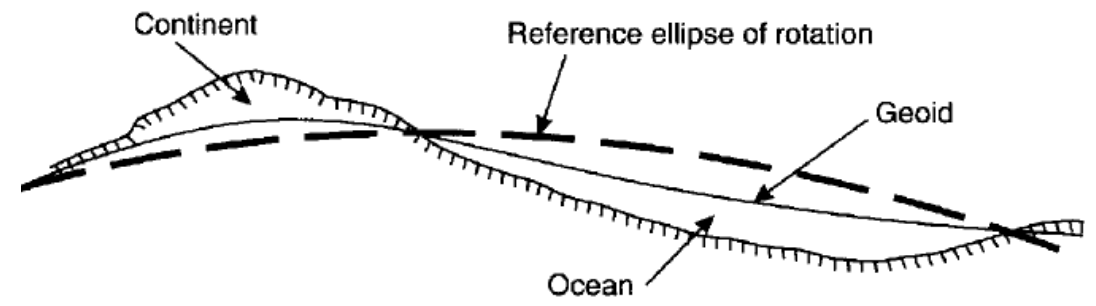

Figura 3.3 - Modelo de deformação do geoide: Efeitos de escala continental. Extraído de Reynolds (1997).

\subsubsection{DAdOS GRAVIMÉTRICOS}

Para análise gravimétrica foram utilizados dados de gravimetria de satélite e de gravimetria terrestre. Os dados de anomalia Bouguer de satélite (Figura 3.4 A) foram obtidos do modelo World Gravity Map 2012 - WGM 2012 (Bonvalot et al. 2012), com espaçamento de 1'x1', que faz parte de um conjunto de dados com grids computados em escala global disponibilizados pela Bureau Gravimetrique International - BGI. Estas informações são derivadas do modelo Geopotential Model 2008 - EGM 2008, adquiridas pela National Geospatial Intelligence Agency - NGA. Os dados foram interpolados pelo método de kriging (Krige, 1966; Cressie, 1990).

Os dados de gravimetria terrestre utilizados são públicos e fazem parte da compilação de projetos anteriores desenvolvidos por Vidotti (1998) e instituições, como o Instituto Brasileiro de Geografia e Estatística (IBGE), Instituto de Astronomia, Geofísica e Ciências Atmosféricas, Universidade de São Paulo (IAG/USP) e Instituto de Geociências, Universidade de Brasília (IG/UnB), e possuem espaçamento médio de 5.000m entre as estações (Figura $3.4 \mathrm{~B}$ ) Os dados terrestres foram interpolados por mínima curvatura (Briggs, 1974) com células de $6.000 \mathrm{~m}$ (Figura 
3.4 C). Os dados de satélite foram utilizados a fim de realizar análise qualitativa das anomalias que trazem resposta do manto, enquanto que os dados de gravimetria terrestre trouxeram informações de estruturas em fontes mais rasas da crosta. 

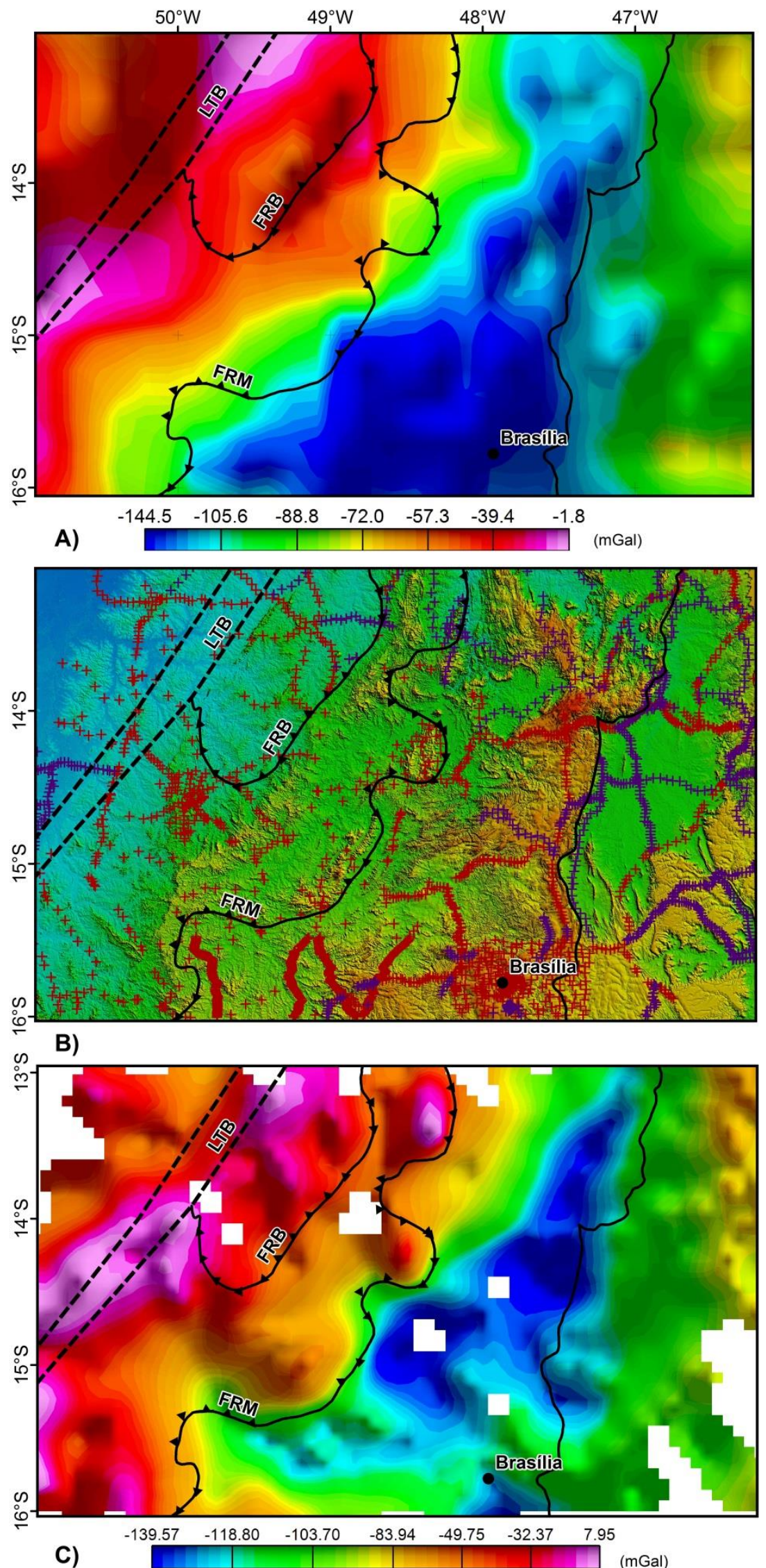

Figura 3.4 - A) Mapa de anomalia Bouguer de satélite; B) mapa de pontos de levantamentos terrestres sobre o modelo digital de terreno; C) mapa de anomalia Bouguer de dado terrestre. Limites tectônicos com base em Pimentel et al. (2004) e Fuck et al. (2014), LTB - Lineamento Transbrasiliano; FRB - Falha Rio dos Bois; FRM - Falha Rio Maranhão. 


\subsection{Processamento doS DAdOS}

Os dados adquiridos nos levantamentos geofísicos, de acordo com Hinze et al.(2013) estão sujeitos a grande quantidade de ambiguidade e erros, sejam eles aleatórios ou sistemáticos, também denominados ruídos e que, de acordo com a necessidade da pesquisa devem ser entendidos e minimizados. Para isso, devem ser aplicados os devidos procedimentos de processamento de dados adequados para o estudo (Hinze et al., 2013). O processamento consiste em realçar o sinal, com intuito de identificar as anomalias presentes nos dados de aeromagnetometria. Os dados foram processados no programa Oasis Montaj 7.1 da Geosoft (Geosoft, 2008) e foram integrados aos dados geológicos no programa SIG ArcGis 10.1 da ESRI, no qual foram confeccionados os mapas.

Com intuito de realçar as anomalias, foram aplicados filtros sobre o mapa do campo magnético anômalo ao qual inicialmente foram aplicadas as Derivadas Direcionais em Gx, Gy e Gz (Telford et al., 1990) Posteriormente aplicou-se o GHT - Gradiente Horizontal Total (Cordel, 1979; Cordell e Grauch, 1985; Grauch e Cordell, 1987, Blakely, 1995), GT - Gradiente Total ou sinal Analítico 3D (Nabighian, 1972, 1984; Roest et al., 1992; Nabighian et al., 2005), Derivada tilt ou Tilt derivative (Miller e Singh, 1994; Verduzco et al., 2004) e a Derivada Tilt do Gradiente Horizontal Total (Ferreira et al., 2013). Estas técnicas de realce são importantes para o reconhecimento de lineamentos magnéticos e feições de variação de densidade, consequentemente estruturas que possam indicar diferenciação entre os blocos tectônicos, assim como na realização de estimativas de profundidade das anomalias.

\subsubsection{DERIVADAS DIRECIONAIS}

As derivadas tendem a realçar as bordas das anomalias e destacam feições superficiais que estão relacionadas aos menores comprimentos de onda, podendo ser aplicadas tanto em dados magnéticos quanto em dados de gravimétricos (Telford et al.,1990). A primeira derivada é o filtro passa-alta mais amplamente usado, por ser facilmente interpretado no contexto magnético de corpos rochosos (Isles e Rankin, 2013).

De acordo com Telford et al. (1990), as derivadas horizontais (Gx e Gy) são utilizadas para realçar os gradientes horizontais nas direções x e y em função do campo magnético $\mathrm{M}$, onde o gradiente é maior na horizontal e nas bordas dos contatos, possibilitando observar possíveis anomalias e seus contatos verticais. A figura 3.5 e 3.6 mostram os mapas da derivada $\mathrm{x}(\mathrm{Gx})$. As figuras 3.7 e 3.8 mostram os mapas da derivada em y (Gy). O gradiente horizontal na direção x (Gx)é definido como a derivada de $G x=\frac{\partial M}{\partial x}$ e o gradiente horizontal na direção y (Gy) como a derivada $G y=\frac{\partial M}{\partial y}$. 
A derivada vertical $(\mathrm{Gz})$ é definida como $G z=\frac{\partial M}{\partial z}$, que amplifica a informação de comprimentos de onda curto em detrimento dos comprimentos de onda longos, em função de $\mathrm{z}$ (Telford et al., 1990). O resultado desta função é mostrado nas figuras 3.9 e 3.10. 


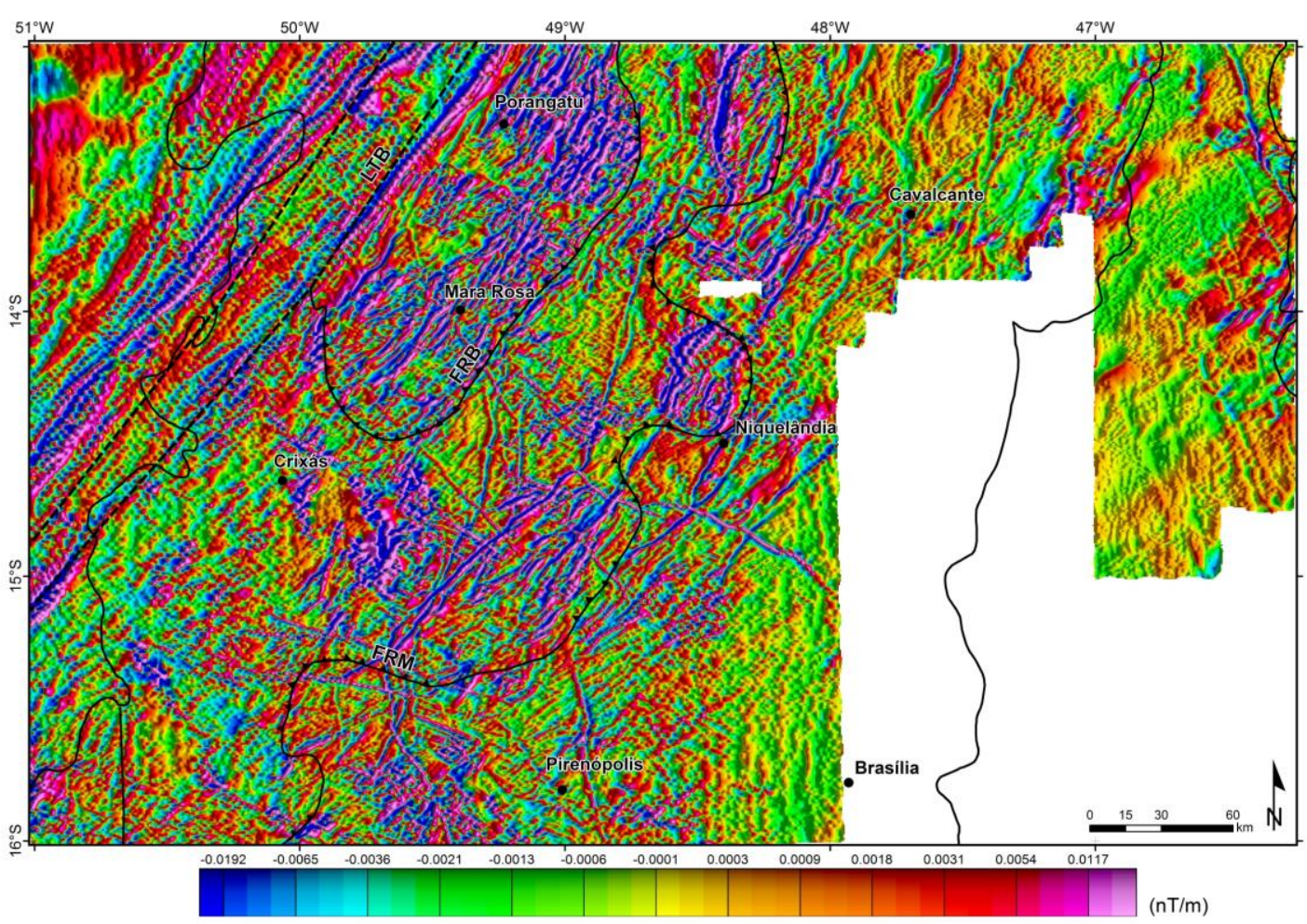

Figura 3.5 - Mapa de derivada em x (Gx) do CMA com iluminação a 90.LTB - Lineamento Transbrasiliano, FRB - Falha Rio dos Bois, FRM - Falha Rio Maranhão.

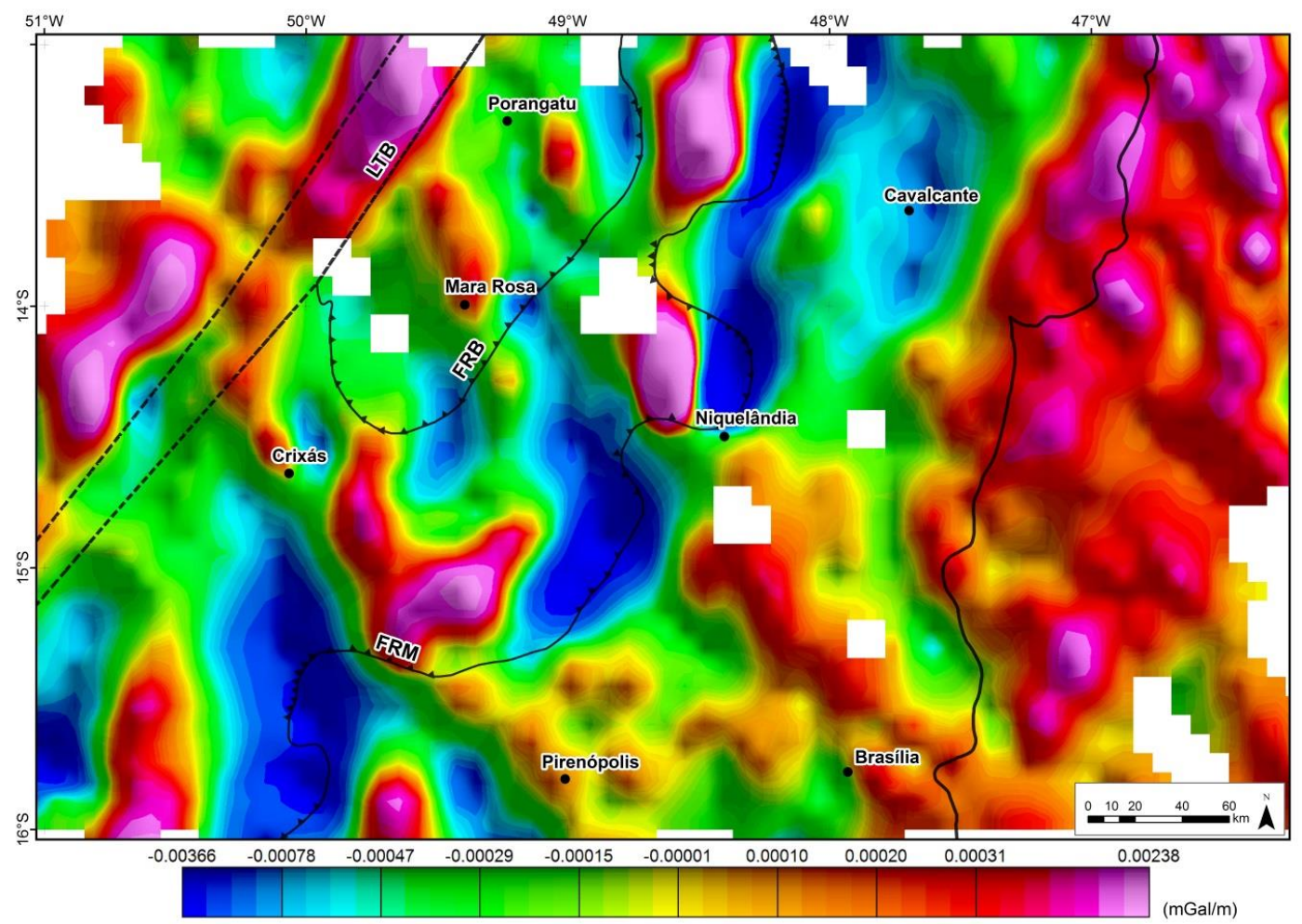

Figura 3.6 - Mapa da derivada $\mathrm{x}(\mathrm{Gx})$ da anomalia Bouguer dos dados gravimétricos terrestre. LTB Lineamento Transbrasiliano, FRB - Falha Rio dos Bois, FRM - Falha Rio Maranhão. 


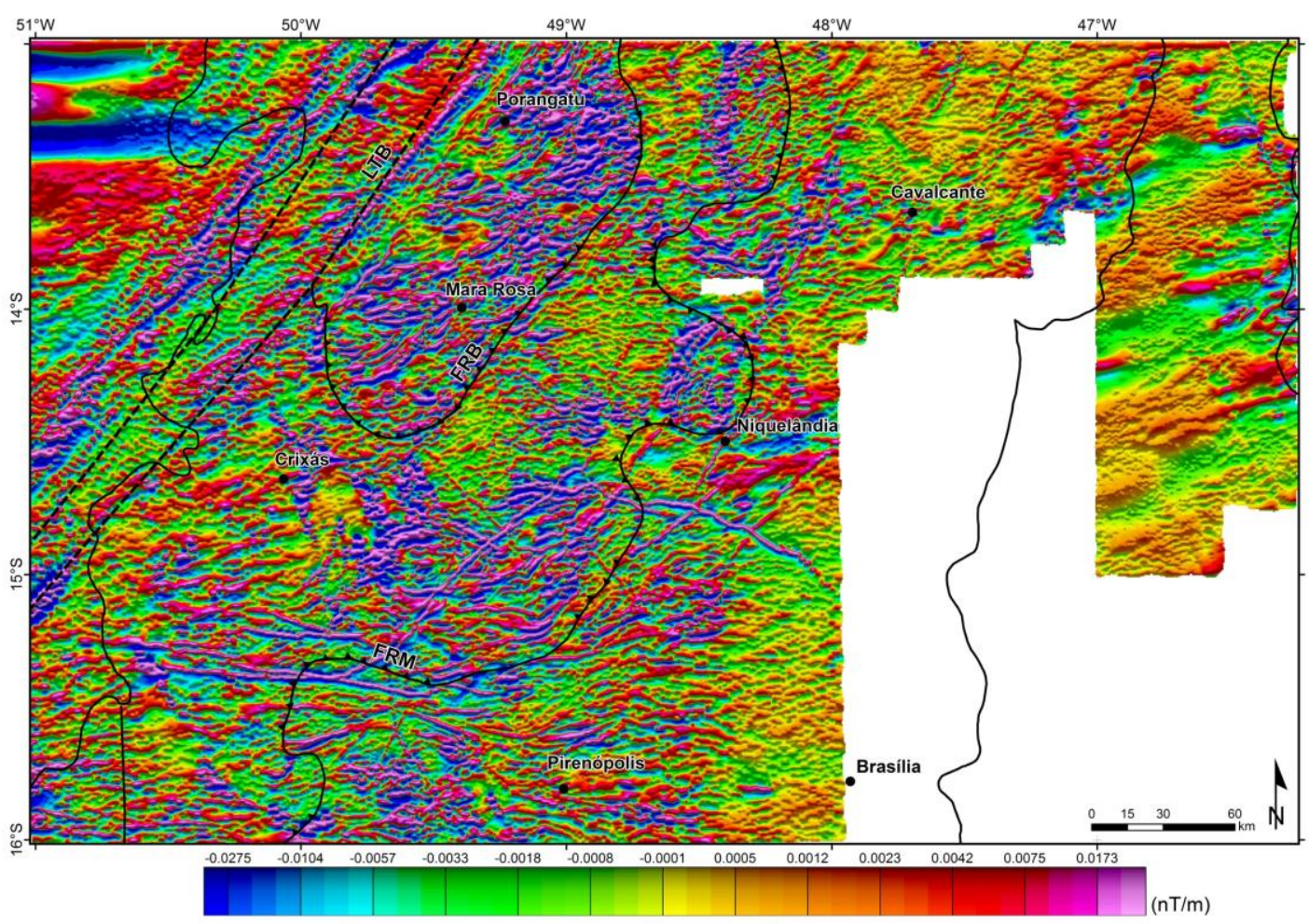

Figura 3.7 - Mapa de derivada y (Gy) do CMA, com iluminação a $0^{\circ}$. LTB - Lineamento Transbrasiliano, FRB - Falha Rio dos Bois, FRM - Falha Rio Maranhão.

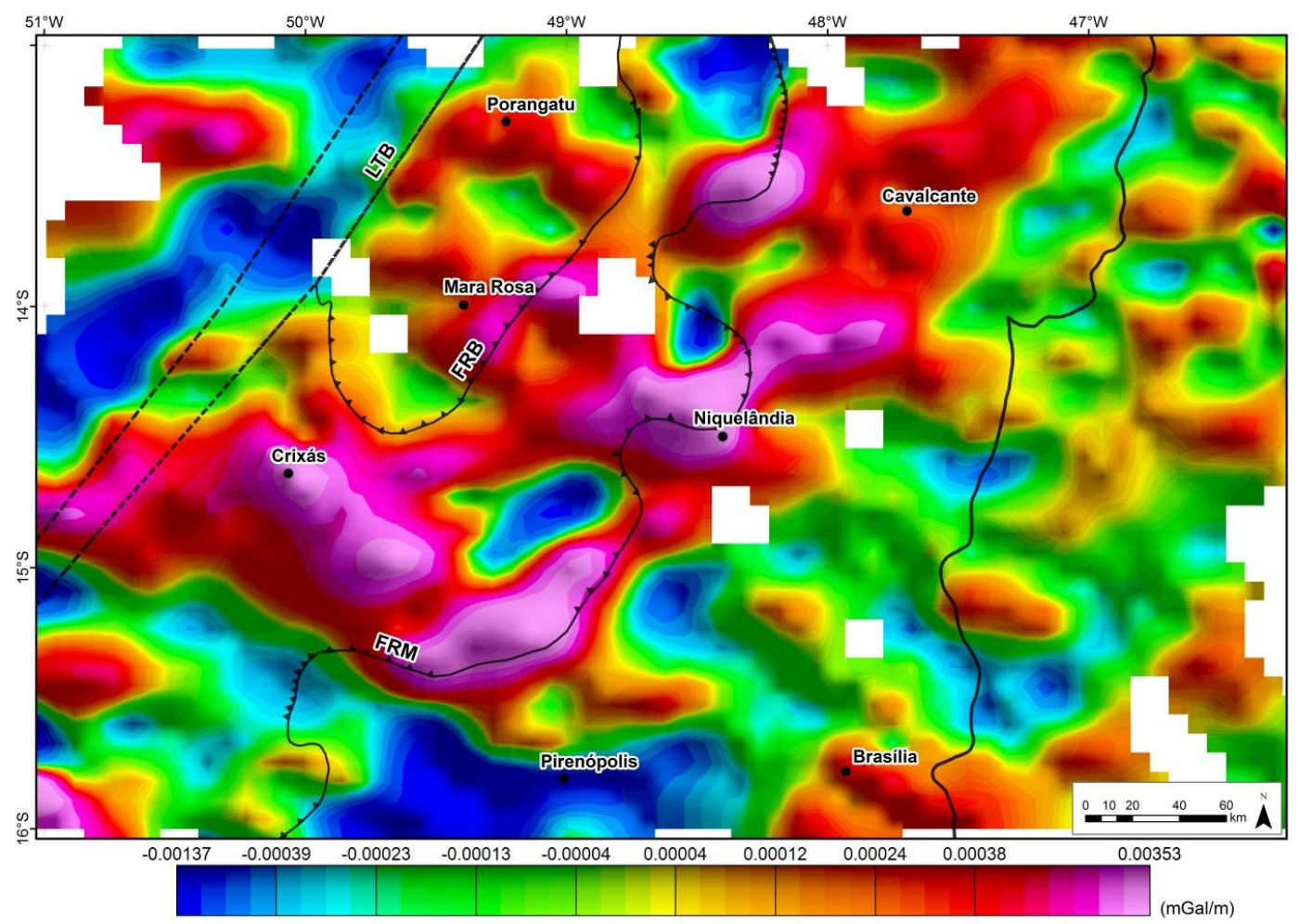

Figura 3.8 - Mapa da derivada y (Gy) da anomalia Bouguer dos dados gravimétricos terrestre. LTB Lineamento Transbrasiliano, FRB - Falha Rio dos Bois, FRM - Falha Rio Maranhão. 


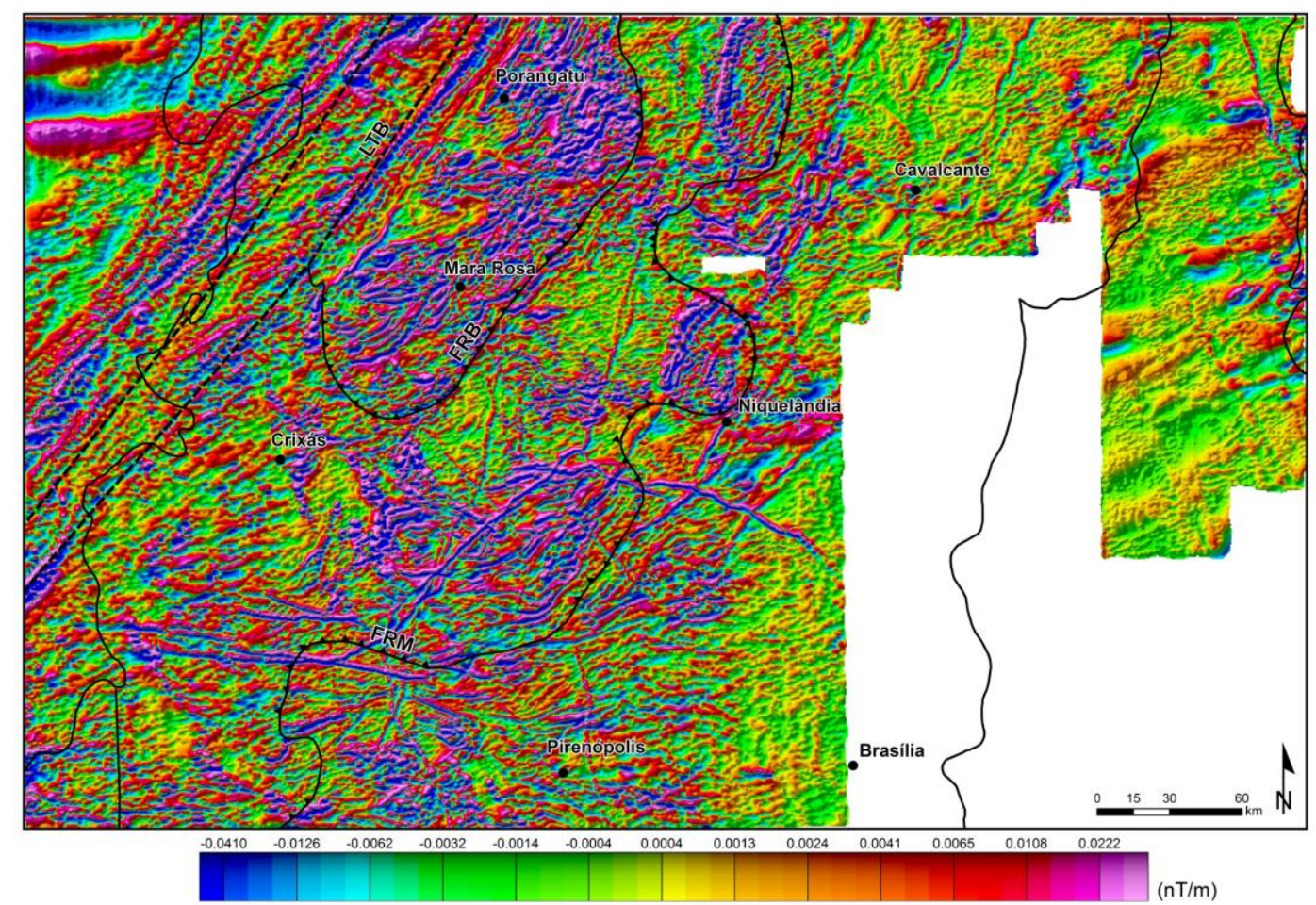

Figura 3.9 - Mapa da derivada z (Gz) do CMA, com iluminação a $-45^{\circ}$.

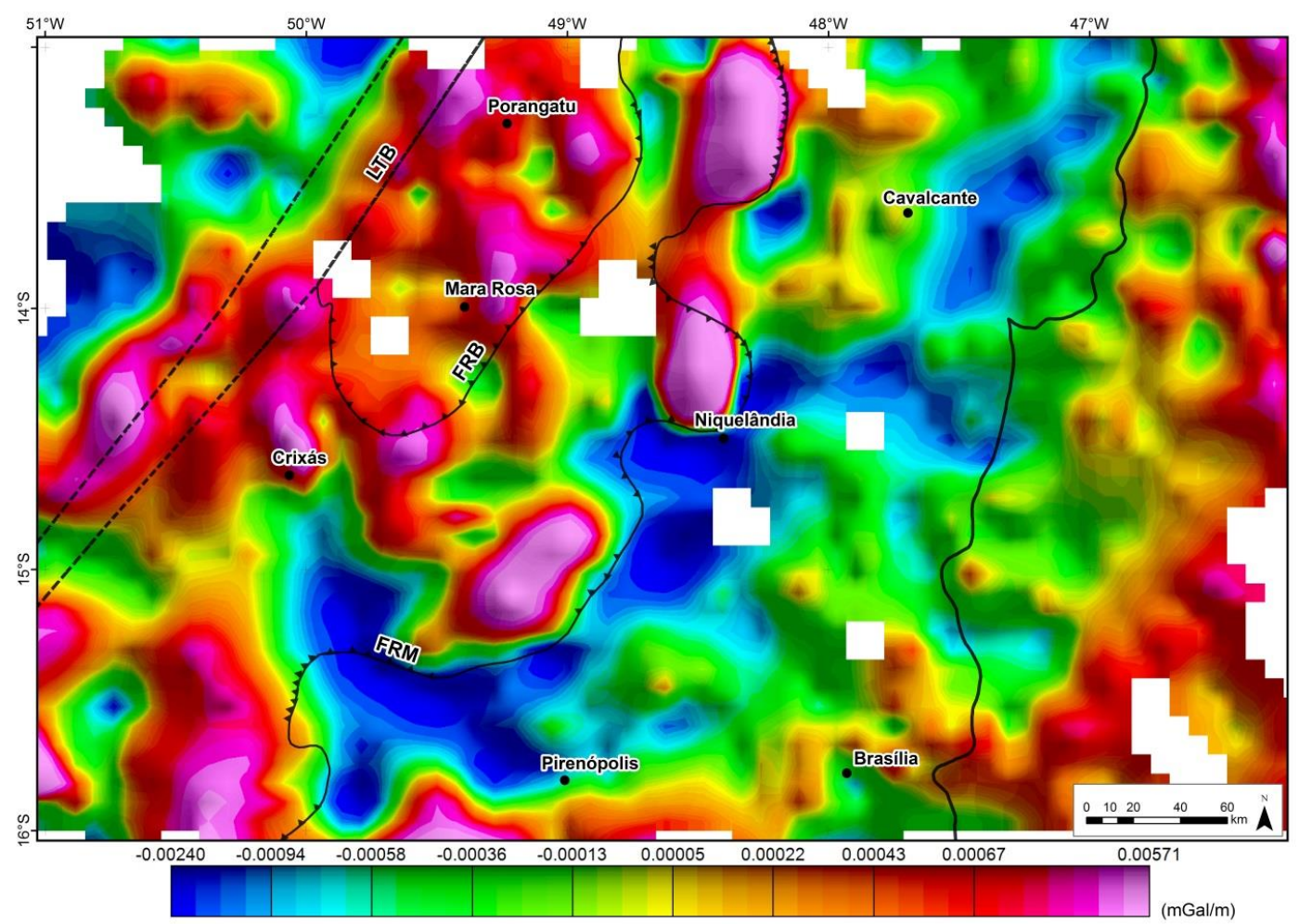

Figura 3.10 - Mapa da derivada $\mathrm{z}(\mathrm{Gz})$ da anomalia Bouguer dos dados gravimétricos terrestre. LTB Lineamento Transbrasiliano, FRB - Falha Rio dos Bois, FRM - Falha Rio Maranhão. 


\subsubsection{GRADIENTE HORIZONTAL TOTAL}

O método do gradiente horizontal tem sido usado desde a década de 1980 para localizar contatos de variações de densidade ou contatos magnéticos com dados de gravidade (Cordell, 1979) ou dados de pseudogravidade (Cordell e Grauch, 1985). Dados magnéticos podem ser transformados em dados de pseudogravidade usando a técnica de Fourier de modo que ele se comporte como um dado de gravidade (Grauch e Cordell, 1987).

O método tem base no princípio de que contatos quase verticais, falhas que produzem uma anomalia de gravidade,em que gradiente horizontal é maior diretamente sobre a borda do contato e centro da fonte (Grauch e Cordell, 1987). Este filtro realça as altas frequências e posiciona os picos das anomalias bem próximas das bordas dos corpos, com valores mínimos na parte central, diminuindo a força do sinal com o aumento da profundidade (Ferreira et al., 2013).

O gradiente horizontal total (Figuras 3.11 e 3.12), de acordo com Blakely (1995), é calculado a partir da raiz quadrada da soma dos quadrados das derivadas das anomalias nas direções x e y. A magnitude do gradiente horizontal total (GHT) é dada por:

$$
G H T=\sqrt{\left(\frac{\partial M}{\partial x}\right)^{2}+\left(\frac{\partial M}{\partial y}\right)^{2}}
$$


Universidade de Brasília -Instituto de Geociências - Programa de Pós-graduação em Geociências Aplicadas

Arcabouço Tectônico da Porção Centro-Norte da Faixa Brasília com Base em Dados Magnéticos e Gravimétricos

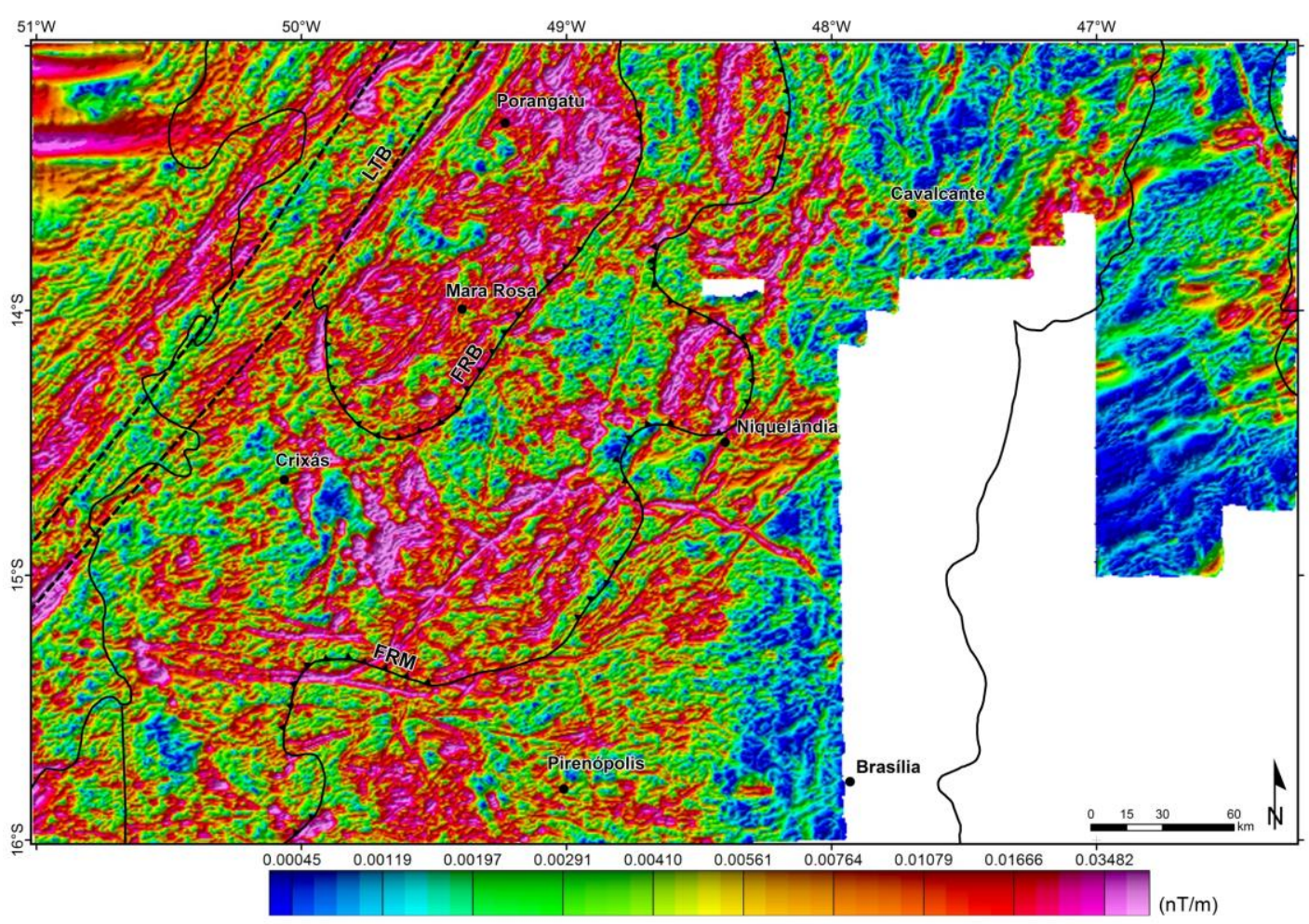

Figura 3.11 - Mapa do gradiente horizontal total (GHT) do CMA, realçando as feições de contato das anomalias magnéticas.

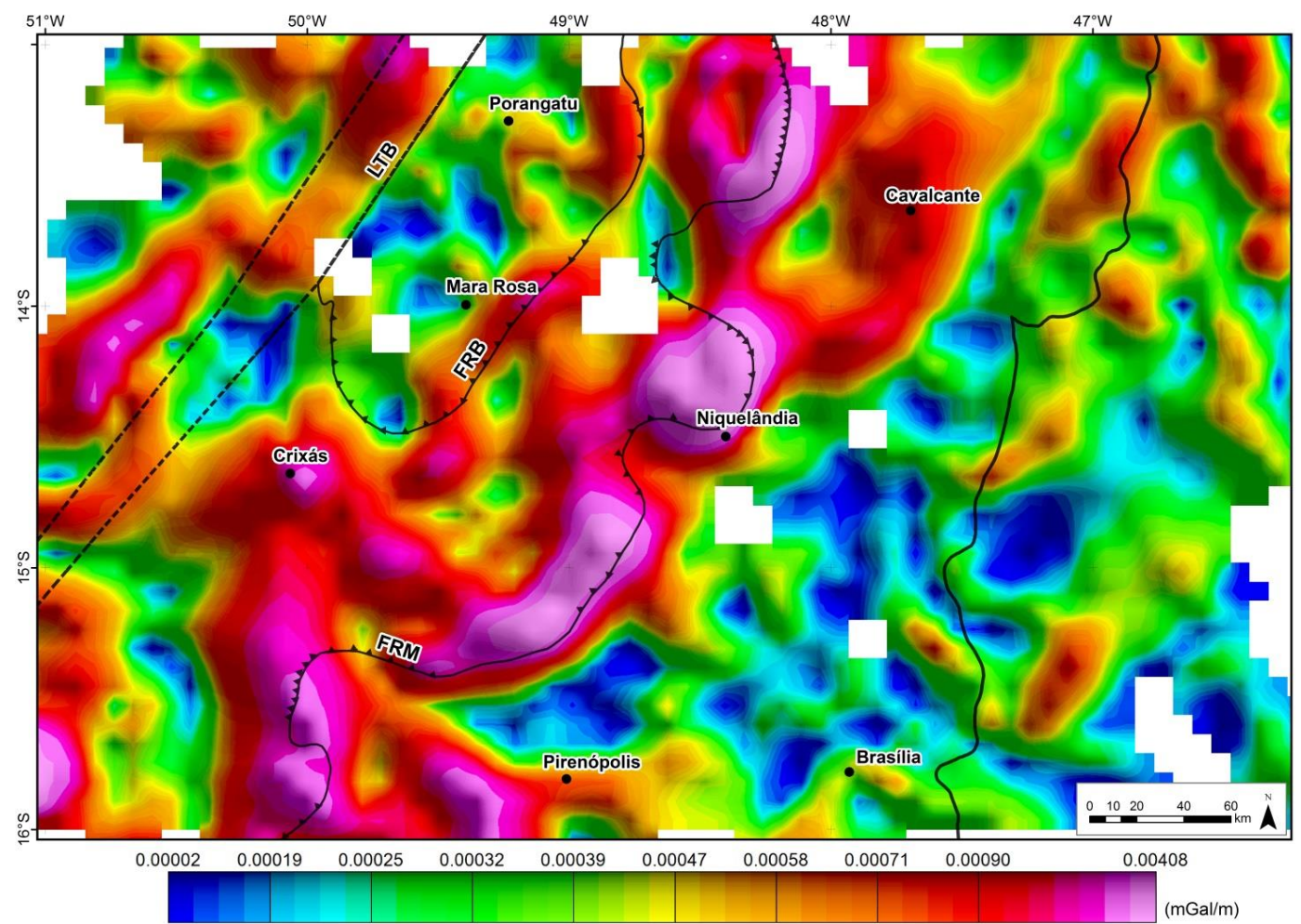

Figura 3.12 - Mapa do gradiente horizontal total da anomalia Bouguer de dados gravimétricos terrestre. LTB - Lineamento Transbrasiliano, FRB - Falha Rio dos Bois, FRM - Falha Rio Maranhão. 


\subsubsection{GRADIENTE TOTAL}

O conceito de sinal analítico foi inicialmente definido por Ville (1948), em que $a(x)$ da função complexa $f(x)$ contendo uma parte real e uma imaginária, onde $H[f(x)]$ é a transformada de Hilbert de $f(x)$, sendo: $a(x)=f(x)-i H[f(x)]$. Nabighian $(1972,1974)$ aplicou o conceito do sinal analítico aos dados do campo potencial em duas dimensões, denominado de sinal analítico $2 \mathrm{D}$, onde $A(x)=\emptyset_{x}+i \emptyset_{z}$. E a amplitude do sinal analítico 2D do campo potencial independe da direção de magnetização, de acordo com a função $|A(x)|=\sqrt{\emptyset^{2}{ }_{x}+\emptyset^{2}{ }_{z}}$.

Posteriormente Nabighian (1984) generalizou a transformada de Hilbert e o sinal analítico de 2D (ASA 2D) para sinal analítico 3D (ASA 3D), obtendo uma função $A(x)=\emptyset_{x}+\emptyset_{y}+i \emptyset_{z}$.Com a amplitude do sinal analítico 3D, Roest et al. (1992), tendo como principal finalidade a detecção de limite de borda dos corpos que perfazem contatos verticais, apresentou o sinal analítico como um vetor que contém as derivadas direcionais e suas transformadas de Hilbert, mediando a amplitude do sinal analítico em um plano horizontal. Definindo x, y e z como vetores de unidade nas direções x, y e z, respectivamente, permite que o sinal analítico 3D de um campo potencial de uma anomalia M pode ser descrito da seguinte forma (Roest et al., 1992):

$$
|A(x)|=\sqrt{\left(\frac{\partial M}{\partial x}\right)^{2}+\left(\frac{\partial M}{\partial y}\right)^{2}+\left(\frac{\partial M}{\partial z}\right)^{2}}
$$

O ASA 2D independe da direção de magnetização dos corpos e do campo magnético terrestre, geralmente é aplicado para estimativa de profundidade e estudo de magnetização remanente de contatos verticais. Enquanto que, o ASA 3D depende da inclinação e declinação de magnetização dos corpos e do campo magnético terrestre, devido isto, pode ser usado para detecção do limite de borda dos corpos com contatos verticais (edge detection). Para detecção de bordas o ASA 3D pode ser associado à redução ao polo e a técnica de gradiente horizontal, desde que estejam em profundidade rasas, assim como, em baixas latitudes magnéticas (Nabighian, 1972, 1974, 1984; Roest et al., 1992, Roest e Pilkington, 1993; Li, 2006). No caso de uma interpretação qualitativa o ASA 3D pode ser vantajoso sobre o campo magnético total, porém na ausência de informações da magnetização remanente precisa e/ou em baixas latitudes, o ASA 3D apresenta uma possibilidade de interpretação reforçada com auxílio de outros dados geofísicos (Li, 2006).

Li (2006) considera um erro denominar sinal analítico de ASA 3D, o uso dotermo gradiente total. Diferente de outros autores, ele considera que a amplitude do gradiente total ou gradiente total, tanto da gravidade quanto do campo magnético, dependem de diversos fatores, tais como a profundidade, extensão, ângulo de mergulho de um corpo fonte, além da direção de magnetização dele e a direção do campo magnético da Terra. Devido à complexidade de fatores envolvidos, ele sugere considerar os dados geológicos existentes para análise dos dados. Contudo, este produto é indicado para detecção de bordas 
com contatos verticais em fontes rasas; e o resultado gerado a partir deste filtro pode ser visto nas figuras 3.13 e 3.14 .

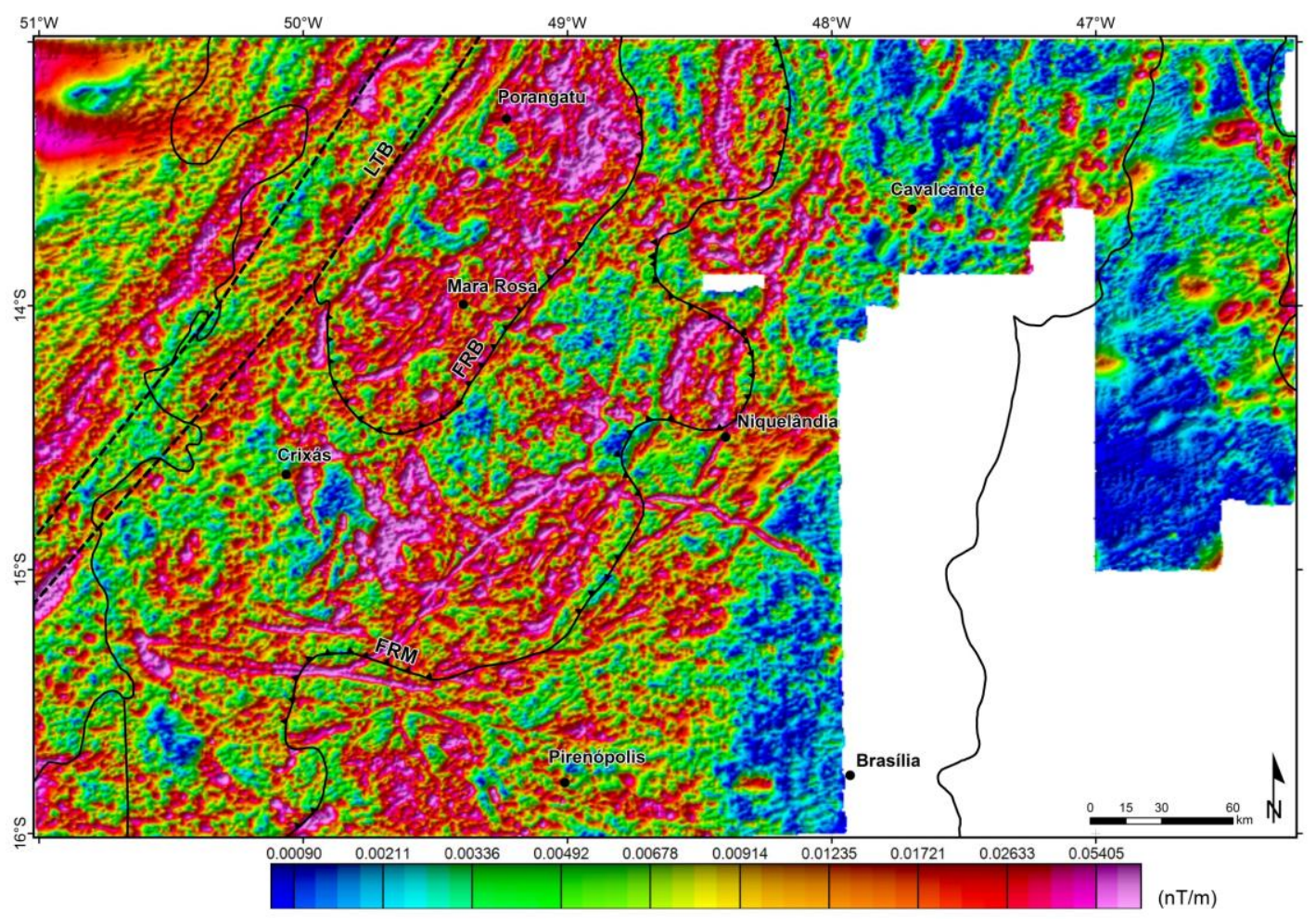

Figura 3.13 - Mapa do sinal analítico ou gradiente total do campo magnético anômalo.

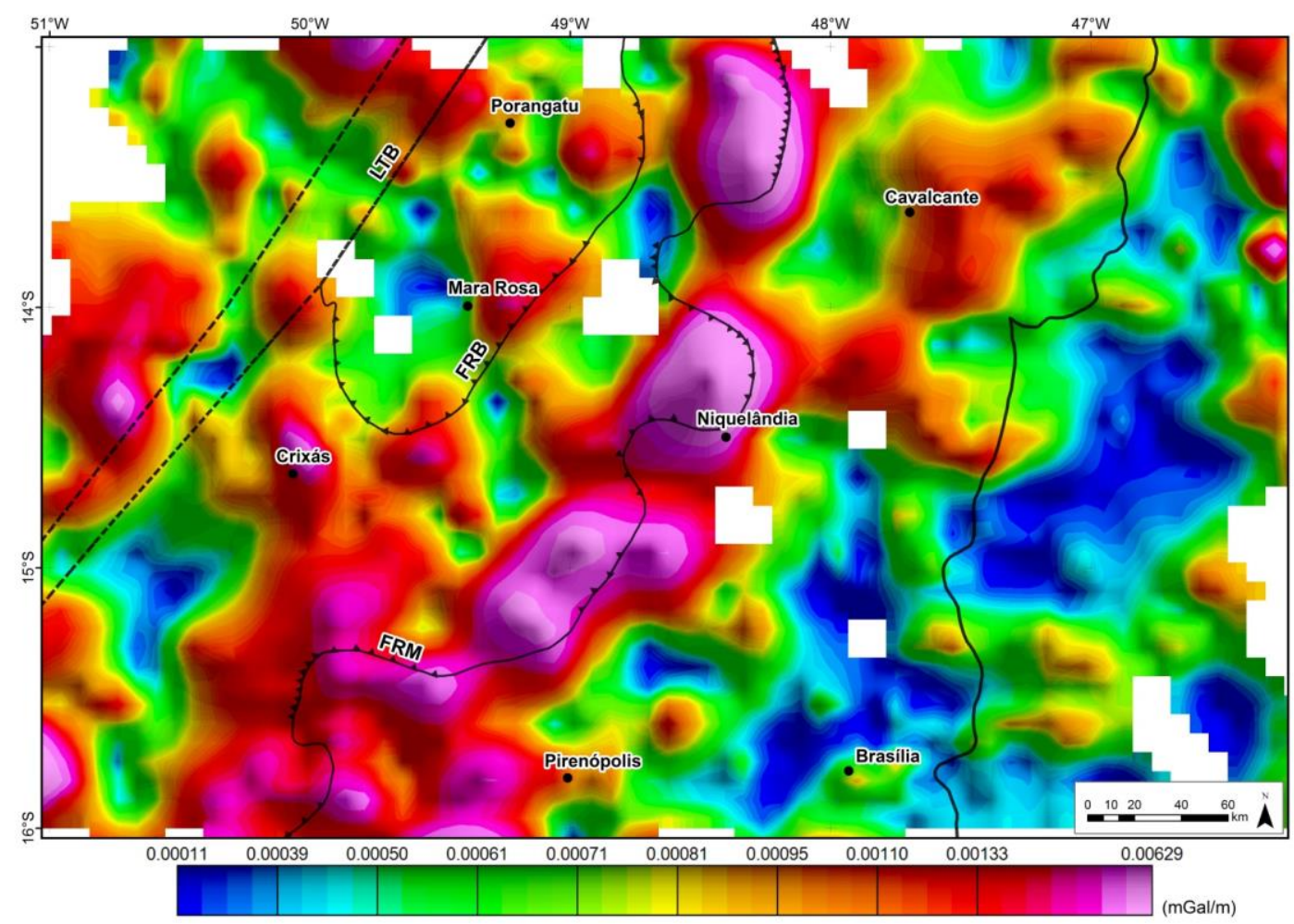

Figura 3.14 - Mapa do sinal analítico ou gradiente total da anomalia Bouguer de dados gravimétricos terrestre. LTB Lineamento Transbrasiliano, FRB - Falha Rio dos Bois, FRM - Falha Rio Maranhão. 


\subsubsection{TILT DERIVATIVE}

De acordo com Miller e Singh (1994) o arco tangente da razão entre a derivada vertical e o gradiente horizontal resulta na Derivada Tilt (Tilt derivative), também conhecido como inclinação do sinal analítico (ISA), como descrito por Blum (1999). Uma vez que é derivada a partir de uma proporção, tem uma faixa de dados normalizada e desta forma retrata as respostas de fontes mais profundas e fontes rasas de forma semelhante. Portanto a análise deste produto deve ser comparada aos demais filtros gerados (Miller e Singh,1994).

Este método equaliza as amplitudes e posiciona a amplitude máxima da anomalia sobre o centro da fonte (Ferreira et al., 2013), tanto magnética quanto gravimétrica (Figuras 3.15 e 3.16). A vantagem do tilt derivative é a capacidade de normalizar uma imagem de campo magnético e separar sinal de ruído, uma vez que o zero da derivada tilt está próximo da borda da estrutura (Salem et al., 2007). De acordo com estas definições, a derivada tilt pode ser representada por:

$$
\text { Tilt }=\tan ^{-1}\left[\frac{\left(\frac{\partial M}{\partial z}\right)}{\sqrt{\left(\frac{\partial M}{\partial x}\right)^{2}+\left(\frac{\partial M}{\partial y}\right)^{2}}}\right]
$$

O ângulo TILT pode variar entre $-90^{\circ}$ até $90^{\circ}$; tem valor máximo, positivo, no centro da fonte, apresenta valor zero ou próximo de zero nas bordas da fonte, e valores mínimos, negativos, fora da região da fonte (Miller e Singh,1994).

\subsubsection{TILT DERIVATIVE DO GRADIENTE HORIZONTAL TOTAL}

Este método tem como finalidade realçar o gradiente horizontal total das anomalias magnéticas por meio da aplicação da inclinação do sinal analítico, de acordo com proposto por Ferreira et al. (2013). Estes autores comprovaram que este método equaliza as amplitudes com os máximos situados nas bordas dos corpos (Ferreira et al., 2013), sendo esta uma função significativa na análise qualitativa de dados magnéticos e gravimétricos (Figuras 3.17 e 3.18).

O método partiu de estudos relacionados à derivada tilt de Miller e Singh (1994), seguido posteriormente por Verduzco et al.(2004), que aplicaram a técnica do gradiente horizontal total na inclinação do sinal analítico com intuito de realçar e centralizar as máximas amplitudes sobre os limites das fontes (Ferreira et al. 2013). A técnica pode ser definida da seguinte forma:

$$
\text { Tilt }- \text { GHT }=\operatorname{Arctg} \frac{G H T}{\text { Derivada Vertival }}
$$




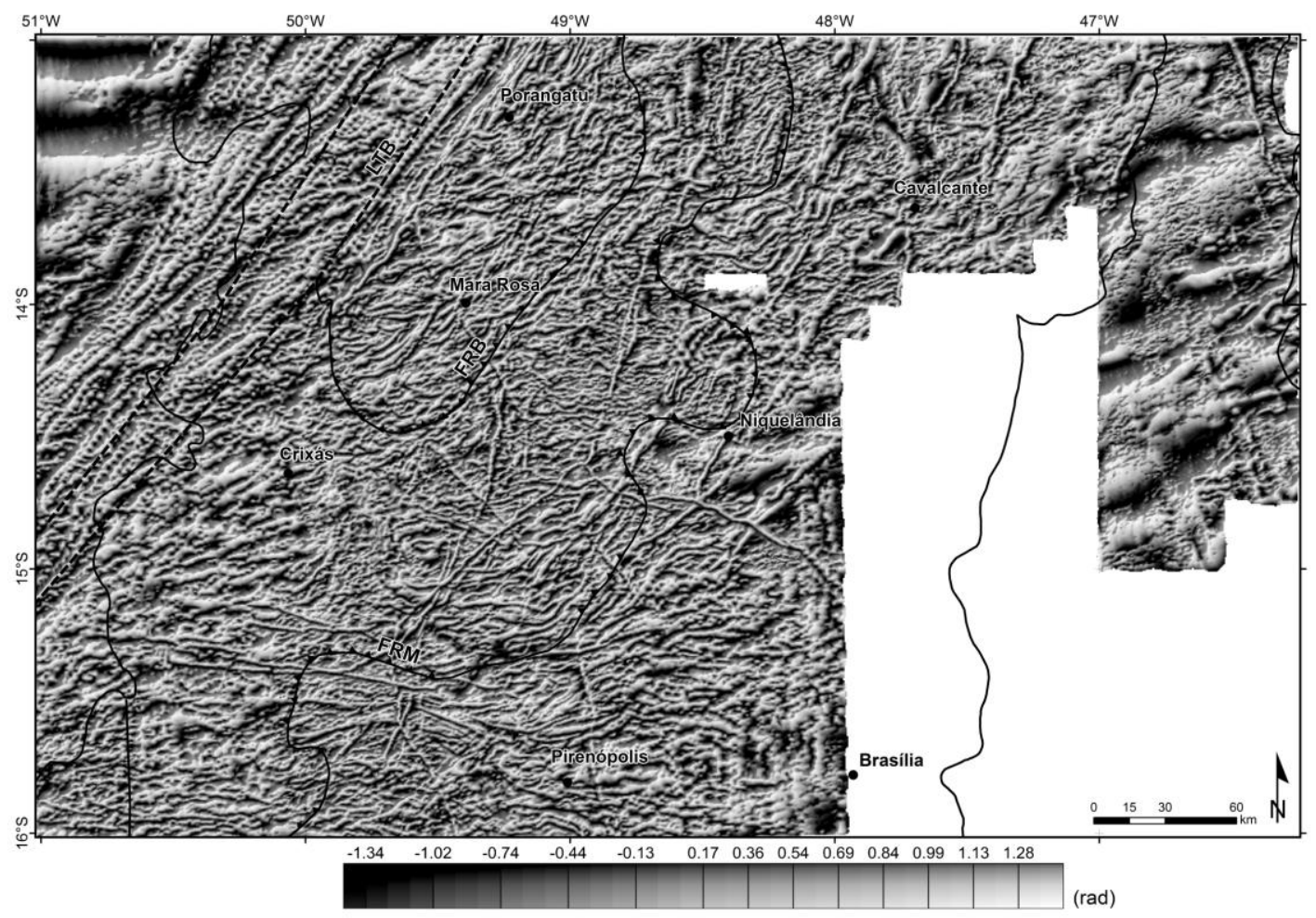

Figura 3.15 - Mapa do tilt derivative do campo magnético anômalo.

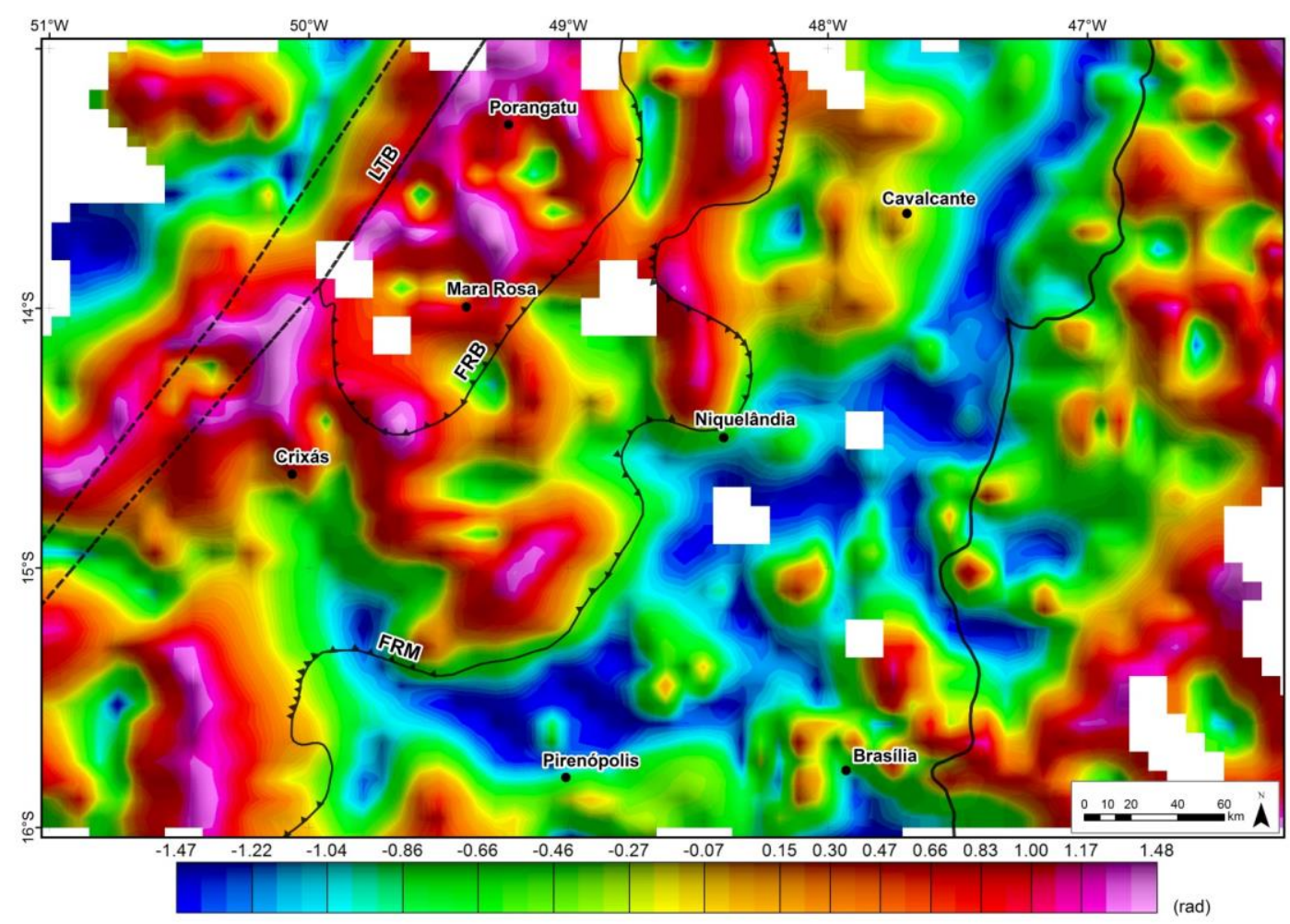

Figura 3.16 - Mapa do tilt derivative da anomalia Bouguer de dados gravimétricos terrestre. LTB - Lineamento Transbrasiliano, FRB - Falha Rio dos Bois, FRM - Falha Rio Maranhão. 


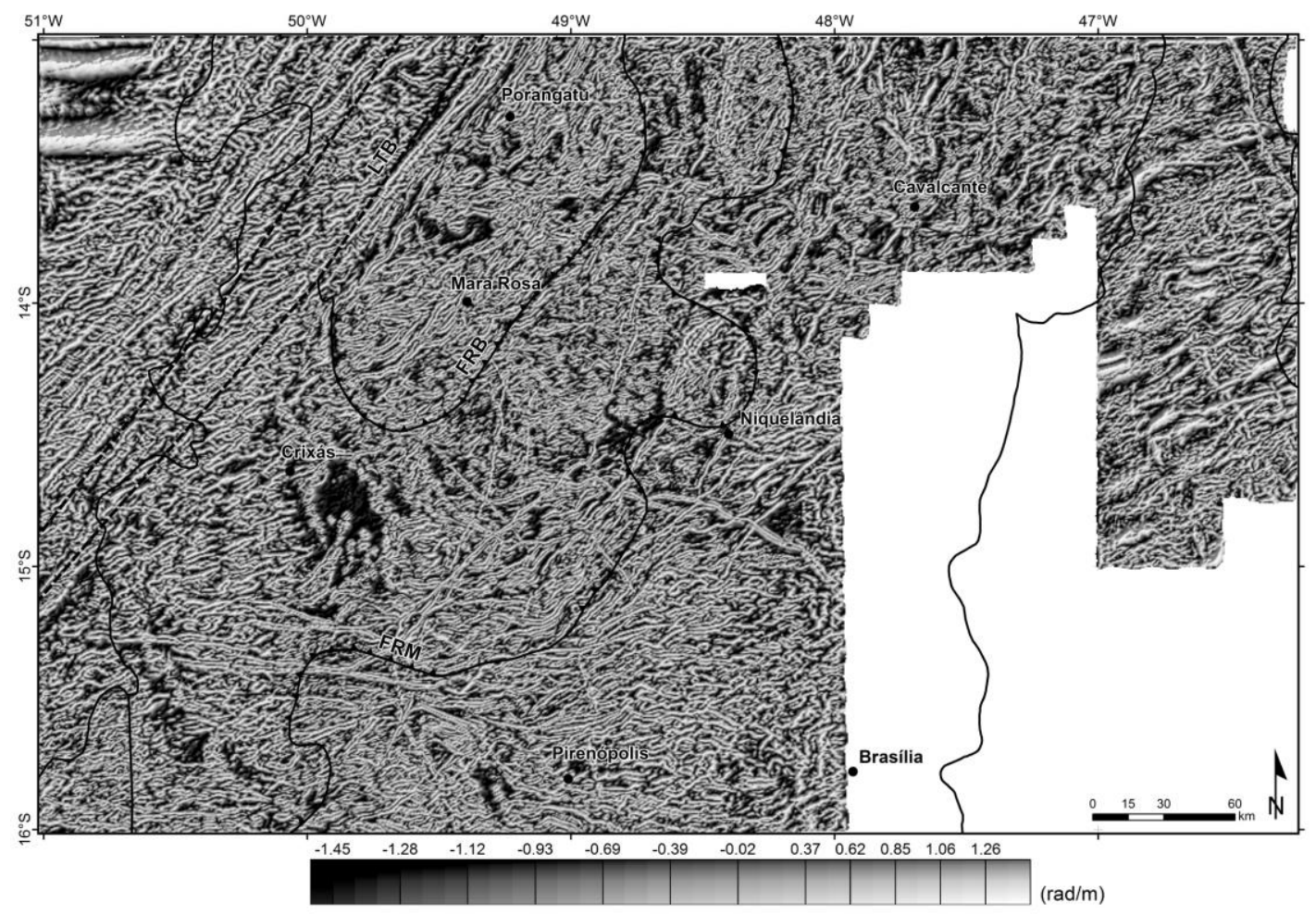

Figura 3.17 - Mapa tilt derivative do gradiente horizontal total do campo magnético anômalo.

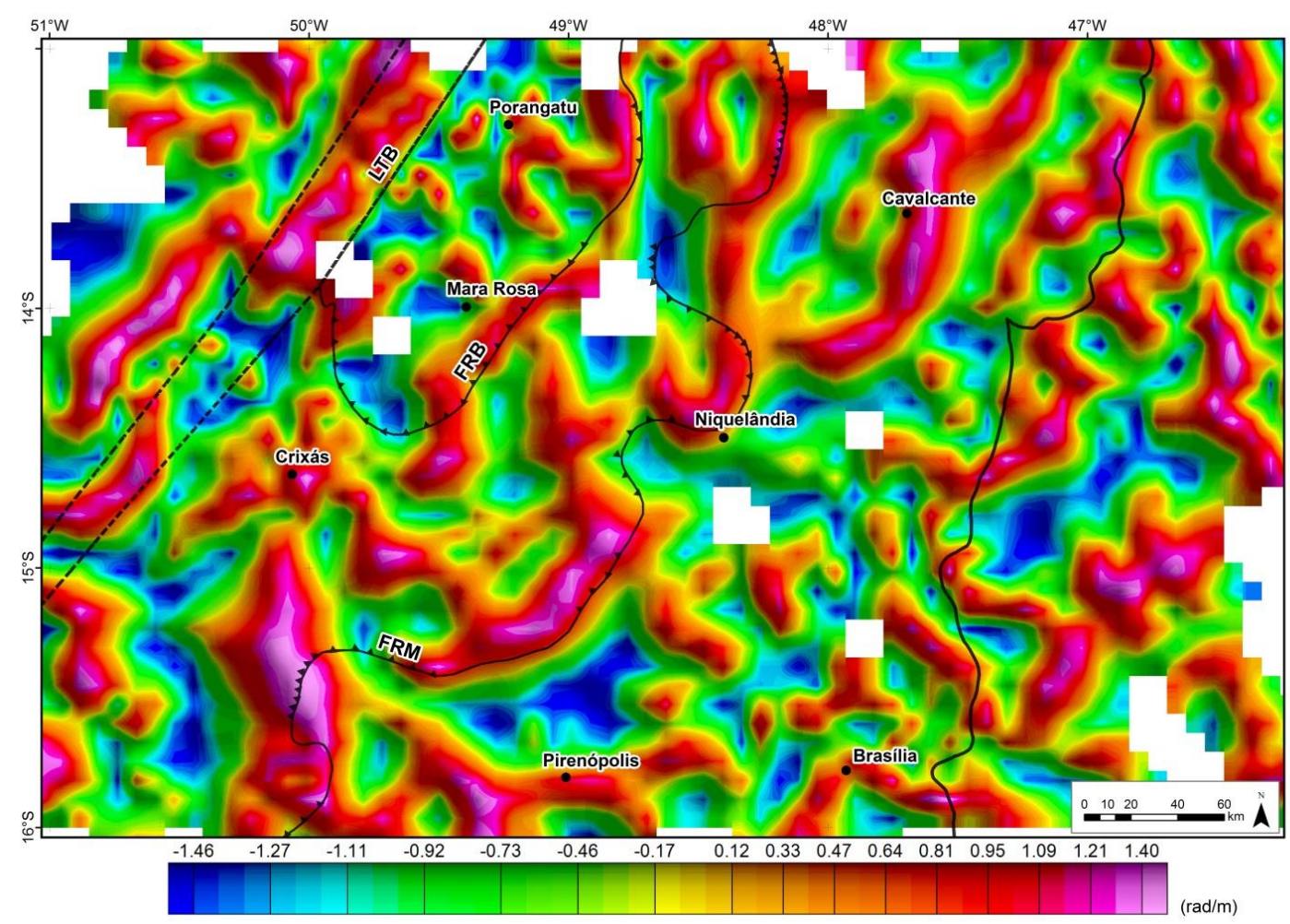

Figura 3.18 - Mapa do tilt derivative do gradiente horizontal total da anomalia Bouguer dos dados gravimétricos terrestre. LTB - Lineamento Transbrasiliano, FRB - Falha Rio dos Bois, FRM - Falha Rio Maranhão. 


\subsubsection{MATCHED FILTER}

O Matched filter é um método de filtragem que utiliza o espectro de potência do sinal analisado, tais como o campo magnético anômalo, e dados da anomalia Bouguer, na concepção do filtro (Telford et al., 1990). Spector (1968), Spector e Grant (1970) mostraram que o espectro logarítmico radial de dados magnéticos de um grid contém segmentos com inclinações constantes, que são provenientes das amostras estatísticas das fontes magnéticas ou camadas de fontes equivalentes em diferentes profundidades (Nabighian et al.,2005). No trabalho de Spector (1968) foram projetados os primeiros filtros no domínio de Fourier e filtro de convolução para separar as anomalias magnéticas produzidas em duas profundidades e fontes diferentes. $\mathrm{O}$ termo Matched Filter foi usado pela primeira vez por Syberg (1972), que em seu trabalho combinou parâmetros de filtros com espectro de potência no domínio de Fourier para separar o campo magnético de uma camada fina e rasa, de um campo magnético de uma camada mais profunda (Nabighian et al.,2005). O uso deste filtro, em geral, está focado em separar anomalias de componentes regionais de componentes residuais, usando um modelo de fonte equivalente para as camadas extraídas do espectro (Phillips, 2001).

Este filtro tem por objetivo realizar uma estimativa de profundidade média de uma área, que é observada por meio da inclinação dos segmentos de reta no espectro de potência, que possivelmente foram geradas por distribuição de fontes não correlacionadas espacialmente, onde as altas frequências indicam fontes mais rasas e as baixas frequências indicam fontes mais profundas, sendo este um fundamento da aplicação da técnica definida por Phillips (2001). A figura 3.19 mostra o espectro de potência do CMA, em que foram marcados os intervalos de profundidades em função das amplitudes do sinal. O mesmo método foi aplicado aos dados de anomalia Bouguer terrestre, figuras 3.20 que mostra a separação das fontes gravimétricas em função da frequência. Em ambos os dados a linha verde representa o espectro de potência gerado e a linha azul é o resultado do ajuste do filtro às profundidades interpretadas nos segmentos de reta. Para geração dos mapas de estimativa de profundidade, foi utilizada a extensão USGS dentro do software Oasis Montaj da Geosoft, em que foram gerados diversos resultados, a fim de obter os intervalos que melhor representassem as fontes magnéticas rasas, intermediárias e profundas. Os mapas selecionados para as interpretações estão dispostos nos itens 4.2 e 4.4 do Capítulo IV, que mostram os resultados dos dados e interpretações desta análise quantitativa. 


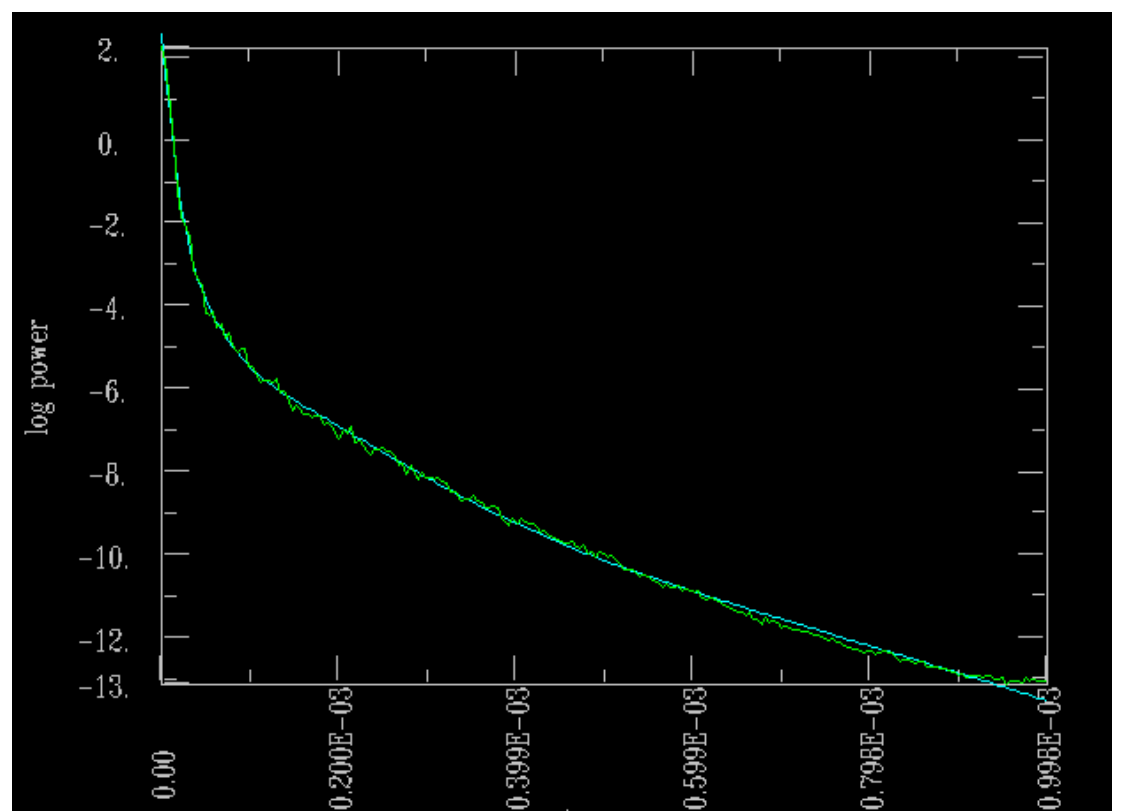

Figura 3.19 - Espectro de potência gerado do dado do campo magnético anômalo, em que foram marcados os intervalos de fontes magnéticas e obtidos os intervalos de profundidade. A linha verde representa o espectro e a linha azul o ajuste de acordo com a interpretação dos segmentos de retas.

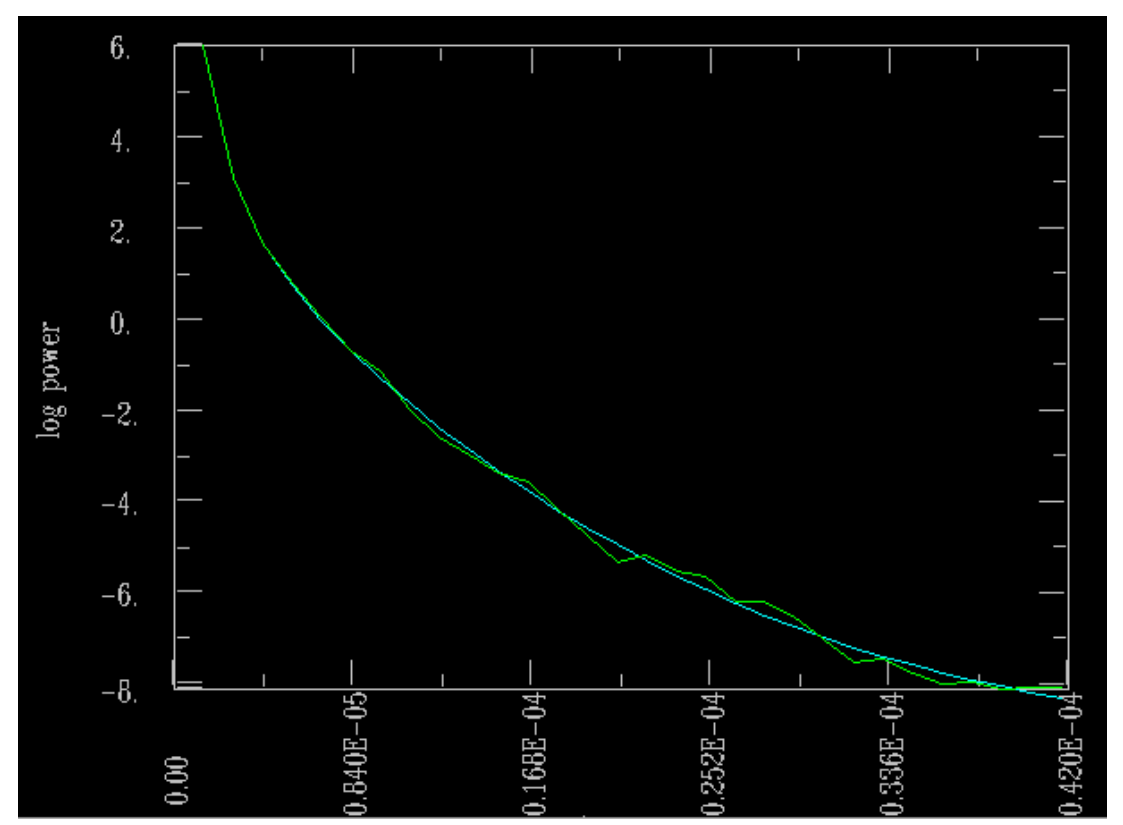

Figura 3.200 - Espectro de potência gerado a partir dos dados de anomalia Bouguer terrestre, a linha verde representa o espectro de potência e a linha azul o ajuste de acordo com a interpretação dos dados, em que foram calculadas as profundidades das fontes e os parâmetros dos filtros. 


\section{Capítulo IV}

\section{RESULTADOS}

A interpretação qualitativa dos dados se iniciou com a extração de lineamentos magnéticos de $1^{\mathrm{a}}, 2^{\mathrm{a}}$ e $3^{\mathrm{a}}$ ordens, diferenciados de acordo com sua extensão e valores de intensidade do sinal em função de altas e baixas frequências, assim como pela variação de gradiente entre as unidades. O matched filter (Phillips, 2001) foi aplicado para verificar a continuidade destes lineamentos e obter uma estimativa sobre a continuidade destas feições em profundidade.

\subsection{LiNEAMENTOS MAGNÉTICOS}

A observação de lineamentos magnéticos de $1^{\mathrm{a}}, 2^{\mathrm{a}}$ e $3^{\mathrm{a}}$ ordens tem por objetivo propor uma diferenciação entre os blocos tectônicos ZE, MG, e AMG, a fim de caracterizar feições de variações estruturais nas unidades ou mesmo zonas de descontinuidade na crosta subjacente. Inicialmente os lineamentos foram extraídos a partir dos produtos da aplicação dos filtros nos dados do campo magnético anômalo, principalmente a derivada vertical, o gradiente horizontal total, a derivada tilt e a derivada tilt do gradiente horizontal total, considerando que estes produtos são propícios para identificação de estruturas e contatos entre domínios magnéticos.

A figura 4.1 mostra que os lineamentos extraídos têm direção preferencial NE-SW, acompanhando o trend do Lineamento Transbrasiliano e mostrando que este sistema de falhas transcorrentes exerce forte influência na região. Vale ressaltar que na parte sudeste da área não há levantamento aeromagnético, e por este motivo temos uma lacuna de informação sobre a relação de contato e estruturas magnéticas entre ZE e CSF nessa região.

No bloco ZE os lineamentos possuem direção preferencial NE-SW. Os lineamentos de $1^{\mathrm{a}}$ ordem indicam extensas descontinuidades, uma de direção NNE-SSW e outra de direção ENE-WSW, com inflexões para WNW-ESE, que coincidem com o grande complexo estrutural da Megaflexura dos Pirineus, de acordo com a definição de Fonseca et al. (1995) ou Sintaxe dos Pirineus, segundo Araújo Filho (1999), onde estas estruturas magnéticas formam sigmoides.

No bloco MG os lineamentos de $1^{\mathrm{a}}$ ordem têm direção NNE-SSW, subordinadamente NE-SW, que são truncados por lineamentos de $2^{\mathrm{a}}$ ordem E-W, seguido de lineamentos NE-SW. Nota-se que os lineamentos de $2^{\mathrm{a}}$ ordem estão flexionados na região de contato com AMG.

No bloco AMG, os lineamentos têm direção NE-SW e E-W, seguido dos lineamentos de $2^{\mathrm{a}}$ ordem NE-SW e alguns ENE-WSW, sendo que grande parte dos lineamentos de $3^{\mathrm{a}}$ ordem tem direção E-W. 
Universidade de Brasília -Instituto de Geociências - Programa de Pós-graduação em Geociências Aplicadas

Arcabouço Tectônico da Porção Centro-Norte da Faixa Brasília com Base em Dados Magnéticos e Gravimétricos

\subsection{ESTIMATIVAS DE PROFUNDIDADE DAS FONTES MAGNÉTICAS}

Para estimativa de profundidade foi aplicado o método matched filter (Phillips, 2001). O objetivo desta técnica para estes dados é verificar a continuidade em profundidade das estruturas magnéticas analisadas nos mapas de realce. A partir da interpretação do espectro de potência nos dados de CMA no matched filter, foram obtidos quatro estimativas de profundidades de fontes: rasa, $700 \mathrm{~m}$; intermediárias, $2 \mathrm{~km}$ e $8 \mathrm{~km}$; e profunda, $19 \mathrm{~km}$ (Figuras 4.2 A, B, C e D).

As fontes a $700 \mathrm{~m}$ mostram que os lineamentos magnéticos de $1^{\mathrm{a}}, 2^{\mathrm{a}}$ e $3^{\mathrm{a}}$ ordem ainda são representativos, semelhante aos lineamentos extraídos dos produtos do CMA (Figuras 4.3 A). Nas fontes estimadas a $2 \mathrm{~km}$, os lineamentos de $1^{\mathrm{a}}$ ordem passam a aparecer em menor intensidade, assim como os lineamentos de $2^{\mathrm{a}}$ ordem, e os lineamentos de $3^{\mathrm{a}}$ raramente aparecem, ou seja, muitos destes lineamentos menores são feições relacionadas a fontes rasas (Figuras $4.3 \mathrm{~B}$ ).

Nas fontes estimadas a $8 \mathrm{~km}$ é possível notar a continuidade dos lineamentos de $1^{\mathrm{a}}$ e $2^{\mathrm{a}}$ ordem. Os lineamentos de $1^{\mathrm{a}}$ ordem aparecem com maior extensão e mais expressivos em função das amplitudes (Figuras $4.3 \mathrm{C}$ ). Nas fontes estimadas a $19 \mathrm{~km}$ somente lineamentos de $1^{\mathrm{a}}$ ordem são observados, notando-se trend preferencial NE, alguns NNE e EW, indicando que podem ser as principais estruturas magnéticas de descontinuidade na crosta (Figuras 4.3D). 


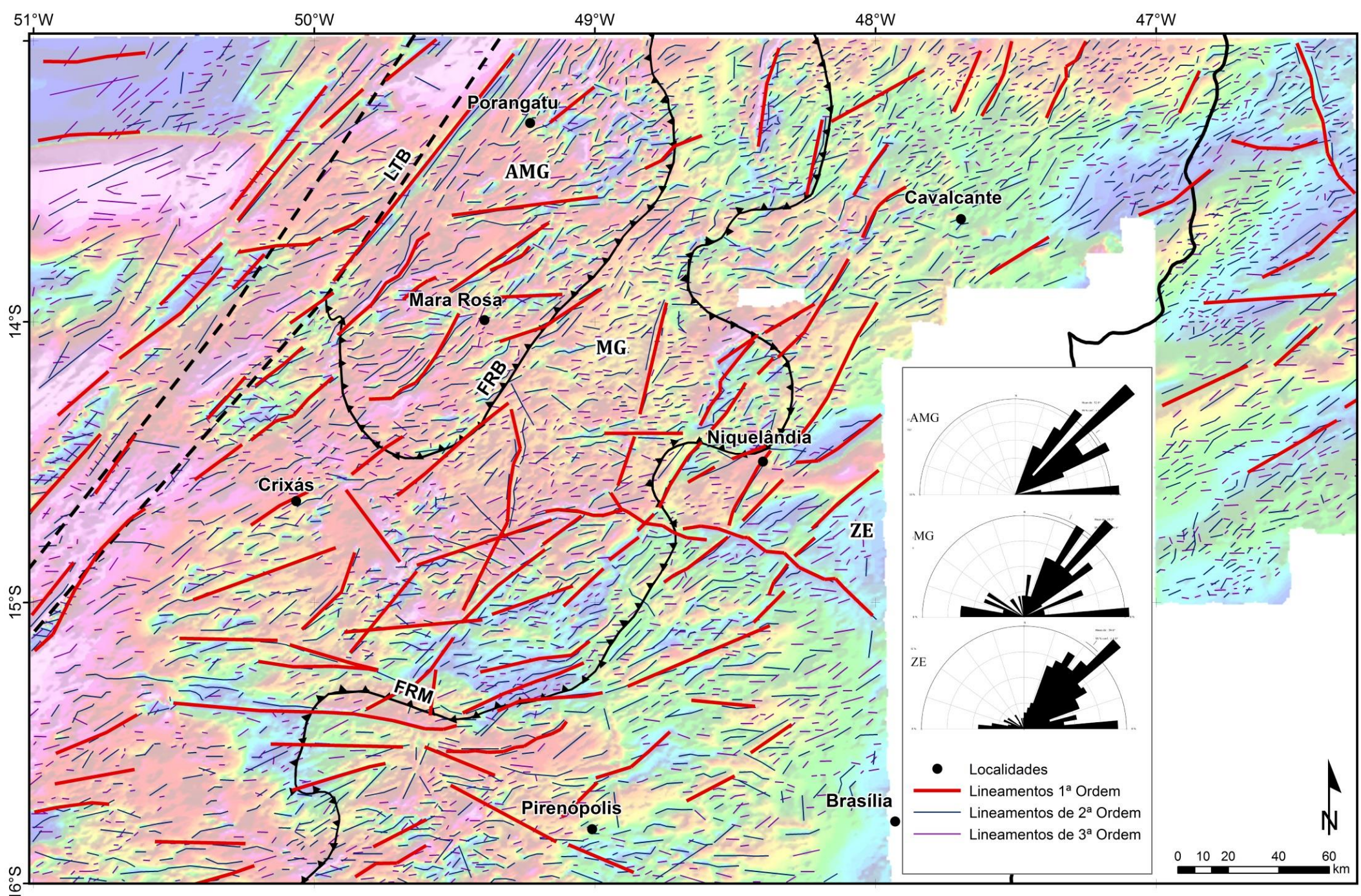

Figura 4.1 - Mapa de lineamentos magnéticos interpretados a partir dos produtos do campo magnético anômalo sobre o mapa do CMA, diagrama de rosetas dos domínios tectônicos estudados em destaque, limites geotectônicos conhecidos e localidades da região. Os limites geotectônicos da área de estudos com base no mapa modificado de Pimentel et al. (2004) e Fuck et al., (2014). LTB - Lineamento Transbrasiliano; FRB - Falha Rio dos Bois; FRM - Falha Rio Maranhão; AMG - Arco Magmático de Goiás; MG - Maciço de Goiás; ZE - Zona Externa; CSF - Cráton São Francisco. 

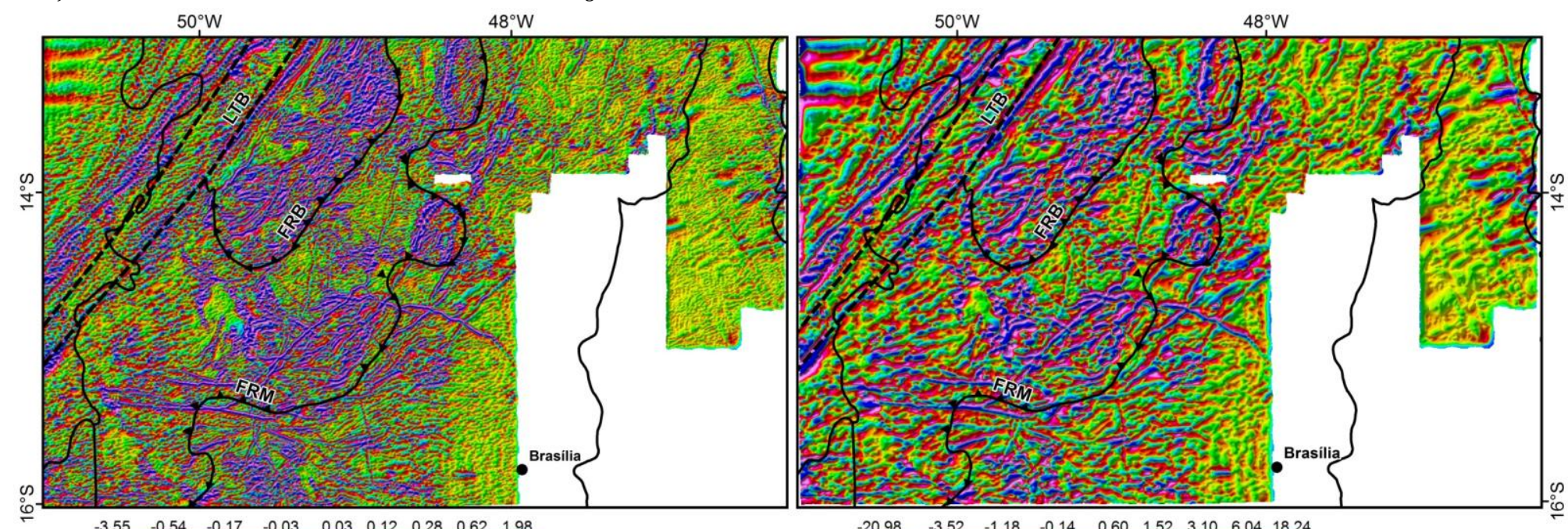

$\begin{array}{lllllllllll}\text { A) } & -3.55 & -0.54 & -0.17 & -0.03 & 0.03 & 0.12 & 0.28 & 0.62 & 1.98 & \\ \end{array}$
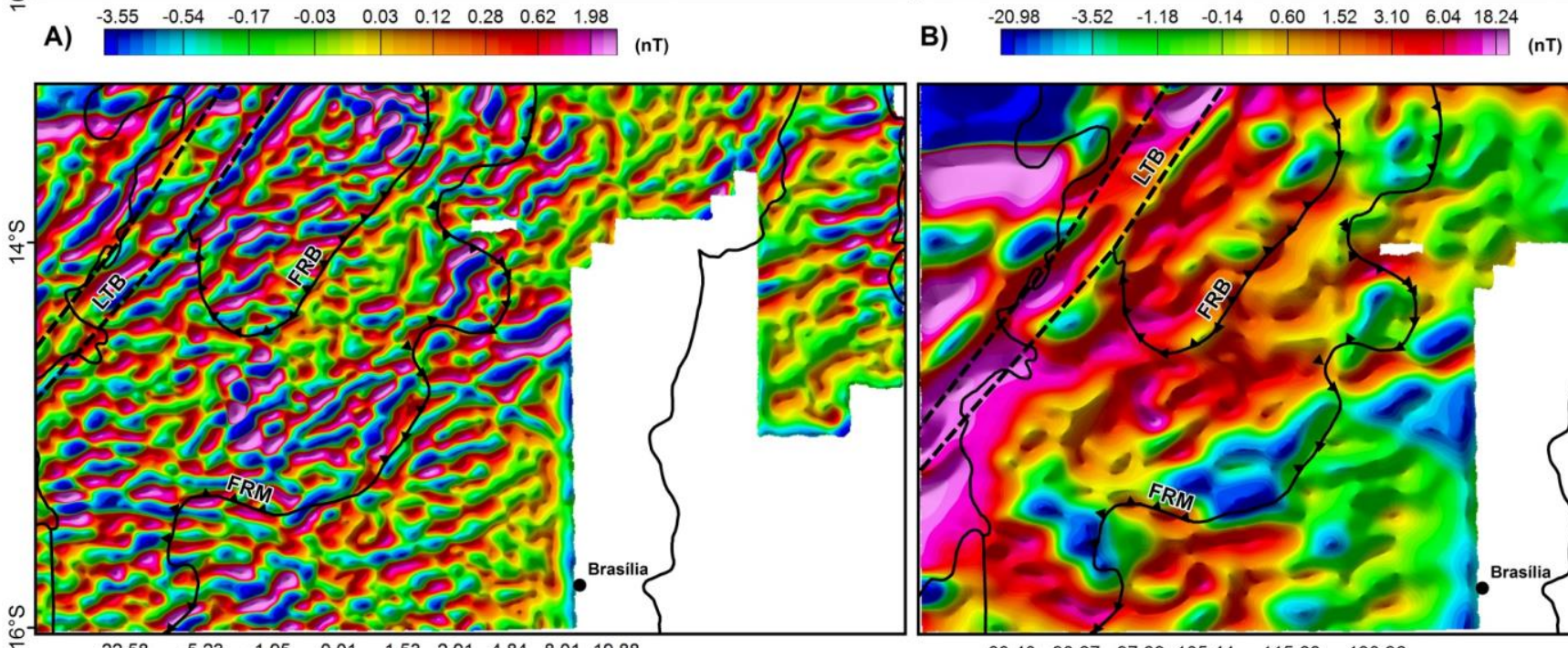

C)

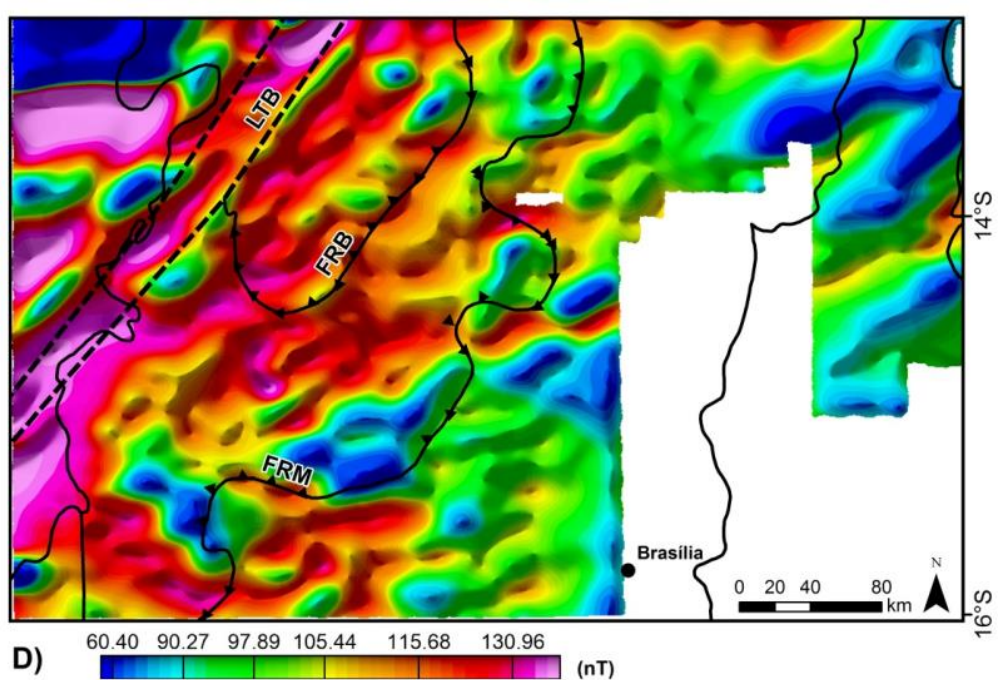

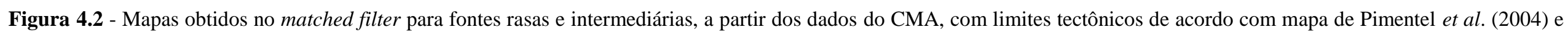

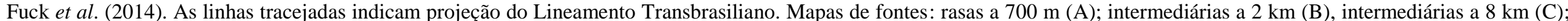
profundas a 19 km (D). LTB - Lineamento Transbrasiliano; FRB - Falha Rio dos Bois; FRM - Falha Rio Maranhão. 
Universidade de Brasília -Instituto de Geociências - Programa de Pós-graduação em Geociências Aplicadas

Arcabouço Tectônico da Porção Centro-Norte da Faixa Brasília com Base em Dados Magnéticos e Gravimétricos
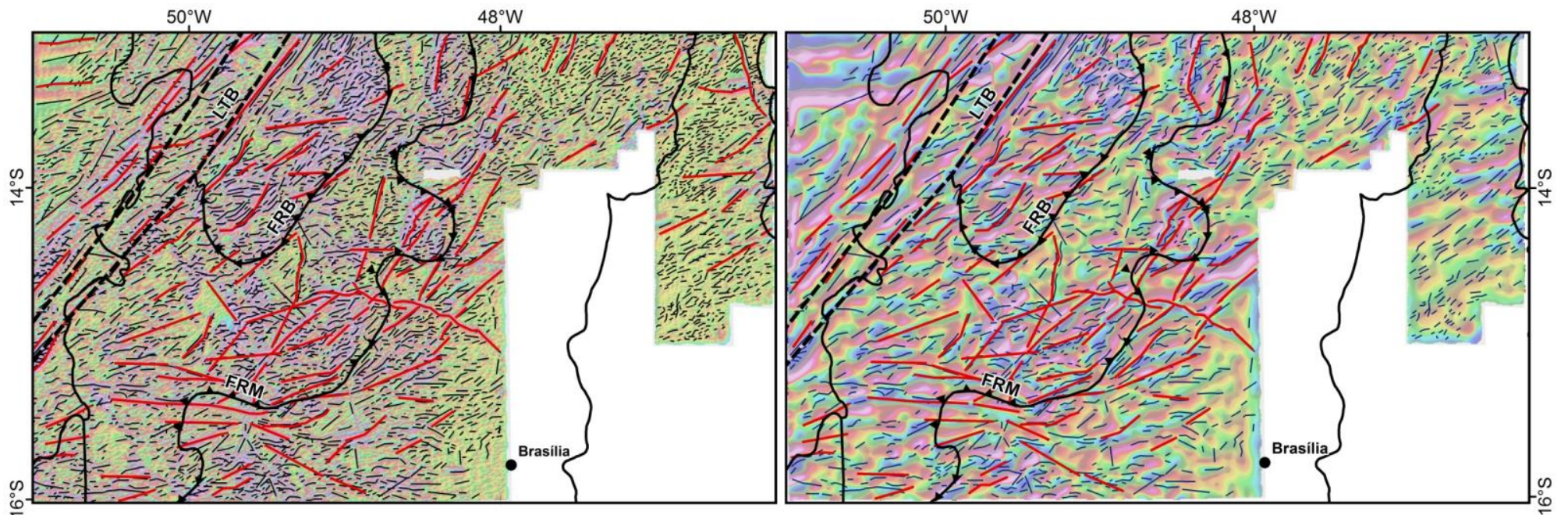

A)

B)
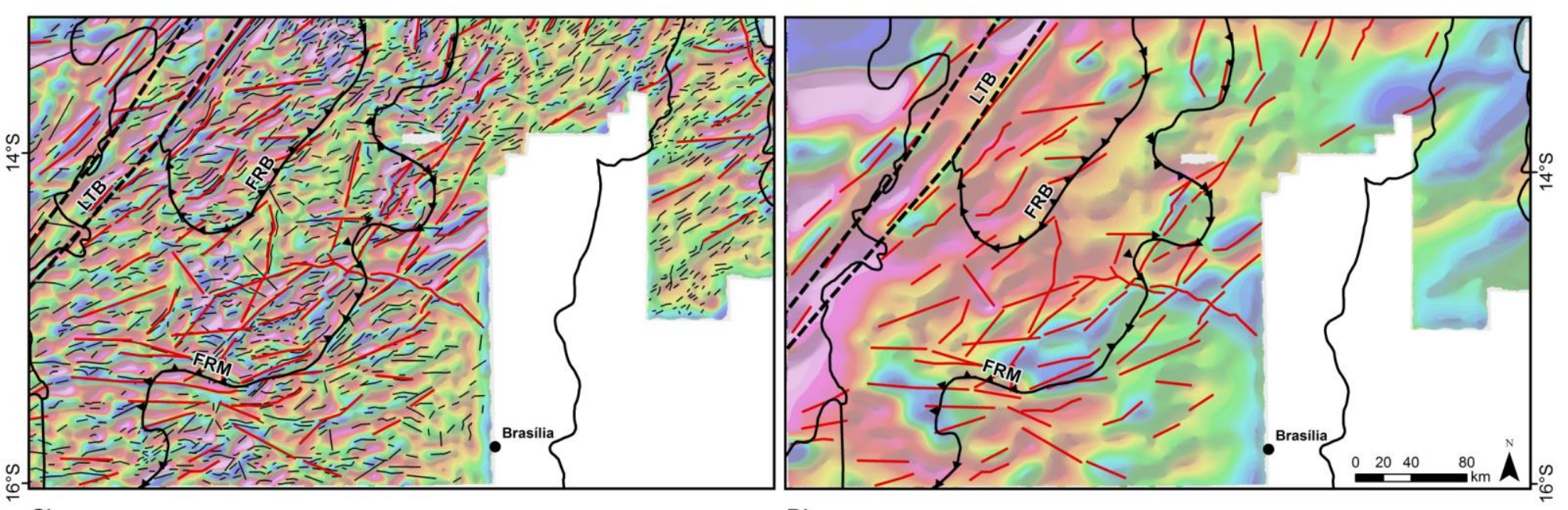

C)

D)

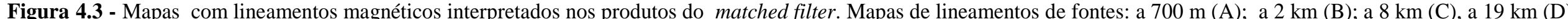

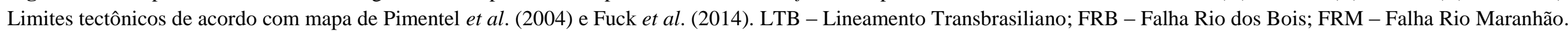


Para caracterização das fontes magnéticas dentre os blocos AMG, MG e ZE, foram elaboradas sub-janelas de tamanhos iguais, a fim de verificar os principais intervalos de fontes magnéticas, em cada bloco (Figura 4.4). A partir dos valores das profundidades obtidas no matched filter para cada sub-janela, foi realizada análise estatística, de onde foi extraída a média ponderada das populações com valores aproximados. Os valores amostrados foram separados de acordo com as profundidades, em rasas, intermediárias e profundas. As profundidades obtidas para os blocos AMG, MG e ZE foram analisadas separadamente para verificar a existência de variações de profundidade médias das fontes e desta forma estabelecer suaa individualização.

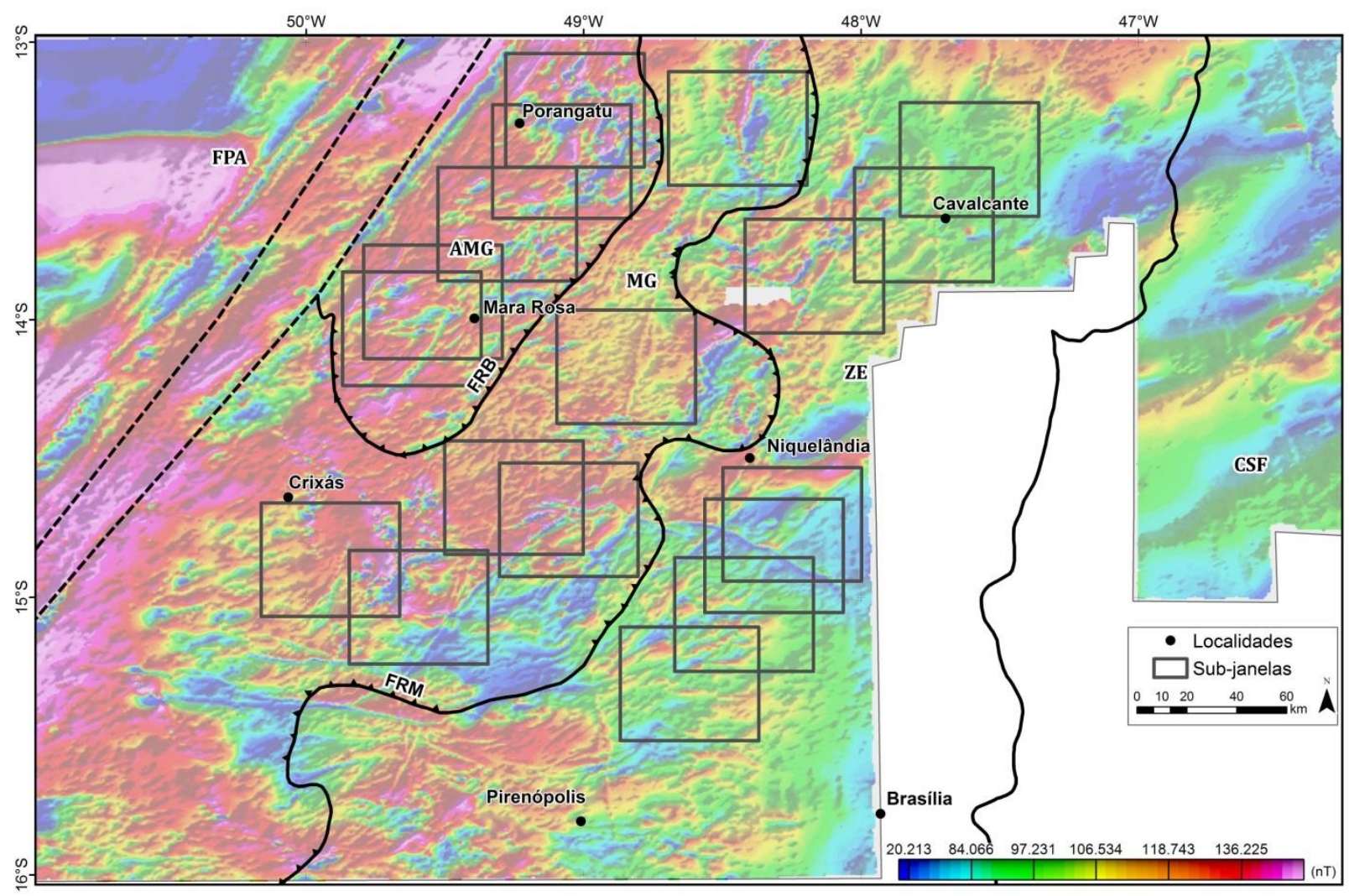

Figura 4.4 - Mapa do campo magnético anômalo com a localização das sub-janelas elaboradas para análise de profundidade usando matched filter de cada bloco tectônico.

No bloco ZE, para as fontes rasas, intermediárias e profundas, foram obtidas as seguintes médias: 1,3 km, 5,2 km e 12,1 km. Para o bloco MG, do mesmo modo, foram obtidas as médias 1,4 km, 5,6 km e 10,2 km. Para o bloco AMG, obtivemos: 1,4 km, 5,8 km e 11,9 km. Os intervalos de profundidade das fontes consideradas para o cálculo estão na tabela 2. Estes dados indicam que no bloco MG as fontes mais profundas estão relativamente mais rasas em relação aosblocos AMG e ZE. 
Universidade de Brasília -Instituto de Geociências - Programa de Pós-graduação em Geociências Aplicadas

Arcabouço Tectônico da Porção Centro-Norte da Faixa Brasília com Base em Dados Magnéticos e Gravimétricos

Tabela 4.1 - Intervalos e médias para cada bloco tectônico obtidos no matched filter.

\begin{tabular}{lccc}
\hline $\begin{array}{l}\text { Blocos } \\
\text { Tectônicos }\end{array}$ & $\begin{array}{c}\text { Min.-Máx./Média } \\
(\mathbf{k m})\end{array}$ & $\begin{array}{c}\text { Min.-Máx./Média } \\
(\mathbf{k m})\end{array}$ & $\begin{array}{c}\text { Min.-Máx./Média } \\
(\mathbf{k m})\end{array}$ \\
\hline AMG & $0,3-1,8 / 1,4$ & $2,9-6,3 / 5,8$ & $7,5-15,1 / 11,9$ \\
MG & $0,3-1,9 / 1,4$ & $4,3-6,1 / 5,6$ & $7,7-12,3 / 10,2$ \\
ZE & $0,3-1,9 / 1,3$ & $3,6-6,3 / 5,2$ & $6,8-17,2 / 12,1$ \\
\hline
\end{tabular}

\subsection{GRAVIMETRIA}

Para análise gravimétrica foram utilizados dados de gravimetria de satélite e de gravimetria terrestre (Figuras 4.5, A, B, C, D). Os dados de satélite foram utilizados a fim de realizar análise qualitativa das anomalias que trazem resposta do manto, enquanto que os dados de gravimetria terrestres trouxeram informações de estruturas mais rasas da crosta.

\subsubsection{DADOS GRAVIMÉTRICOS DO WGM}

Os dados do World Gravity Map - WGM 2012 (Bonvalot et al., 2012) auxiliaram na caracterização qualitativa dos blocos tectônicos que constituem a área. No mapa de anomalia Bouguer (Figura 4.5) observa-se uma tendência na variação de gradiente de NW para SE, que varia de um alto gravimétrico, de $-1,8 \mathrm{mGal}$, para baixo gravimétrico, com cerca de $-144,5 \mathrm{mGal}$, tendo assim um gradiente de $0,59 \mathrm{mGals} / \mathrm{km}$ que segue o trend regional NE-SW.Este valor de gradiente é obtido por meio da diferença dos valores das anomalias de mais alto gravimétrico e mais baixo gravimétrico pela distância entre elas. 


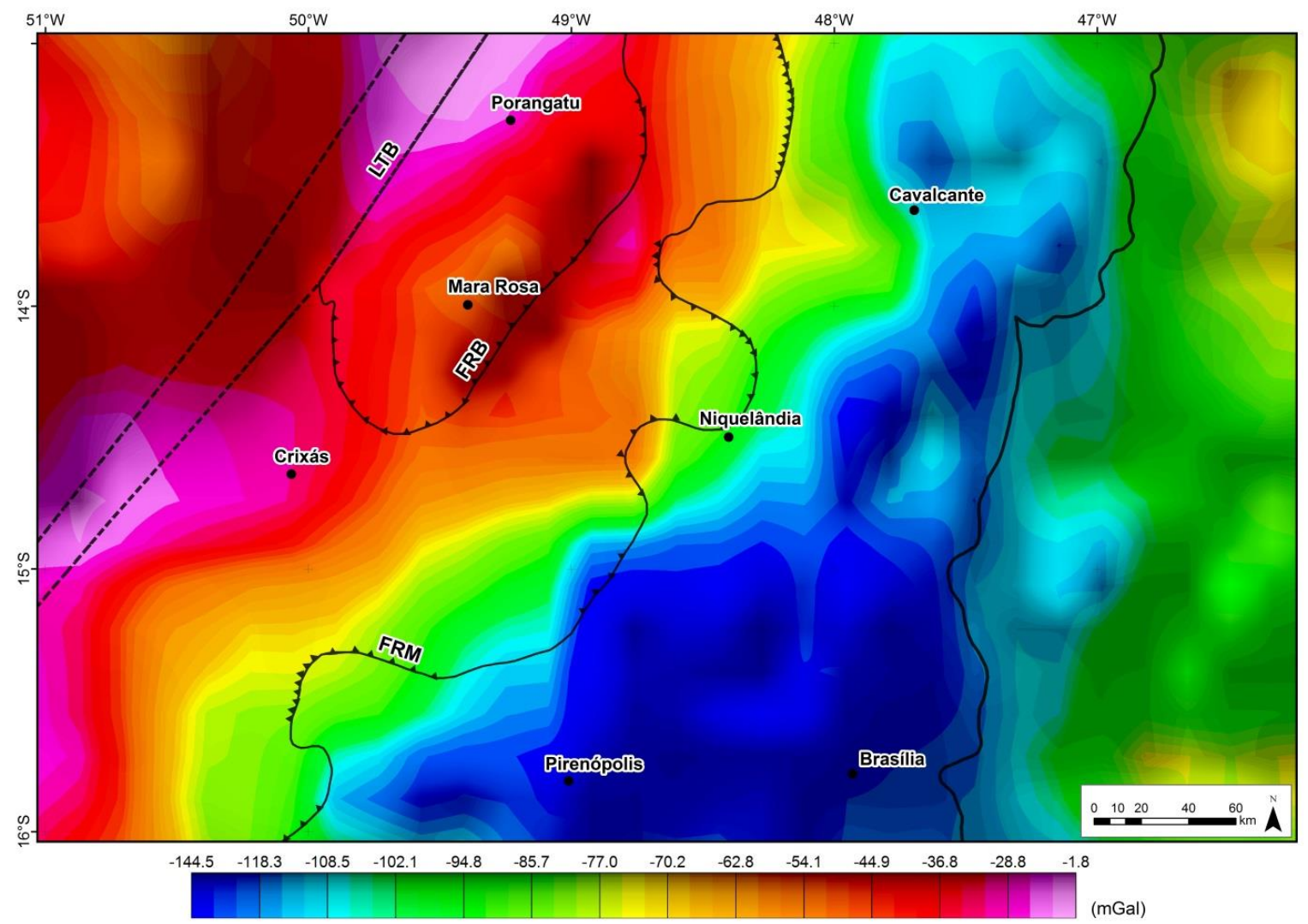

Figura 4.5 - Mapa de anomalia Bouguer do WGM 2012; Limites tectônicos com base em Pimentel et al. (2004) e Fuck et al. (2014) e as falhas de empurrão Rio Maranhão e Rio dos Bois. LTB - Lineamento Transbrasiliano; FRB Falha Rio dos Bois; FRM - Falha Rio Maranhão.

\subsubsection{GRAVIMETRIA TERRESTRE}

Estes dados possibilitaram uma melhor visualização de distribuição das anomalias, como pode ser observado no mapa de anomalia Bouguer (Figura 4.6), e sobre estes dados foram aplicadas estimativas de profundidade do matched filter para checar quais são as principais descontinuidades em função da profundidade. Para uma análise qualitativa foram usados os mapas da derivada vertical, do gradiente horizontal total e da derivada tilt e derivada tilt do gradiente horizontal total, por ter melhor resolução dos dados (Figuras 4.7 A, B, C, D, respectivamente).

Os dados de gravimetria terrestre destacaram anomalias de partes mais rasas da crosta, não observadas nos dados de satélite, a fim de destacar os corpos aflorantes e feições de descontinuidade na crosta relacionadas a eles, e com isso, junto com a análise dos dados de satélite, caracterizar cada um dos blocos tectônicos. O mapa de anomalia Bouguer mostrou o trend NE-SW, com gradiente de $0,5 \mathrm{mGal} / \mathrm{km}$, de oeste para leste (Figura 4.6). No bloco ZE, predominam baixos gravimétricos, que variam de -139,5 a -103,7 mGal, comgradiente de 0,596 $\mathrm{mGal} / \mathrm{km}$, em função da distância entre eles. No bloco MG observa-se altos gravimétricos em torno de $-33,9$ a $-10,6 \mathrm{mGal}$, e gradiente de 2,33 $\mathrm{mGal} / \mathrm{km}$. No bloco AMG predominam altos gravimétricos de aproximadamente -28 a $-15,7 \mathrm{mGal}$, com gradiente de 1,23 mGal $/ \mathrm{km}$. 


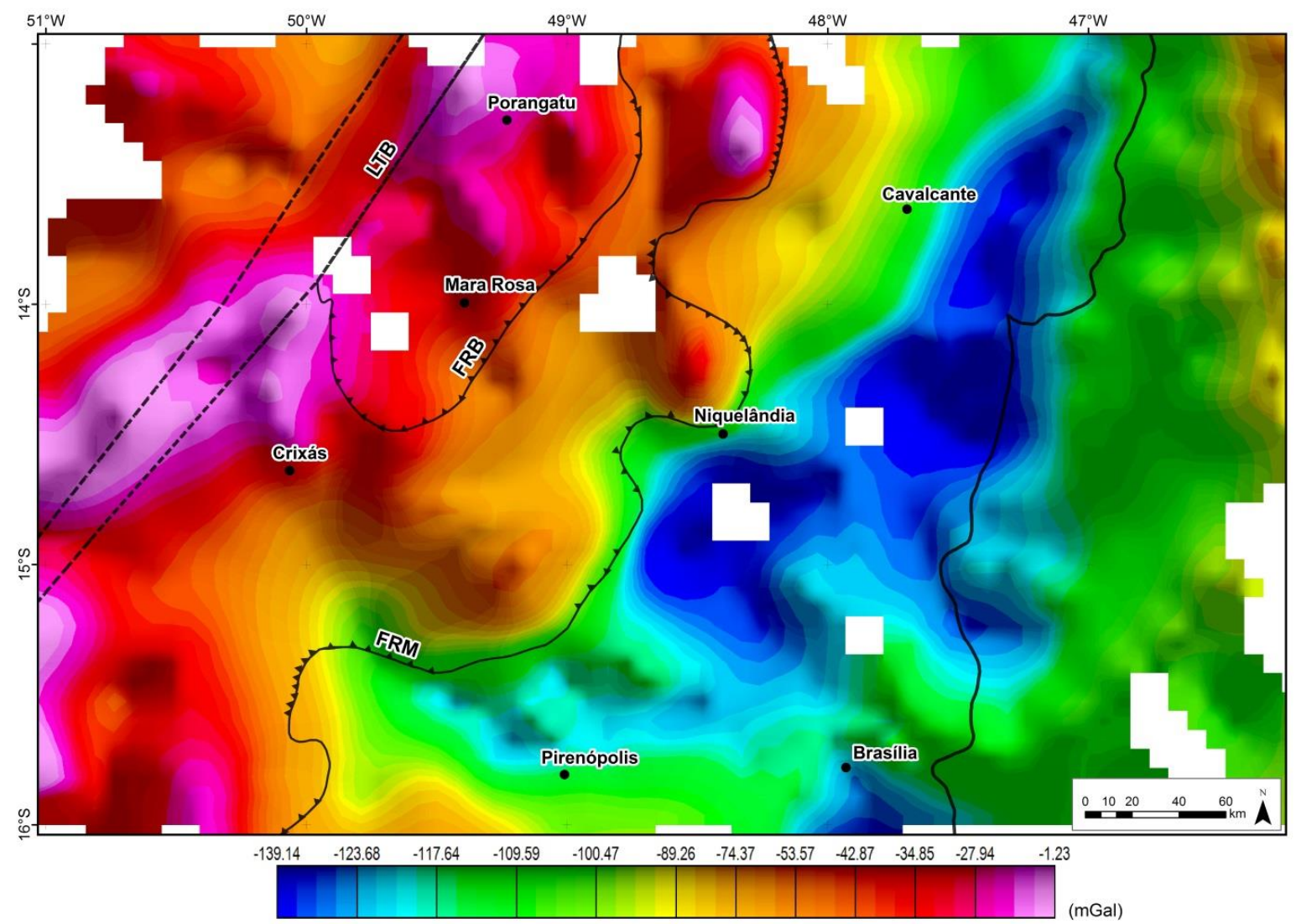

Figura 4.6 - Mapa de anomalia Bouguer do WGM 2012; Limites tectônicos com base em Pimentel et al. (2004) e Fuck et al. (2014) e as falhas de empurrão Rio Maranhão e Rio dos Bois. LTB - Lineamento Transbrasiliano; FRB Falha Rio dos Bois; FRM - Falha Rio Maranhão.

No mapa da derivada vertical (dz) a tendência das estruturas NE-SW fica mais evidente (Figura 4.7 A). No bloco ZE uma grande região com baixo gradiente de $-0,00110 \mathrm{mGal} / \mathrm{m}$, e gradiente intermediário de $-0,00009 \mathrm{mGal} / \mathrm{m}$, que segue o trend preferencial indicado pelas estruturas magnéticas e atravessa toda extensão do bloco, no sentido das localidades de Cavalcante a Pirenópolis. No bloco MG, destacam-se três anomalias gravimétricas, com alto gradiente de $0,00241 \mathrm{mGal} / \mathrm{m}$, forma semicircular e alongados paralelos a FRM. As regiões com gradientes intermediários, em torno de $-0.00039 \mathrm{mGal} / \mathrm{m}$, estão distribuídas ao longo do bloco. No bloco AMG, predominam altos gradientes em torno de $0,000152 \mathrm{mGal} / \mathrm{m}$, e que estão alinhados na direção NW-SE.

No mapa GHT (Figura 4.7 B) o bloco ZE apresenta anomalias de forma semelhante ao mapa de derivada vertical, com baixos gradientes, entre 0,00001 a $0,00022 \mathrm{mGal} / \mathrm{m}$, e intermediários, em torno de $0,00034 \mathrm{mGal} / \mathrm{m}$, em grande parte do bloco, com direção NE-SW . Neste bloco o gradiente baixo $0,00015 \mathrm{mGal} / \mathrm{m}$ indica uma região de descontinuidade. No bloco MG os altos gradientes de $0,00457 \mathrm{mGal} / \mathrm{m}$, encontram-se na transição com o bloco ZE ainda neste bloco, sobre a FRM o gradiente de $0,00343 \mathrm{mGal} / \mathrm{m}$, marca o limite com o bloco AMG. No bloco AMG predominam gradientes intermediários, que varia entre 0,00026 a 0,00036 mGal/m, sendo que na região do Lineamento Transbrasiliano aparece um aumento do gradiente para 
Universidade de Brasília -Instituto de Geociências - Programa de Pós-graduação em Geociências Aplicadas

Arcabouço Tectônico da Porção Centro-Norte da Faixa Brasília com Base em Dados Magnéticos e Gravimétricos

$0,00125 \mathrm{mGal} / \mathrm{m}$. Vale ressaltar que o gradiente horizontal total tende a destacar as anomalias e seus contatos de acordo com a profundidade de ocorrência, e como observado nos dados a FRB, com gradiente de $0,0052 \mathrm{mGal} / \mathrm{m}$, não mostra uma relação de descontinuidade aparente quando comparada com a FRM.

No mapa tilt derivative o comportamento das anomalias é semelhante ao observado na derivada vertical, porém com a equalização das amplitudes do sinal ocorre incremento dos valores relacionados a fontes mais profundas (Figura $4.7 \mathrm{C}$ ). $\mathrm{O}$ mapa da derivada tilt do gradiente horizontal total (Figura 4.7 D) evidencia claramente as feições lineares das anomalias, mesmo em profundidades distintas, em que as feições estruturais importantes para o contexto tectônico estão realçadas por altos gradientes, a FRM, FRB e LTB. No bloco ZE, observa-se alto gradiente alongado com direção NE-SW, que acompanha a direção da FRM. 

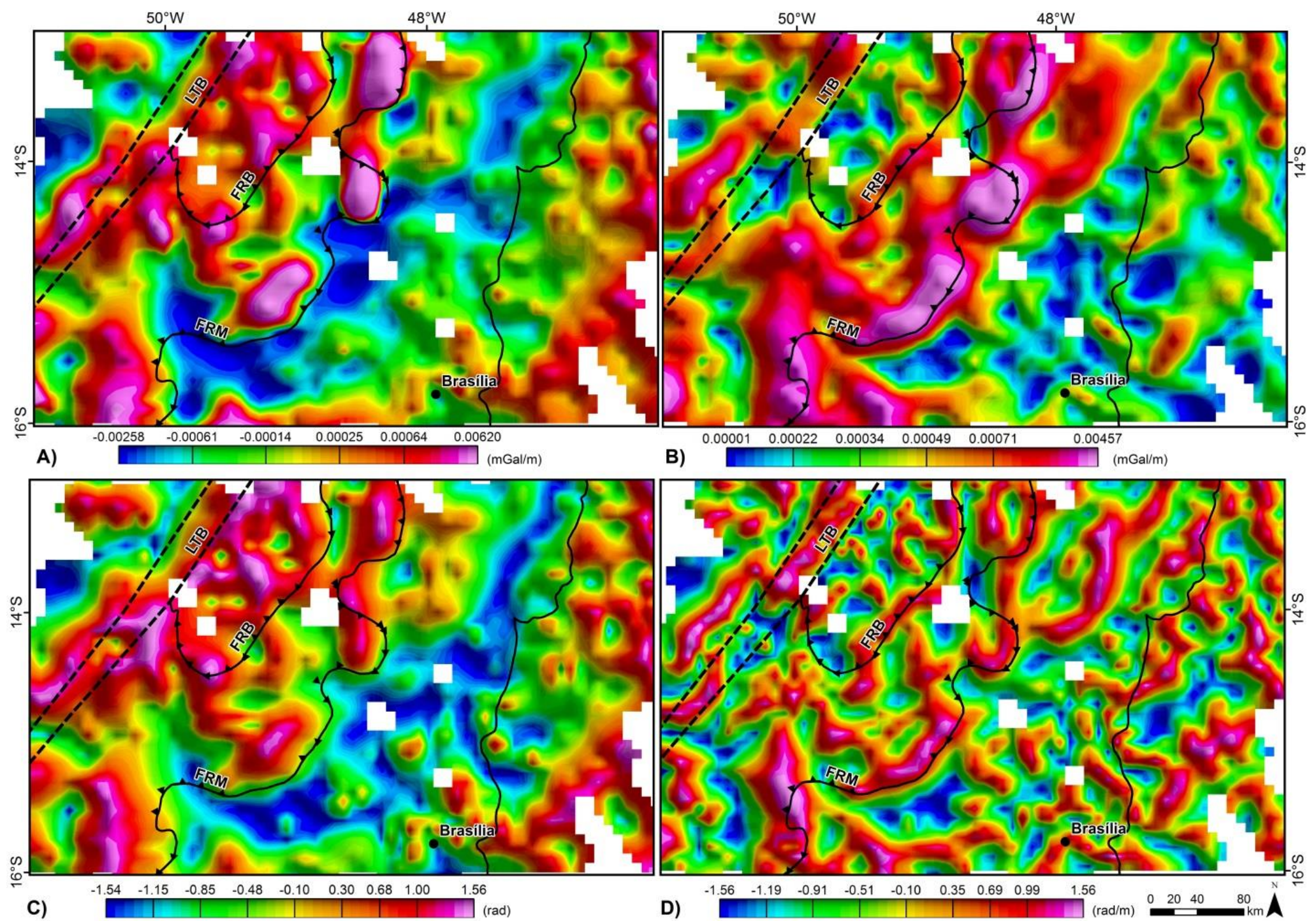

B)

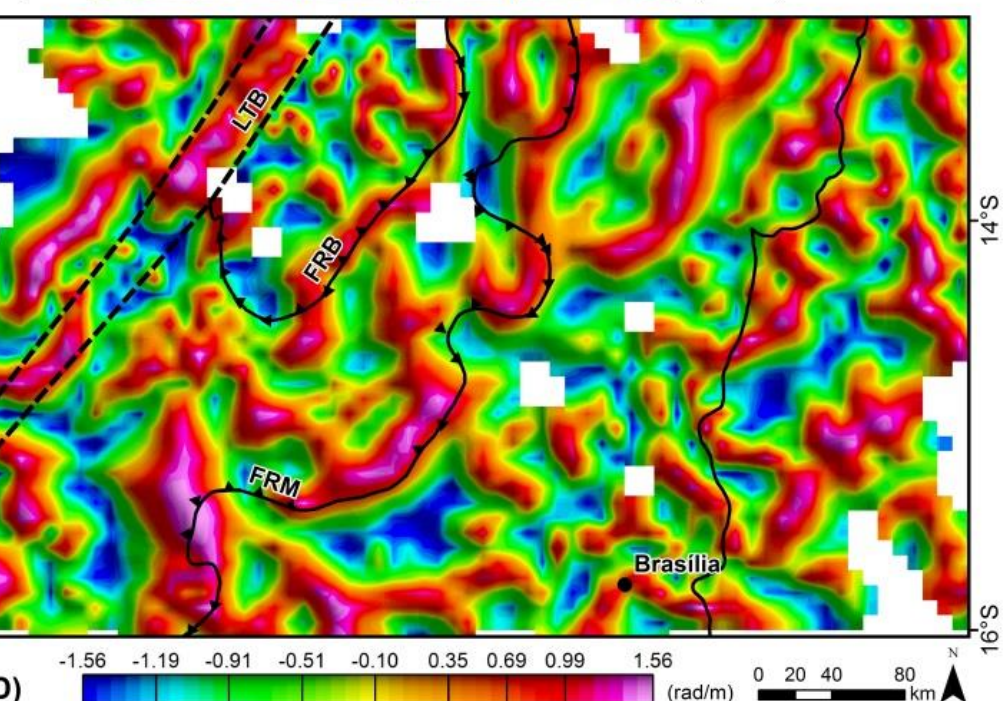

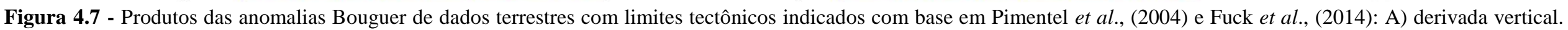

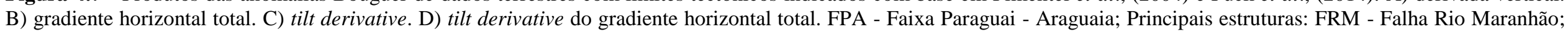
FRB - Falha Rio dos Bois. 


\subsection{ESTIMATIVAS DE PROFUNDIDADE DE GRAVIMETRIA TERRESTRE}

$\mathrm{Na}$ estimativa de profundidade realizada no mapa anomalias Bouguer (Figura 4.8 A)foram obtidos quatro intervalos de profundidade de fontes: rasas, $2 \mathrm{~km}$; intermediárias/rasas, 7 $\mathrm{km}$; intermediárias, $15 \mathrm{~km}$; e profundas, $50 \mathrm{~km}$ Embora tenham sido obtidos 4 intervalos de fontes gravimétricas no matched filter, as fontes localizadas a $2 \mathrm{~km}$ não são indicadas para caracterização dos blocos tectônicos, bem como na indicação de contatos entre eles, devido à baixa resolução do mapa.

Nas fontes intermediárias/rasas a $7 \mathrm{~km}$ (Figura $4.8 \mathrm{~B}$ ) nota-se aumento da amplitude das principais feições lineares. No bloco ZE houve realce dos baixos gravimétricos, pelo aumento de amplitude, que pode ser notado nas anomalias NE-SW. As anomalias que constituem altos gravimétricos ficaram mais evidentes na direção E-W e NW-SE. No bloco MG as anomalias que constituem altos gravimétricos também se tornam mais evidentes e podem ser correlacionadas aos complexos máficos-ultramáficos (Marangoni et al., 1995, Carminatti, 2006). No bloco AMG destacam-se anomalias positivas NW-SE em meio a baixos gravimétricos.

Nas fontes estimadas a $15 \mathrm{~km}$ (Figura $4.8 \mathrm{C}$ ) no bloco ZE as anomalias NE-SW estão mais extensas, confirmando as estruturas de primeira ordem observadas nos demais produtos. Os altos gradientes são mais evidentes na direção NE-SW, o que mostra possível relação com a anomalia NE-SW localizada no bloco do CSF. No bloco MG os altos gravimétricos relacionados aos complexos máficos-ultramáficos, passaram a formar anomalias mais centralizadas e circulares. No bloco AMG altos gravimétricos, 8,8 mGal, com direção NW-SE, passam a constituir grande parte do bloco.

No mapa de fontes profundas, em torno de $50 \mathrm{~km}$ (Figura $4.8 \mathrm{D}$ ), tem-se variação regional de gradiente com trend $\mathrm{NW}-\mathrm{SE}$, de $0,45 \mathrm{mGal} / \mathrm{km}$, de um alto gravimétrico, de -20 mGal, no bloco AMG, para um baixo gravimétrico no bloco ZE, de -128 mGal. 

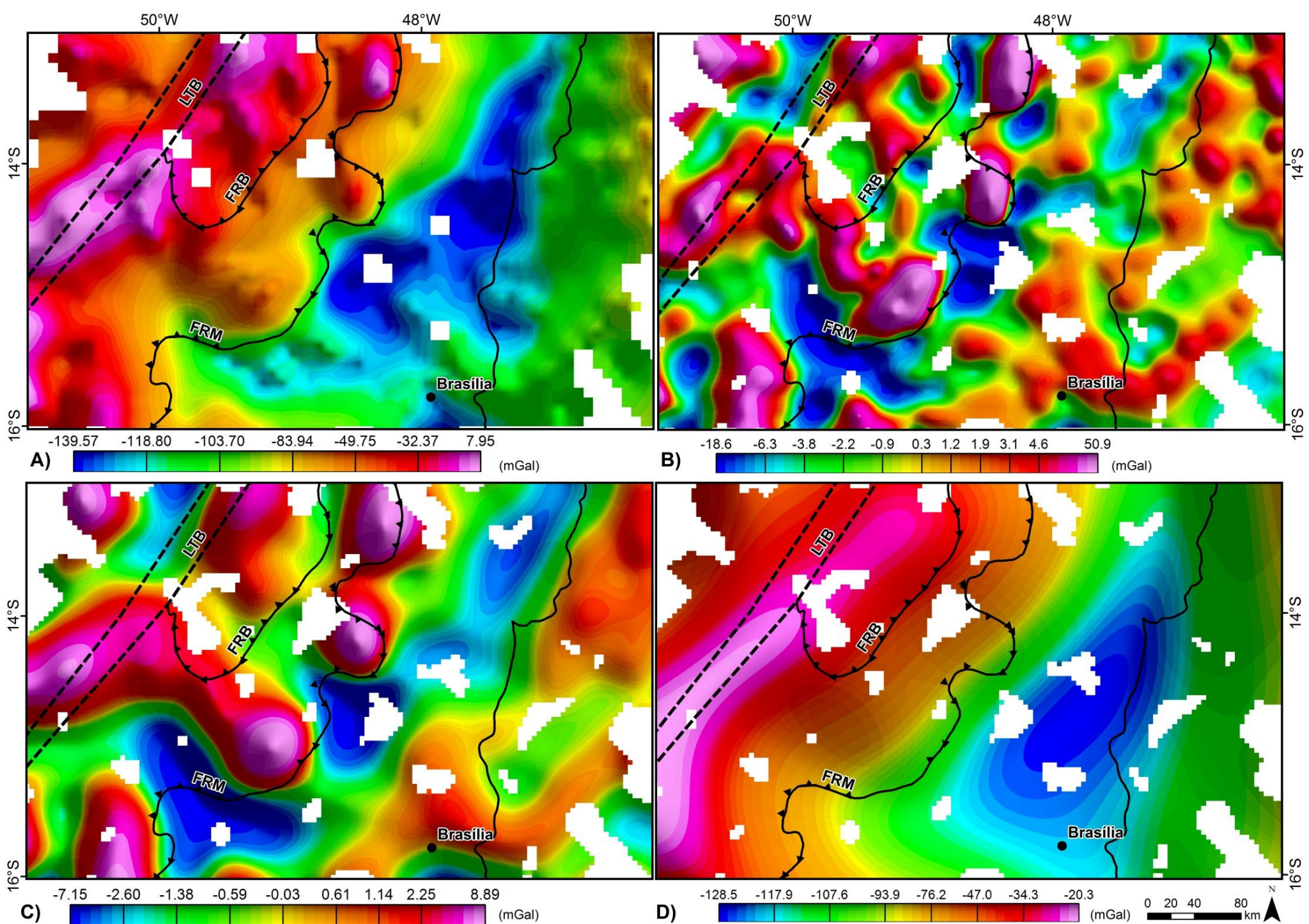

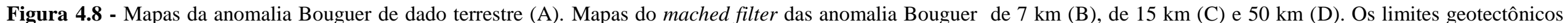
com base em Pimentel et al., (2004) e Fuck et al., (2014). LTB - Lineamento Transbrasiliano e os limites de falhas FRM - Falha Rio Maranhão; FRB - Falha Rio dos Bois. 


\section{Capítulo V}

\section{DISCUSSÕES E CONCLUSÕES}

Neste trabalho, foi utilizada a compartimentação tectônica sugerida nos trabalhos de Pimentel et al., (2004), Valeriano et al. (2008) e Fuck et al. (2014): Zona Externa e Zona Interna (bloco ZE), Maciço de Goiás (bloco MG) e Arco Magmático de Goiás (bloco AMG), que são limitados pelos sistemas de falhas Rio Maranhão (FRM) e Rio dos Bois (FRB) (Figura 2.1). Os métodos de filtragem foram aplicados aos dados do campo magnético anômalo, assim como aos dados de anomalia Bouguer terrestre, em que foi possível identificar feições lineares nos dados magnéticos e gravimétricos. Foram caracterizadas assinaturas geofísicas dos dados em cada bloco tectônico. Para facilitar as interpretações, foram selecionados quatro produtos das técnicas de realce: a primeira Derivada Vertical, o Gradiente Horizontal Total, a Derivada tilt e a Derivada Tilt do Gradiente Horizontal Total.

Dentre as estruturas magnéticas extraídas, foram notadas variações direcionais nos blocos tectônicos (Figura 4.1). No bloco ZE os lineamentos de $1^{\mathrm{a}}$ ordem apresentam em geral direção NNE-SSW. Há inflexões na direção WNW-ESE, onde formam sigmoides e está localizada a Megaflexura dos Pirineus (Fonseca et al., 1995) ou Sintaxe dos Pirineus (Araújo Filho, 1999). No bloco MG também há estruturas de $1^{\text {a }}$ ordem com direção NNE-SSW e NESW. No bloco AMG, os lineamentos de $1^{\mathrm{a}}$ ordem têm direção NE-SW e E-W. Por meio destes lineamentos foi possível notar que há semelhança das direções das estruturas magnéticas entre os blocos ZE e MG, como pode ser visto no mapa e nos diagramas de rosetas na figura 4.1. Os mapas obtidos no matched filter mostraram que as estruturas magnéticas de direção NE-SW podem ser observadas em fontes de até $19 \mathrm{~km}$ (Figuras 4.2 e 4.3), sendo este trend preferencial da área e paralelo ao Lineamento Transbrasiliano.

Estes mapas revelaram estruturas de caráter regional, por alcançar fontes de até $19 \mathrm{~km}$, principalmente relacionados ao Sistema do Lineamento Transbrasiliano (Schobbenhaus et al. 1975), ao sistema Cavalcante-Teresina e ao sistema Teresina - Nova Roma (Fonseca et al., 1995) ao sistema que compõe a Megaflexura dos Pirineus (Fonseca et al., 1995) ou Sintaxe dos Pirineus (Araújo Filho, 1999), à Falha Rio dos Bois e à Zona de cisalhamento Mutunópolis, de acordo com a geologia estrutural (Bizzi et al., 2003) (Figura 5.1). Os lineamentos magnéticos relacionados à Falha Rio Maranhão aparecem até a profundidade $2 \mathrm{~km}$; a partir de fontes de 8 km não é mais visível, indicando que não é uma estrutura profunda, corroborando a proposta de D'el Rey Silva et al. (2008), de que esta é uma estrutura superficial de baixo ângulo resultante do processo orogenético e com características de falha intraplaca. 
As profundidades do matched filter das sub-janelas em de cada bloco mostraram que o bloco MG tem fontes relativamente mais rasas $(10,2 \mathrm{~km})$, com relação aos blocos ZE e AMG (12,1 km e 11,9 km, respectivamente). Esta diferença nas profundidades das fontes magnéticas corrobora os resultados de Ventura et al. (2011), que identificaram uma variação lateral de velocidade da crosta em todas as camadas crustais subjacentes na região da FRB, onde se dá a interação entre a borda leste da Placa Amazônica com a borda oeste da Província Tocantins.

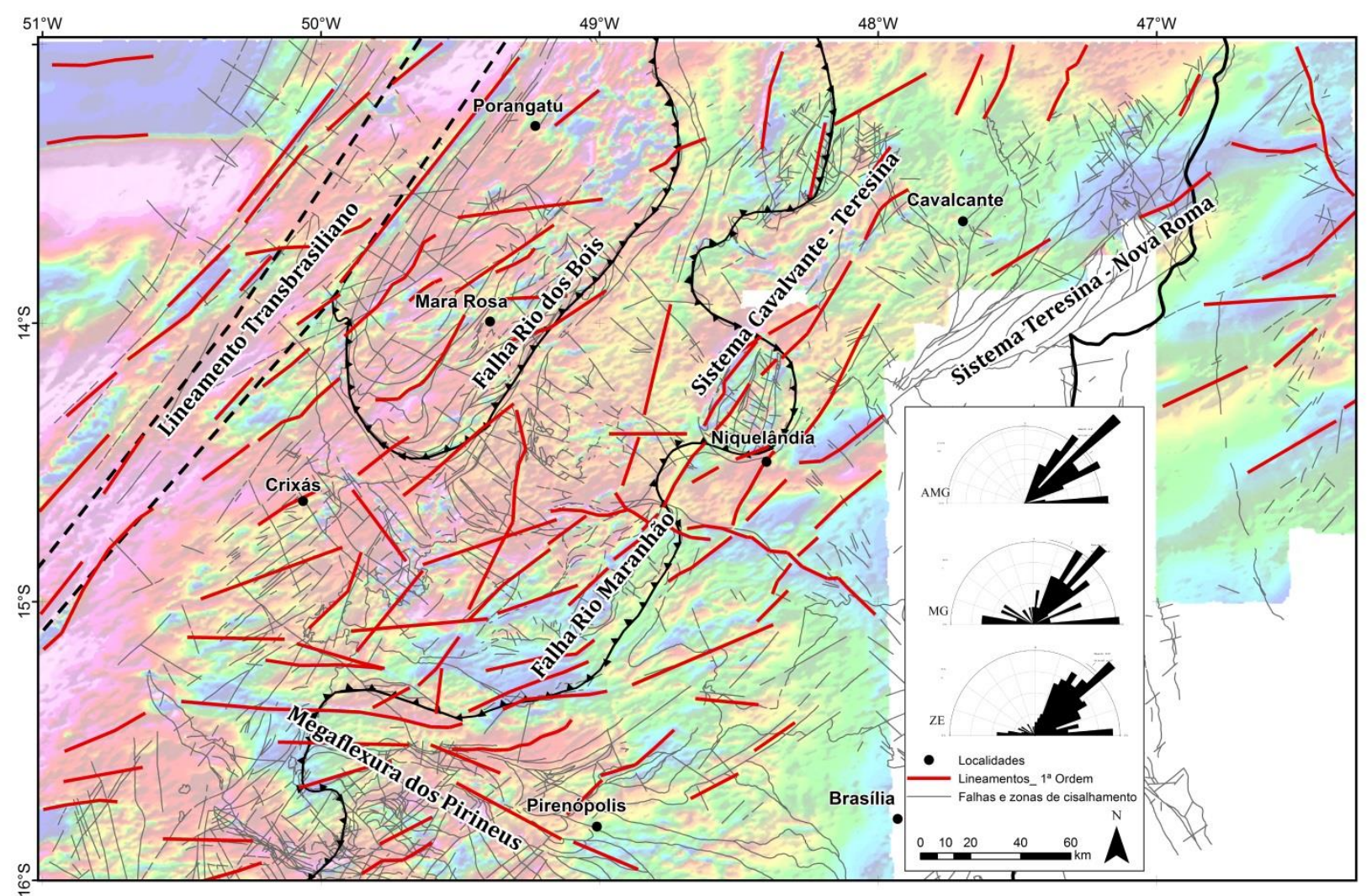

Figura 5.1 - Mapa interpretado com a geologia estrutural de acordo com Bizzi et al. (2003), com base em Valeriano et al., (2008) e Fuck et al. (2014), sobre o mapa do matched filter de $19 \mathrm{~km}$, com os principais lineamentos magnéticos.

Os dados do modelo de satélite WGS 2012 contribuíram com a análise preliminar da anomalia Bouguer da área, ressaltando claramente o trend NE-SW das unidades regionais (Figura 4.5 A). Nos dados de gravimetria terrestre, a anomalia Bouguer demonstra a mesma direção estrutural (Figura $4.5 \mathrm{C}$ ).

Nos dados de gravimetria terrestre foram realçadas anomalias de menor comprimento de onda relacionados a corpos mais rasos. No bloco ZE predominam baixos gravimétricos que variam de -139,5 a -103,7 mGals, no bloco MG altos gravimétricos de -33,9 a -10,6 mGals e no bloco AMG altos gravimétricos de aproximadamente -28 a -15,7 mGal. Nos mapas DZ e GHT o limite entre os blocos ZE e MG é destacado por três anomalias com alto gradiente de 0,00241 $\mathrm{mGal} / \mathrm{m}$ e $0,00457 \mathrm{mGal} / \mathrm{m}$, respectivamente (Figuras 4.6 A e B). A assinatura do bloco AMG é diferente dos demais. Os altos gravimétricos observados no limite do bloco MG estão relacionados aos complexos máfico-ultramáficos que, de acordo com Carminatti (2006), estão 
relacionados a uma zona de fraqueza na crosta que exumou estes complexos. Estes complexos ocultam uma região de transição entre os blocos ZE e MG constituída por anomalia Bouguer de sinal baixo/intermediário, em torno de $-103,7$ mGal.

$\mathrm{Na}$ anomalia Bouguer terrestre foi observada uma variação de aproximadamente 120 mGal no sentido NW-SE, que foi interpretado por Marangoni et al. (1995), como relativo a sobreposição de crosta continental. Nesta região, Padilha et al. (2013) haviam indicado a presença de uma região condutora em profundidades de até $100 \mathrm{~km}$ correlacionada a um rifte continental. Assim, os dados sugerem que a Falha Rio Maranhão se trata de uma estrutura intracontinental, sem expressão em profundidade, e que na região do Sistema de Falhas Rio dos Bois demonstra que há uma região de descontinuidade indicativa de zona de sutura entre o Arco Magmático de Goiás e o Maciço de Goiás.

A análise conjunta dos dados de anomalias magnéticas e gravimétricas demonstrou uma relação das anomalias observadas com grandes falhas e zona de cisalhamento, de acordo com mapa da geologia estrutural extraído de Lacerda Filho et al. (2004) e Souza et al. (2004). Soares et al. (2006),com base em dados sísmicos, observaram que há correspondência direta destas estruturas com a resposta sísmica destas unidades. Os mapas da GHT da magnetometria e gravimetria terrestre (Figuras 3.11 e 3.12, respectivamente), destacam uma estrutura de direção NE-SW no bloco ZE localizado sob o Sistema Cavalcante-Teresina (Fonseca et al., 1995; Tanizaki et al., 2015). Contudo, estas assinaturas reforçam a ideia de que a FRM não é uma zona de sutura, as anomalias indicam que este limite estaria na região da FRB.

A presença dos complexos máfico-ultramáficos de Cana Brava, Niquelândia e Barro Alto no Maciço de Goiás justifica a presença de altos gravimétricos nesta região, que em dados de anomalia Bouguer terrestre mostra que em profundidade de até $15 \mathrm{~km}$ podem ser bem individualizados entre as unidades. Assim como a presença de rochas de mesma idade nos blocos MG e ZE, com base nos dados de Cordeiro et al. (2014) e Fuck et al. (2014) (Figura 5.2). 


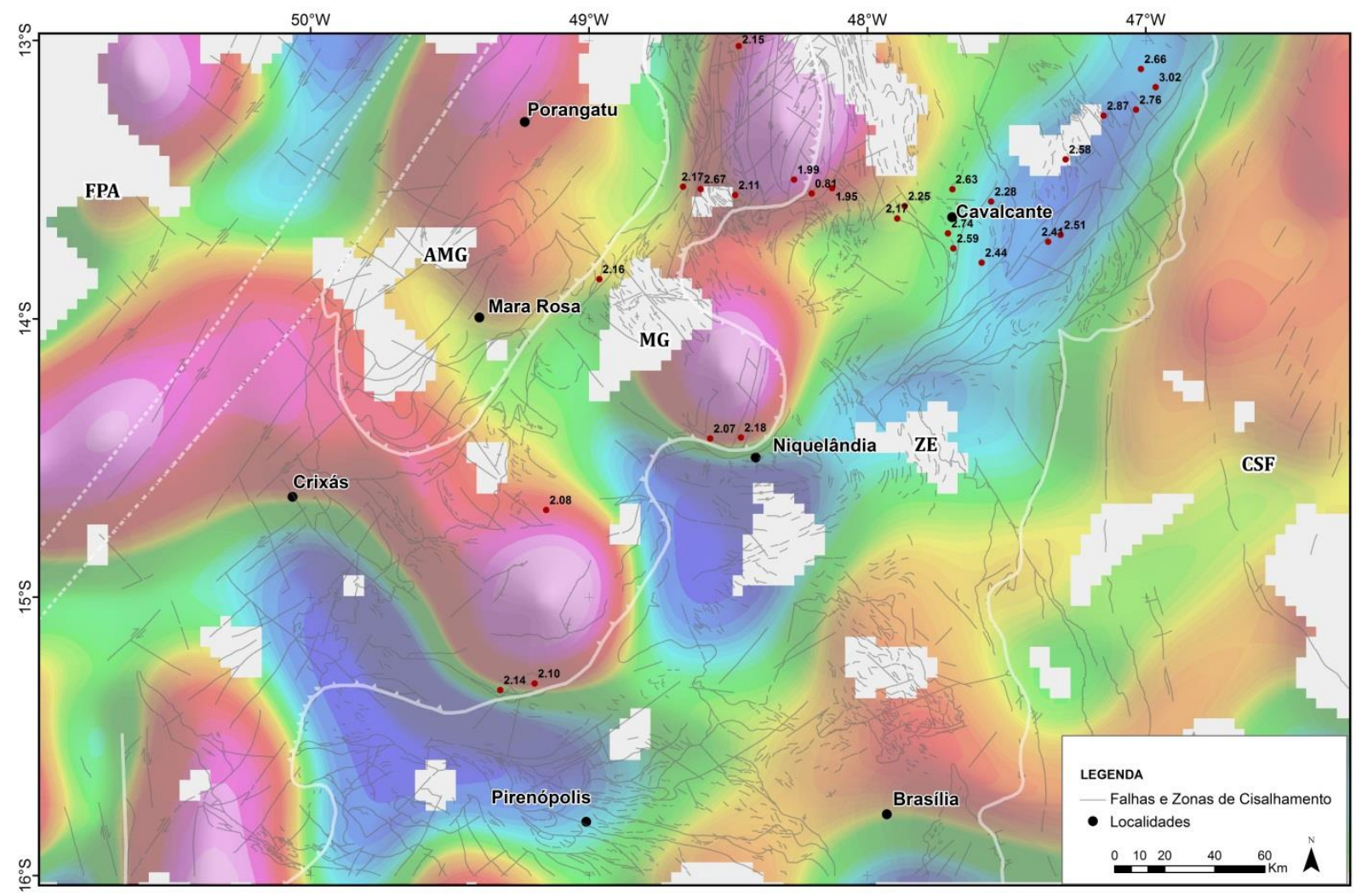

Figura 5.2 - Mapa do matched filter de $15 \mathrm{~km}$ da anomalia Bouguer terrestre, com localização de dados geocronológicos de Cordeiro et al. (2014) e Fuck et al. (2014) e dados estruturais de acordo com Bizzi et al. (2003), e compartimentação tectônica com base em Pimentel et al. (2004) e Fuck et al. (2014).

Portanto, os resultados obtidos mostram-se de acordo com a hipótese de evolução tectônica sugerida por Pereira e Fuck (2005), Soares et al. (2006), Carminatti (2006), D’el-Rey Silva et al. (2008), Ventura et al. (2011), Brito Neves e Fuck (2013), Trindade et al. (2014), Fuck et al. (2014), de que o Maciço de Goiás constituiu a borda oeste do Paleocontinente São Francisco, como parte do embasamento recoberto por rochas metassedimentares da Faixa Brasília. 


\section{Capítulo VI}

\section{REFERÊNCIAS BIBLIOGRÁFICAS}

Alkmim F.F., Neves B.B.B., Alves J.A.C., 1993. Arcabouço Tectônico do Cráton do São Francisco - Uma Revisão. O Cráton do São Francisco, Anais do II Simpósio sobre o Cráton do São Francisco, Salvador, Bahia. 45-62.

Almeida, F. F. M. 1976. Evolução Tectônica do Centro Oeste brasileiro no Proterozóico Superior. Anais da Academia Brasileira de Ciências, 40: 285-295.

Almeida, F.F.M. ; Hasui, Y., 1984. O Pré-Cambriano do Brasil. São Paulo, Edgard Blücher. 378 p.

Almeida F.F.M., Hasui, Y., Brito Neves, B.B., Fuck, R.A., 1981. Brazilian Structural Provinces: an introduction. Earth Science Review, 17:1-19.

Almeida F.F.M.; Hasui, Y.; Brito Neves. B.B.B. \& Fuck, R.A., 1977. Províncias Estruturais Brasileiras. Simpósio de Geologia do Nordeste, 8. Campina Grande, SBG. 363-391.

Almeida F.F.M., Hasui, Y., Brito Neves, B.B., Fuck, R.A., 1981. Brazilian Structural Provinces: an introduction. Earth Science Review, 17:1-19.

Alvarenga, C.J.S., Dardenne, M.A., Vieira, L.C., Martinho, C.T., Guimarães, E.M., Santos, R.V., Santana, R.O., 2012. Estratigrafia da Borda Ocidental da Bacia do São Francisco. Boletim de Geociências Petrobras, 20 (1/2): 145-164.

Araújo Filho, J.O., 1999. Structural characteristics and tectonic evolution of Pirineus sintaxs, central Brazil. PhD Thesis, University of Illinois. 418p.

Bizzi, L.A. Schobbenhaus, C., Vidotti, R.M. e Gonçalves, J.H., 2003. Geologia, Tectônica e Recursos Minerais do Brasil: Texto, Mapas \& SIG. CPRM-SGB - Brasília, 674 p.

Blakely, R. J., 1995. Potential Theory in Gravity \& Magnetic Applications, Cambridge University Press, 464p.

Blum, M.L.B., 1999. Processamento e Interpretação de dados de geofísica aérea no Brasil Central e sua aplicação à geologia regional e à Prospecção Mineral. Instituto de Geociências, Universidade de Brasília, Brasília, Tese de Doutorado, 229 p.

Blum, M.L.B., Jost, H., Moraes, R.A.V., Pires, A.C.B., 2003. Caracterização dos complexos ortognáissicos arqueanos de Goiás por gamaespectrometria aérea. Revista Brasileira de Geociências. 33:. 147-152.

Blum, M.L.B., Pires, A.C.B., 1996. Superfície Curie da região central de Goiás. Revista Brasileira de Geociências 26 (3): 197-208.

Bonvalot, S., Balmino, G., Briais, A., Huhn, M., Peyrefitte, A., Vales, N., Biancale, R., Gabalda, G., Moreaux, G., Reinquin, F., Sarrailh, M., 2012. World Gravity Map Scale 1:50.000.000 - First edition. Co-edited by CGMW (Commission for the Geological Map of the World), BGI, CNES, IRD, France. Explanatory Note. 8.

Briggs, I. C., 1974. Machine contouring using minimum curvature. Geophysics. 39: 39-48.

Brito Neves B.B., Cordani U.G., 1991. Tectonic evolution of South America during the Late Proterozoic. Precambrian Research, 53: 23-40.

Brito Neves, B.B. e Fuck, R.A., 2013. Neoproterozoic evolution of the basament of the South-American plataform. Jornal of South American Earth Sciences, 47: 72-89.

Brito Neves, B.B., Fuck R.A., Pimentel, M.M., 2014. The Brasiliano Collage in South America: A review. Brazilian Journal of Geology, 44(3): 493-518.

Brito Neves, B.B., Van Schmus, W.R., Basei, M.A.S., 1990. Contribuição ao estudo da evolução geocronológica do Sistema de Dobramentos Piancó-Alto Erigida. In: Congresso Brasileiro de Geologia, 36. Natal-RN, 1990. Anais. Natal, SBG, 5: 2697-2710.

Carminatti, M.G., 2006. Modelagem Geofísica dos corpos máficos-ultramáficos de Cana Brava, Niquelândia e Barro Alto, Centro de Goiás. Tese de Doutorado. Universidade de São Paulo. 297p.

Cordani, U.G. Brito Neves, B.B., 1982. The Geologic Evolution of South America during the Archean and Early Proterozoic. Revista Brasileira de Geociências, 12(1/3): 305-312.

Cordani, U.G., Brito Neves, B.B., Fuck, R.A., Porto, R., Thomaz Filho, A., Cunha, F.M.B., 1984. Estudo preliminar de integração do Pré-cambriano com os eventos tectônicos das bacias sedimentares brasileiras. Ciência Técnica Petróleo, 1-70.

Cordani, U.G., D’Agrella-Filho, M.S., Brito Neves, B.B., Trindade, R.I.F., 2003. Tearing up Rodinia: the Neoproterozoic palaeogeography of South American cratonic fragments. Terra Nova, 15: 350 - 359.

Cordani, U.G., Pimentel, M.M., Araújo, C.E.G., Fuck, R.A., 2013. The significance of the Transbrasiliano-Kandi tectonic corridor for the amalgamation of West Gondwana. Brazilian Journal of Geology, 43(3): 583-597. 
Cordani, U.G., Sato, K., 1999. Crustal evolution of the South American Platform, based on Nd isotopic systematic on granitic rocks. Episodes, 22(3): 167-173.

Cordani, U.G., Brito Neves, B.B., Fuck, R.A., Porto, R., Thomaz Filho, A., Cunha, F.M.B., 2010. Estudo preliminar de integração do Pré-Cambriano com os eventos tectônicos das Bacias Sedimentares Brasileiras (Republicação). Boletim de Geociências da PETROBRAS, 17: 137-204.

Cordeiro, P.F.O., Oliveira, C.G., Giustina, M.E.S.D, Dantas, E.L., Santos, R.V., 2014. The Paleoproterozoic Campinorte Arc: Tectonic evolution of a Central Brazil pre-Columbia orogeny. Precambrian Research 251, 4961.

Cordel, L., 1979. Gravimetric expression of graben faulting in Santa Fe country and the Española Basin. New Mexico Geological Society. $\quad 30^{\text {th }}$ field Conference. 30:59-64. Disponível em http://nmgs.nmt.edu/publications/guidebooks/30.

Cordel L., Grauch V.J.S., 1985. Mapping basement magnetization zones from aeromagnetic data in the San Juan basin, New Mexico. SEG. 181-197.

Cressie N.A.C., 1990. The Origins of kriging. Mathematical Geology. 22: 239-252.

D'el-Rey Silva, J.H., Vasconcelos, M.A.R., Silva, D.V.G., 2008. Timing and role of the Maranhão River Thrust in the evolution of the Neoproterozoic Brasília Belt and Tocantins Province, Central Brazil. Gondwana Research. 13: 352-374.

Dardenne M.A., Danni J.C.M., Fuck R.A., 1981. Revisão Estratigráfica do Grupo Araxá na região da Serra Dourada, GO. In: Sociedade Brasileira de geologia, Simpósio de Geologia do Centro-Oeste, 1, Goiânia. Anais, 664-678.

Dardenne, M.A., 1978. Zonação Tectônica na borda ocidental do Cráton São Francisco. In: Congresso Brasileiro de Geologia, 30. Recife. Anais, 299-308.

Ferreira, F.J.F., Souza, J., Bongiolo, A.B.S. e Castro, L.G., 2013. Enhancement of the total horizontal gradiente of magnetic anomalies using the tilt angle. Geophysics, 78(3): J33 - J41.

Fonseca M.A.; Dardenne, M.A.; Uhlein, A.A., 1995. Faixa Brasília, Setor Setentrional: Estilos Estruturais e Arcabouço Tectônico. Revista Brasileira de Geociências, 25(4): 267-278.

Fuck R. A., 1990. Dobramentos Neoproterozóicos da margem Ocidental do Cráton do São Francisco: revisão. In: $36^{\circ}$ C. In: $36^{\circ}$ Congresso Brasileiro de Geologia, Natal. Resumos, Sociedade Brasileira de Geologia, 288-289.

Fuck R.A., 1994. A Faixa Brasília e a compartimentação tectônica na Província Tocantins. In: SBG, Simpósio de Geologia do Centro-Oeste, 4, Anais, 184-187.

Fuck R.A., Dantas, E.L., Pimentel, M.M., Botelho, N.F., Armstrong, R., Laux, J.H., Junges, S.L., Soares, J.E., Praxedes, I.F., 2014. Paleoproterozoic crust-formation for Atlantica supercontinent reconstruction. Precambrian Research. 244: 53-74.

Fuck, R.A., Dantas, E.L., Vidotti, R.M., Roig, H.L., Almeida, T., 2013. Deformação Intracontinental em sistemas transcorrentes: o caso do Lineamento Transbrasiliano: Geometria, idade e significado. In: XIV Simpósio Nacional de Estudos Tectônicos, 2013, Chapada dos Guimarães. XIV Simpósio Nacional de Estudos Tectônicos. São Paulo: SBG.

Fuck, R.A.; Jardim de Sá, E.F., Pimentel, M.M., Dardenne, M.A., Soares, A.C.P., 1993. As Faixas de dobramentos marginais do Cráton São Francisco: Síntese dos Conhecimentos In: Domingues, J.M.L., Missi, A. (Ed). O Cráton São Francisco, 161-185.

Fuck, R.A., Pimentel, M.M., D’el-Rey Silva, L.J.H., 1994. Compartimentação Tectônica na Porção Oriental da Província Tocantins. In: XXXVIII Congresso Brasileiro de Geologia, Camboriú, SBG, Boletim Resumos Expandidos SBG, 1: 215 - 217.

Geosoft 2008. Oasis Montaj: Release 8.1, Geosoft Inc, Toronto, Canadá.

Grauch, V.J.S. and Cordell, L.. 1987. Limitations of determining density or magnetic boundaries from the horizontal gradient of gravity or paseudogravity data. Geophysics, 52: 118-121.

Guimarães, D., 1951. Arqui-Brasil e sua evolução geológica. Boletim. DNPM/DFPM. Rio de Janeiro, 88: 1-314.

Hinze P.W.J., von Frese R.R.B., Saad A.H., 2013. Gravity and Magnetic Exploration: Principles, Practices, and Applications. Cambridge University Press. Cambridge. 525 p.

Isles D. J. and Rankin L. R., 2013. Geological interpretation of aeromagnetic data. Australian Society of Exploration Geophysicists, Australia. 365 p.

Krige D.G., 1966. Two-dimensional weghted moving average trend surfaces for ore valuation. In: Symposium: Mathematical Statistics and Computer Applications in ore valuation, Jour. South African Inst. Mining and Metallurgy, Johannesburg, 13-38. 
Lacerda Filho, J. V., 2000. Arcabouço Geotectônico do Estado de Goiás e do Distrito Federal. In: Lacerda Filho, J.V., Rezende, A. e Silva, A. Programa de Levantamentos Geológicos Básicos do Brasil. Geologia e Recursos Minerais do Estado de Goiás e do Distrito Federal. Escala 1:500.000, $2^{\text {a }}$ Edição. CPRM/METAGO/UnB. Goiânia.

Lacerda Filho, J.V., Frasca, A.A.S., 2008. Compartimentação Geotectônica. In: Moreira, M.L.O., Moreton, L.C., Araújo. V.A., Lacerda Filho, J.V. e Costa, H.F. Geologia do Estado de Goiás e Distrito Federal. Escala 1:500.000. Companhia de Pesquisa de Recursos Minerais - CPRM/SIC - FUNMINERAL. Goiânia. 34-42.

Li, X., 2006. Undestanding 3D analytic signal amplitude. Geophysics. 92: 13-16.

Marangoni Y. R., M. Assumpcão, and E. P. Fernandes., 1995. Gravimetria em Goiás, Brasil, Rev. Brasil. Geofis., 13(3): 205-219.

Martins-Neto, M. A., 2007. Proterozoic first-order sedimentary successions of the São Francisco Basin in eastern Brazil. Zeitschrift der Deutschen Gesellschaft für Geowissenschften, 158, 31-44p.

Martins-Neto, M. A., 2009. Sequence Stratigraphic framework of Proterozoic successuions in eastern Brazil. Marine and Petroleum Geology 26: 163-176.

Miller H. G., Singh V., 1994. Potential field tilt - a new concept for location of potential fiels sources. Journal of Applied Geophysics.32: 213-217.

Nabighian, M. N., 1972. The analytic signal of two-dimensional magnetic bodies with polygonal cross-section: its properties and use for automated anomaly interpretation. Geophysics, 37: 507-517.

Nabighian, M. N., 1974. Additional comments on the analytic signal of two-dimensional magnetic bodies with polygonal cross-section. Geophysics, 39 (91): 85-92.

Nabighian, M. N., 1984. Toward a three-dimensional automatic interpretation of potential field data via generalized Hilbert transforms Fundamental relations. Geophysics, 49: 780-786.

Nabighian M. N., Ander M.E., Grauch V. J.S., Hansen R.O., LaFehr T.R., Li Y., Pearson W.C., Peirce J.W., Phillips J.D. , Ruder M. E., 2005. Historical development of the magnetic method in exploration, Geophysics, 70: 33ND61ND

Padilha A.L., Vitorello I., Pádua M. B., 2013. Deep conductivity structure beneath the northern Brasília belt, central Brazil: Evidence for a Neoproterozoic arc-continent collision. Gondwana Research, 23: 748-758.

Pereira, R.S., 2007. Cráton do São Francisco, Kimberlitos e Diamantes. Universidade de Brasília, Tese de Doutorado, $200 \mathrm{p}$.

Pereira, R.S., Fuck, R.A., 2005. Archean nuclei and the distribution of kimberlite and related rocks in the São Francisco Craton, Brazil. Revista Brasileira de Geociências. 35(3): 93-104.

Phillips, J.D., 2001. Desingning matched bandpass and azimutal filters for the separation of potencial-field anomalies by source region and source type, in: Expanded Abstracts of the Geophysical Conference and Exhibition, 15, ASEG, Brisbane, 1-4.

Pimentel, M.M., Fuck R.A., 1987. Origem e evolução das rochas metavulcânicas e metaplutônicas da região de Arenópolis, GO. Revista Brasileira de Geociências, 17 (1): 2-14.

Pimentel, M.M., Fuck, R.A., 1992. Origin of orthogneiss and metavolcanic rock units in western Goiás: Neoproterozoic crustal accretion in central Brazil. Geochimica Brasiliensis, 5(1-2): 133-152.

Pimentel, M.M., Fuck, R.A., Botelho, N.F., 1999. Granites and the geodynamic history of the Neoproterozoic Brasília belt, Central Brazil: a review. Lithos 46: 463-483.

Pimentel, M.M., Fuck, R.A., Jost, H., Ferreira Filho, C.F., Araújo, S.M., 2000. The basement of the Brasília Belt and the Goiás Magmatic Arc. In: Cordani, U.G., Milani, E.J., Thomaz Filho, A., Campos, D.A. (Eds.), Tectonic Evolution of South America. 31st International Geological Congress . Rio de Janeiro, pp. 195-229.

Pimentel, M.M., Fuck R.A., Machado N., Fuck R.F., Ribeiro R.K., Viana M. das G., 1993. Dados geocronológicos U-Pb preliminares da região de Mara Rosa, Goiás: implicações para a época de mineralização de Au e para a evolução tectônica Neoproterozóica no centro-oeste. In: SBGq, IV Congresso Brasileiro de geoquímica, Atas, $255-258$

Pimentel, M.M., Fuck, R.A., Marini, O.J., 1991. U-Pb zircon geochronology of Precambrian tin-bearing continentaltype acid magmatism in central Brazil. Precambrian Research 52: 321-335.

Pimentel, M.M., Jost H., Fuck R.A., 2004. O Embasamento da Faixa Brasília e o Arco Magmático de Goiás, in: Mantesso Neto V., Bartorelli A., Carneiro C.D.R., Brito Neves B.B. (Eds.). Geologia do Continente SulAmericano: Evolução da obra de Fernando Flávio Marques de Almeida. São Paulo. Editora Beca, $1^{\text {a }}$ Ed., 355368. 
Pimentel, M.M., Rodrigues, J.B., Giustina, M.E.S., Junges, S., Matteini, M., Armstrong, R., 2011. The tectonic evolution of the Neoproterozoic Brasília Belt, central Brazil, based on SHRIMP and LA-ICPMS U-Pb sedimentary provenance data: a review. Journal of South American Earth Sciences. 31: 345-357.

Reeves, C., 2005. Aeromagnetic Surveys: Principles, Practice e Interpretation, Geosoft. 115 p.

Reynolds, J.M., 1997. An Introduction to Applied and Environmental Geophysics. Chichester. John Wiley and Sons Ltd. 796 p.

Roest, W.R., Pilkington, M., 1993. Identifying remanent magnetization effects in magnetic data. Geophysics. 58 (5): 653-659.

Roest, W.R., Verhoef, J., Pilkington, M., 1992. Magnetic interpretation using the 3D analytic signal. Geophysics. 57 (1): $116-125$

Salem, A. Williams, S., Fairhead, J.D., Ravat, D., Smith, R., 2007. Tilt-depth method: A simple depth estimation method using first-order magnetic derivatives. The Leading Edge, 26 (12): 1502-1505.

Schobbenhaus, C., Ribeiro, C.L., Oliva, L.A., Takanohashi, J.T. Lindenmayer, Z.G., Vasconcelos, J.B., Orlandi, V., 1975. Folha Goiás - SD-22. In: Carta Geológica do Brasil ao Milionésimo, DNPM, Brasília, 113 p.

Schobbenhaus, C., Campos, D.A., 1984. A evolução da Plataforma Sul-Americana no Brasil e suas principais concentrações minerais. In: Schobbenhaus, C., Campos, D.A., Derze, G.R. Asmus, H.E. (coords.). Geologia do Brasil, DNPM, Brasília, p. 9-53.

Soares, J.E., Berrocal, J., Fuck, R.A., Mooney, W.D., Ventura, D.B.R., 2006. Seismic characteristics of central Brazil crust and upper mantle: a deep seismic refraction study. J. Geophysics. 111: 1-31.

Souza J.D., Kosin, M., Heineck, C. A., Lacerda Filho, J.V. Teixeira, L.R., Valente, C.R., Guimarães, J.T., Bento, R.V., Borges, V. P., Santos, R.A., Leite, C. A., Neves, J.P., Oliveira, I. W. B., Carvalho, L. M., Pereira, L. H. M., Paes, V. J. C., 2004. Folha SD. 23 - Brasília. In: Shobbenhaus, C., Gonçalves, J.H., Santos, L.O. S., Abram, M.B., Leão Neto, R., Matos, G.M.M., Vidotti, R.M., Ramos, M. A. B., Jesus, J.D.A. de. (eds.). Carta Geológica do Brasil do Brasil ao Milionésimo, Sistemas de Informações Geográficas - SIG. Programa Geologia do Brasil, CPRM, Brasília. CD-ROM.

Spector, A., 1968. Spectral Analysis of Aeromagnetic maps. Tese de Pós Doutorado - Universidade de Toronto.

Spector A., Grant F. S., 1970. Statistical models for interpretation of aeromagnetic data, Geophysics, 35: 293-302.

Steenkamp B., 1998. Some questions and answers about the Mesozoic diamond mineralization potential of the Paramirim Shield. Geophysical Service Division, Internal Report, De Beers Brasil, Brasilia.

Syberg F.J.R., 1972. A Fourier method for the regional-residual problem of potential fields. Geophysical Prospecting, 20 (1): 47-75.

Tanizaki, M. L. N., Campos, J. E. G., Dardenne, M. A., 2015. Estratigrafia do Grupo Araí: Registro de rifteamento paleoproterozóico no Brasil Central. Brazilian Journal of Geology, 45(1): 95-108.

Telford, W.M., Geldart L.P., Sheriff R.E., 1990. Applied geophysics, Cambridge. Cambridge University Press. 770p.

Trindade C.R., Soares, J.E., Fuck, R.A., Carmelo, A.C., 2014. Estrutura Crustal do Brasil Central. Laboratório Nacional de Energia e Geologia. Porto, Portugal. Comunicações Geológicas, Especial I, 101: 339-343.

Trompette R., 1994. Geology of Western Gondwana 2000-500 Ma. The Pan-African Brasiliano Amalgamation of South America and Adjacent Africa. Balkema, Rotterdam. 360p.

Valeriano, C.M., Almeida, J.C.H., Simões, L.S.A., Duarte, B.P., Roig, H.L., Heilbron, M., 1995. Evolução estrutural do Domínio Externo da Faixa Brasília no Sudoeste de Minas Gerais: Registros de uma tectônica PréBrasiliana. Revista Brasileira de Geociências, 25 (4): 221-234.

Valeriano C.M., Pimentel M.M., Heilbron M., Almeida J.C.H. and Trouw R.A.J., 2008. Tectonic evolution of the Brasília Belt, Central Brazil, and early assembly of Gondwana. The Geological Society of London, London, Special Publications, 294: 197-210.

Ventura D.B.R., Soares, J.E.P., Fuck, R.A., Caridade, L.C.C., 2011. Caracterização sísmica e gravimétrica da litosfera sob a linha de refração sísmica profunda de Porangatu, Província Tocantins, Brasil Central. Revista Brasileira de Geociências 41(1): 130-140.

Verduzco B., Fairhead J.D., Green C.M., Mackenzie C., 2004. New insights into magnetic derivatives for structural mapping. The Leading Edge. 23: 116-119.

Ville, J., 1948. Theorie et application de la notion de signal analytique, SSM 3507, Câbles et Transmissions, Paris.

Vidotti, R.M., Ebinger, C.J., Fairhead, J.D., 1998. Gravity signature of the western Paraná basin, Brazil. Earth and Planetary Science Letters. 159: 117-132. 
Universidade de Brasília -Instituto de Geociências - Programa de Pós-graduação em Geociências Aplicadas

Arcabouço Tectônico da Porção Centro-Norte da Faixa Brasília com Base em Dados Magnéticos e Gravimétricos

Vidotti, R.M., Curto, J.B., Fuck, R.A., Dantas, E.L., Roig, H.L., Almeida, T., 2011. Magnetic expression of the Transbrasiliano Lineament, Brazil. AGU Fall Meeting. SanFrancisco, USA. Disponível em: http://abstractsearch.agu.org/meetings/2011/FM/GP41A-0986.html. Consultado em 18/08/2015. 